\title{
WestVirginiaUniversity
}

THE RESEARCH REPOSITORY @ WVU

Graduate Theses, Dissertations, and Problem Reports

2008

\section{Methods for reconstruction of transient emissions from heavy -duty vehicles}

Madhava R. Madireddy

West Virginia University

Follow this and additional works at: https://researchrepository.wvu.edu/etd

\section{Recommended Citation}

Madireddy, Madhava R., "Methods for reconstruction of transient emissions from heavy -duty vehicles" (2008). Graduate Theses, Dissertations, and Problem Reports. 2826.

https://researchrepository.wvu.edu/etd/2826

This Dissertation is protected by copyright and/or related rights. It has been brought to you by the The Research Repository @ WVU with permission from the rights-holder(s). You are free to use this Dissertation in any way that is permitted by the copyright and related rights legislation that applies to your use. For other uses you must obtain permission from the rights-holder(s) directly, unless additional rights are indicated by a Creative Commons license in the record and/ or on the work itself. This Dissertation has been accepted for inclusion in WVU Graduate Theses, Dissertations, and Problem Reports collection by an authorized administrator of The Research Repository @ WVU.

For more information, please contact researchrepository@mail.wvu.edu. 


\title{
Methods for Reconstruction of Transient Emissions from Heavy-Duty Vehicles
}

\author{
Madhava R. Madireddy \\ Dissertation submitted to the \\ College of Engineering and Mineral Resources \\ at West Virginia University \\ in partial fulfillment of the requirements \\ for the degree of
}

Doctor of Philosophy

in

Mechanical Engineering

Committee Members:

Nigel N. Clark, Ph.D., Chair

Eric K. Johnson, Ph.D.

Jacky C. Prucz, Ph.D.

Natalia A. Schmid, Ph.D.

W. Scott Wayne, Ph.D.

Department of Mechanical and Aerospace Engineering

Morgantown, WV

2008

Keywords: Dispersion Function, Reconstruction of Emissions, Engine

Dynamometer, Instantaneous Emissions, Deconvolution 


\section{ABSTRACT \\ Methods for Reconstruction of Transient Emissions from Heavy-Duty Vehicles}

\section{Madhava R. Madireddy}

Emissions measurement analyzers give out a response that may not reflect the true instantaneous engine-out emissions. Currently, the heavy-duty diesel engines are being certified for emissions measured in a thirty second time window with certain specification requirements for the analyzers. Since these measured emissions values may not be the same as the true instantaneous emissions, integrated values for the thirty second windows may be affected by analyzer response.

This document presents and examines reconstruction techniques to estimate instantaneous heavy-duty engine-out emissions. These techniques will take as the input, the continuous set of emissions data and approximate dispersion characteristics of the analyzer employed in measuring the continuous data. For this purpose, this research dealt with understanding and modeling the transient dynamics (dispersion function) of the analyzers and the sampling system to establish a relationship between the measured and instantaneous heavy-duty emissions.

Four methods of reconstruction were presented in this study: Sequential Inversion Technique (SIT), Differential Coefficients Method (DCM), Inverse Fast Fourier Transform (IFFT) and Modified Deconvolution Technique (MDT). The application of each method in reconstructing real-time emissions data was presented. While SIT failed in practical applications, each of the other three methods was shown to offer advantage in the post-processing of the measured emissions data. DCM accounted for the small errors 
in the computation of the analyzer dispersion function. IFFT was able to reconstruct just as well as DCM; however the Fast Fourier Transform of the dispersion function should be high enough to ensure stability of the method. In other words, the dispersion function should not have elements that were almost equal to zero for the method to be stable. Both the DCM and IFFT improved the correlation of emissions with power by an average of about $2 \%$. MDT employs fitting a gamma distribution to the dispersion function and searches for the best possible distribution within a prescribed range to improve the reconstruction. With emissions reconstruction using MDT, the improvement of correlation of emissions with power was approximately about $3 \%$.

The measured continuous data of $\mathrm{CO}_{2}$ mass flow rate from the New Flyer 2006 transit bus was divided into several operating bins, each bin having a specific speed and acceleration range. MDT was used to generate continuous reconstructed emissions from the measured continuous data. This reconstructed data is again divided into identical bins following a similar procedure. By comparing the two sets of bins, it was found that at low accelerations, the average mass flow rate of the measured $\mathrm{CO}_{2}$ was lesser than that of the reconstructed $\mathrm{CO}_{2}$. However, the reverse was found true at high accelerations.

This work could enhance the existing inventory models, help the calibrators appreciate the affect of time dispersion and can take the certifiers one step closer to estimating the true transient emissions by compensating for the distortion of the measurement systems. 


\section{ACKNOWLEDGEMENTS}

I am extremely grateful to my advisor Dr. Nigel Clark. He has been a great support for me throughout my doctorate program. I am glad I had an opportunity to work under his guidance to obtain the highest degree in my career. I would like to thank Dr. Eric Johnson, Dr. Jacky Prucz, Dr. Natalia Schmid, and Dr. Scott Wayne for being my committee members and for their suggestions.

I want to express my sincere gratitude to everyone who worked at the EERC at WVU who have helped me during the research work. Firstly, I need to thank Richard Atkinson, who helped me repair the Fast $\mathrm{NO}_{\mathrm{x}}$ analyzer and Bradley Ralston who helped me collect data for different runs. I would like to thank Ajtay and Weilenmann, since I applied a theory suggested by them in this dissertation. I also thank Matthew Spears of the EPA for drawing my attention to their work. I would like to thank Lijuan for collaborating with me in some of my data analysis. I would also like to specially thank Xiaohan Chen and Nikhil Burri for providing me invaluable help in understanding and applying signal processing in my data analysis. I would like to thank my colleagues Kevin Flaim, Major Khan, Emre, Kuntal, Clinton and Lijuan for their cooperation. Next I would like to thank Mimi Roy and my wife, Greeshma for her editing help. I am very grateful to my family who had been supportive of me pursuing a doctoral degree. I dedicate my dissertation to them. Finally, I would like to thank the Department of Transportation (contract number 10009291.1.1.1003596R) for their continual sponsorship for this study. 


\section{TABLE OF CONTENTS}

1 INTRODUCTION, OVERVIEW \& OBJECTIVES............................................................... 1

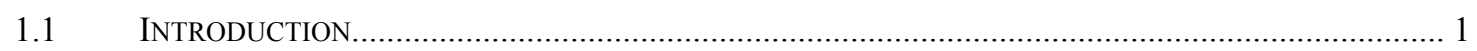

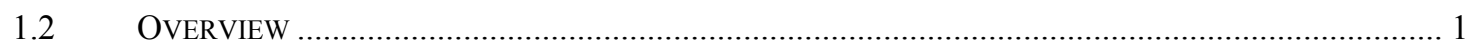

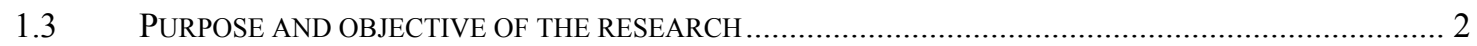

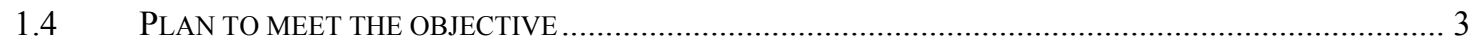

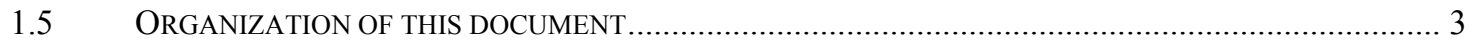

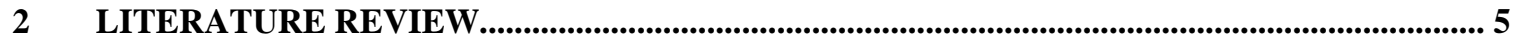

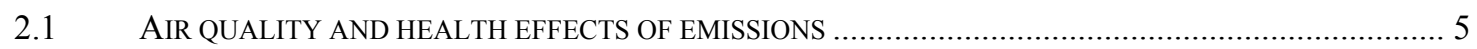

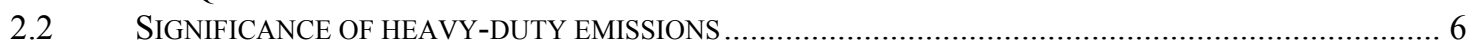

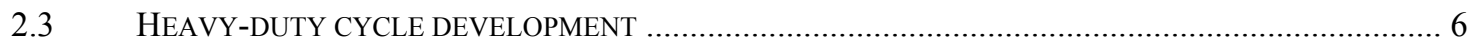

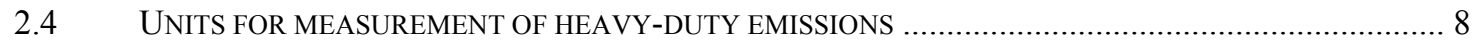

2.5 STEADY STATE AND TRANSIENT EMISSIONS TEST CYCLES ................................................... 9

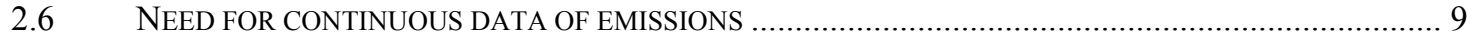

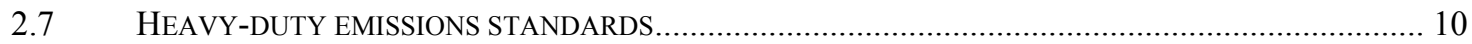

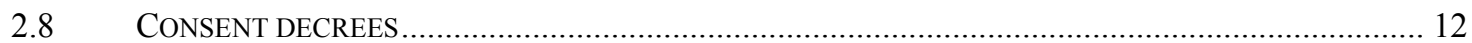

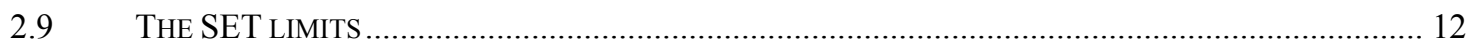

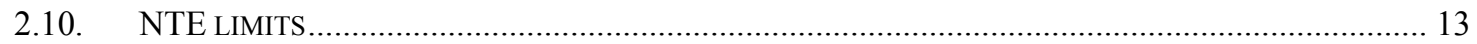

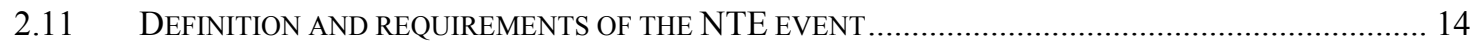

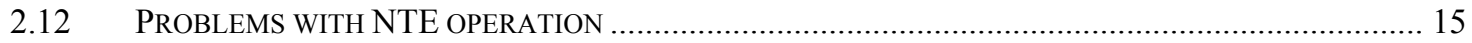

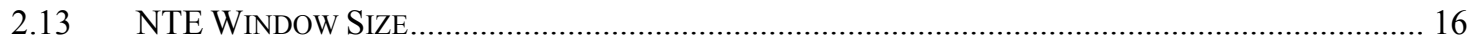

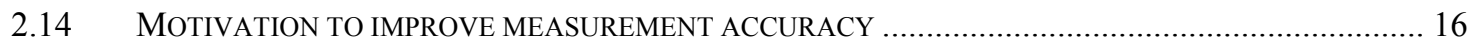

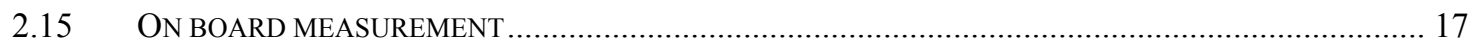

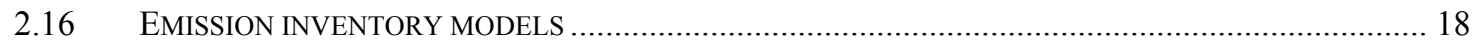

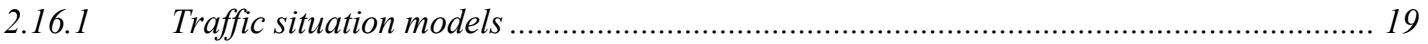

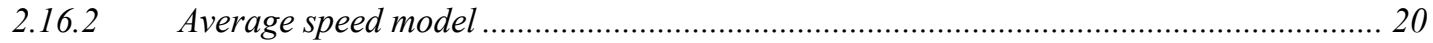

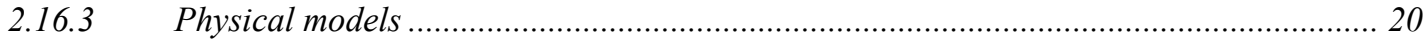

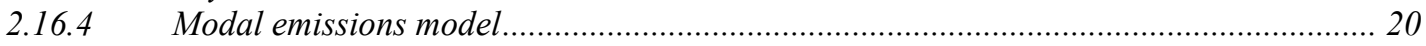

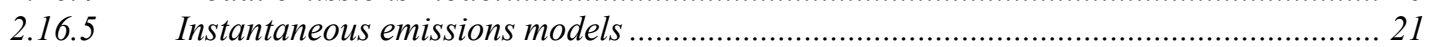

3 THEORY OF DELAY AND DISPERSION OF DATA ............................................................... 22

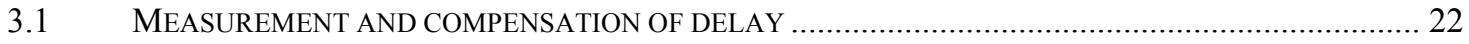

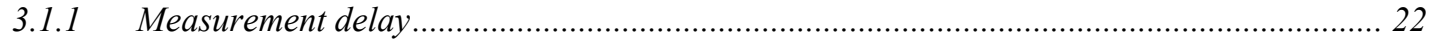

3.1.2 Compensation for delay and brief review of literature ...................................................... 23

3.2 TIME DISPERSION OF DATA AND EARLIER WORK RELATED TO DATA DISPERSION......................... 24

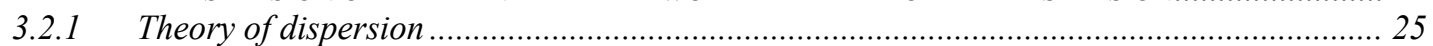

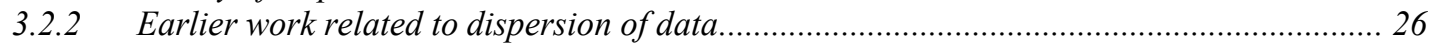

3.2.3 Understanding the transient dynamics of the analyzers ..................................................... 27

3.2.4 Understanding the effects of dispersion on a step input .................................................... 30

3.2.5 Emissions 'lost' in measurement due to dispersion ............................................................. 31

3.2.6 The 'gain' of emissions that corresponds to the 'loss' of emissions ....................................... 34

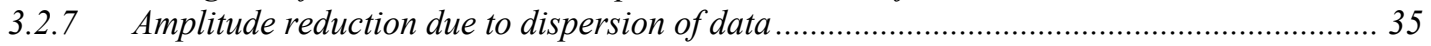

4 EXPERIMENTAL EQUIPMENT, PROCEDURES AND AVAILABLE DATA........................ 36

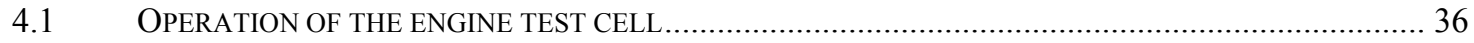

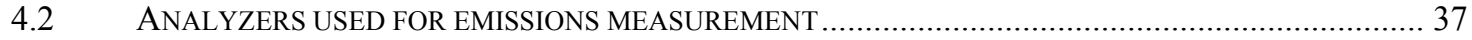

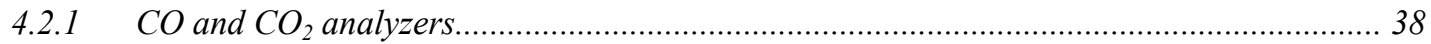

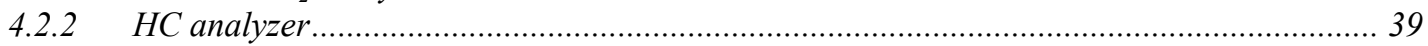

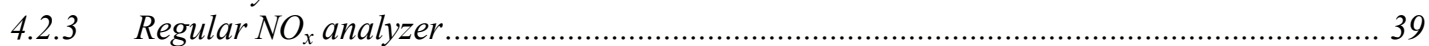

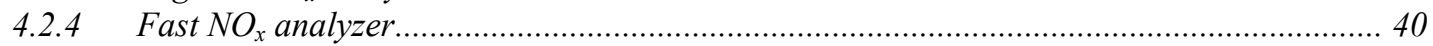

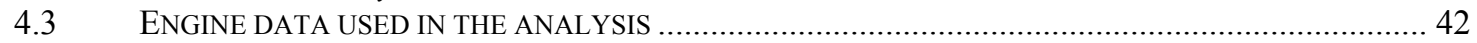

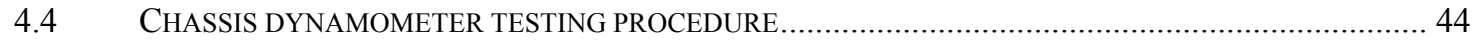

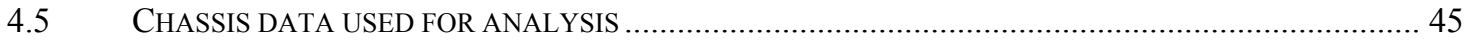




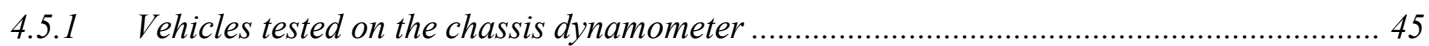

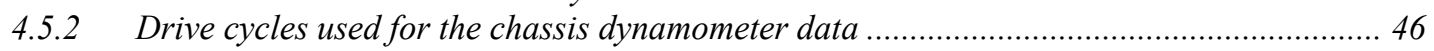

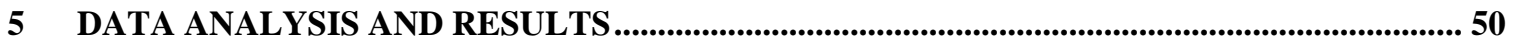

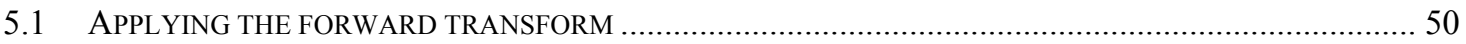

5.1.1 Operating variables that can simulate instantaneous data .................................................. 50

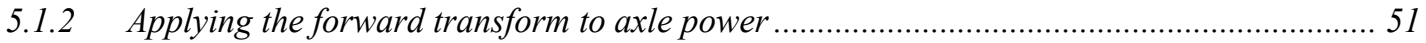

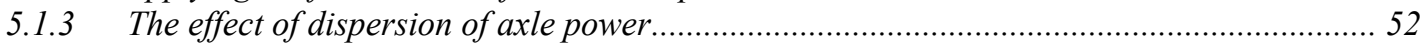

5.1.4 Constraint on emissions data for back-transformation ……………………........................ 53

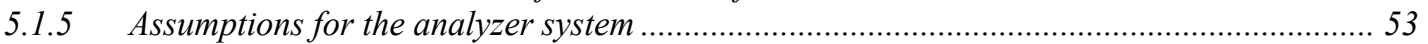

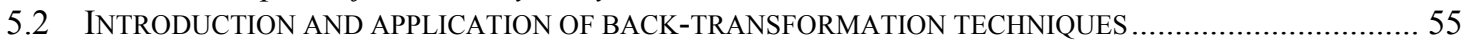

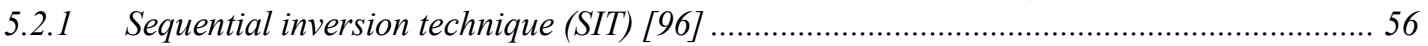

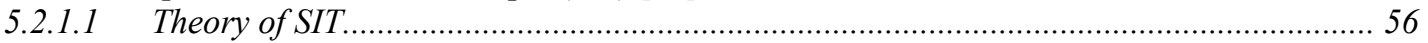

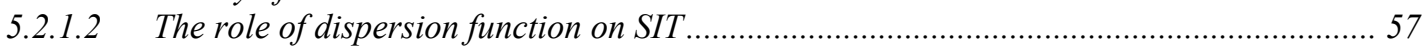

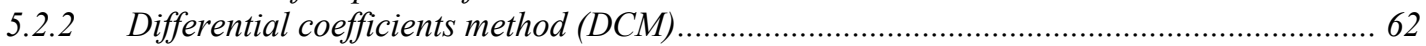

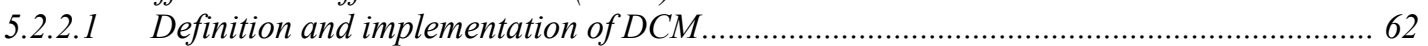

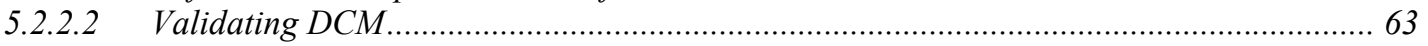

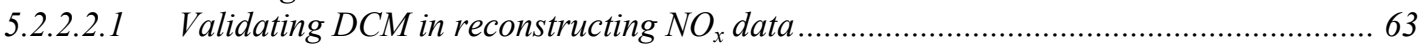

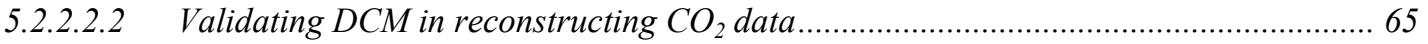

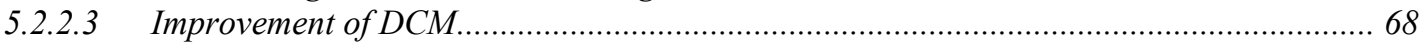

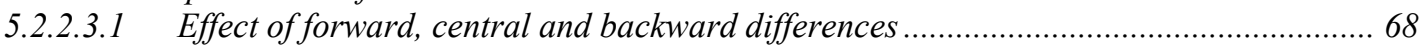

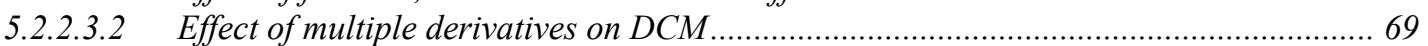

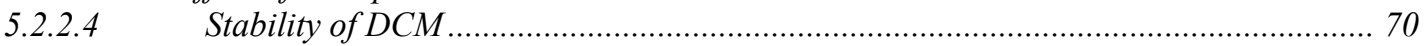

5.2.3 Fast Fourier Transform (FFT) and Inverse Fast Fourier Transform (IFFT) ...................... 71

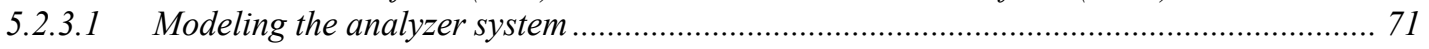

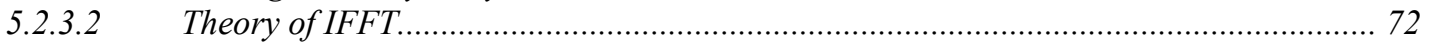

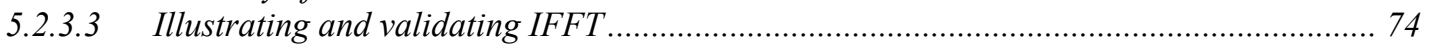

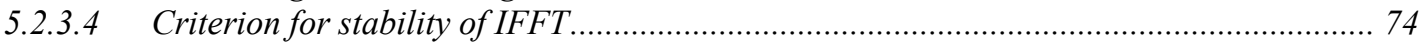

5.2.3.5 Comparing reconstruction 'efficiency' of IFFT and DCM .......................................... 77

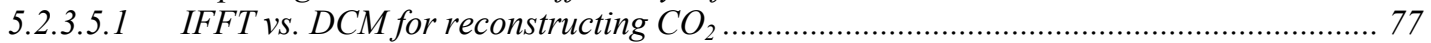

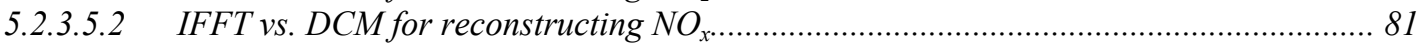

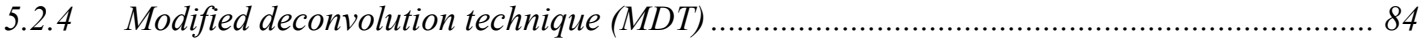

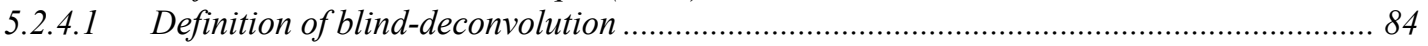

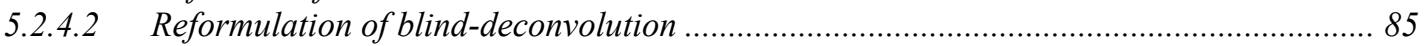

5.2.4.3 Theory and application of modified deconvolution technique (MDT) .............................. 86

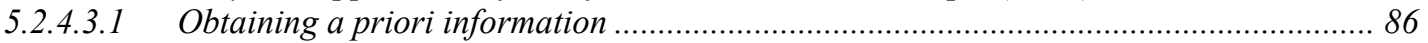

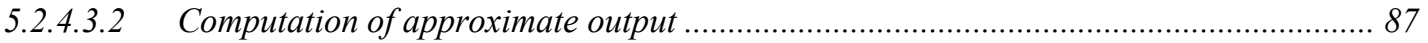

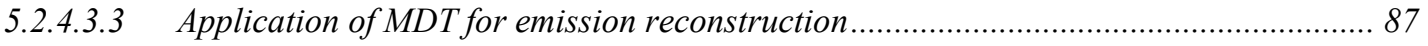

5.2.5 Influence of the operating condition on emission reconstruction ……................................. 89

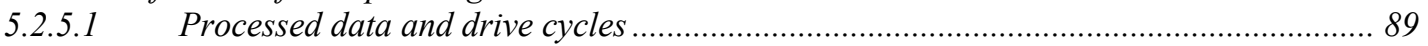

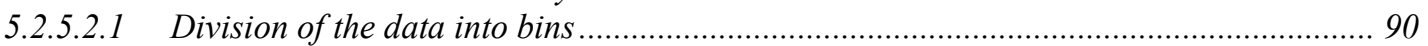

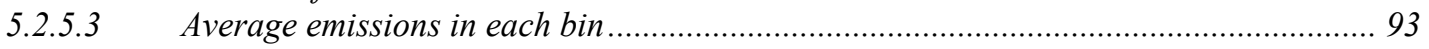

5.2.5.4 The standard deviation of emissions in each bin ........................................................... 96

6 CONCLUSIONS AND RECOMENDATIONS................................................................................ 98

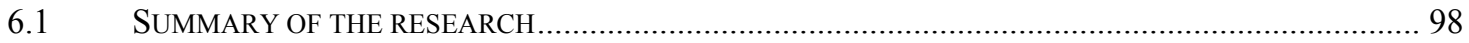

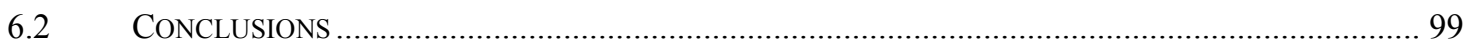

6.3 RECOMMENDED THEME FOR HEAVY-DUTY EMISSIONS RECONSTRUCTION ..................................100

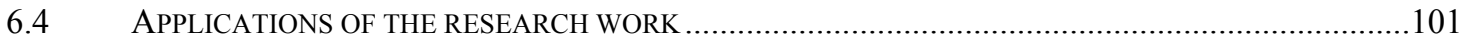

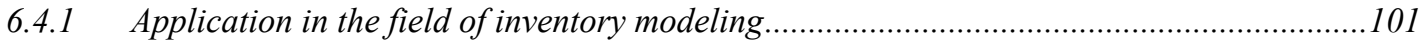

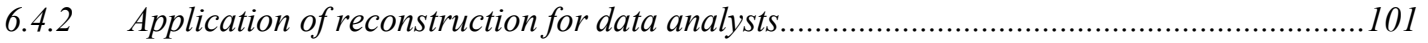

6.4.3 Application in the field of engine certification by EPA ……............................................102

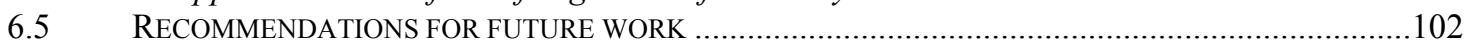




\section{LIST OF FIGURES}

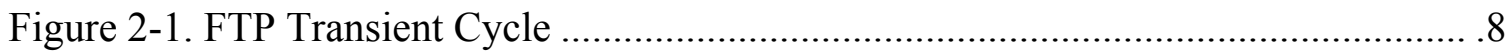

Figure 2-2. NTE torque and speed boundaries .......................................................... 14

Figure 3-1 (a). Impulse response of Rosemount $955 \mathrm{NO}_{\mathrm{x}}$ analyzer .............................. 29

Figure 3-1 (b). Impulse response of Horiba AIA 210 analyzer .................................... 30

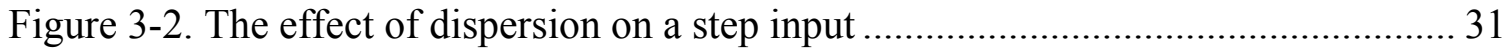

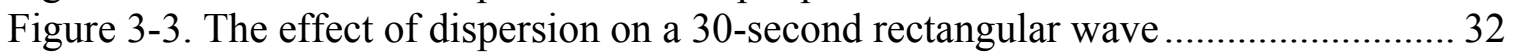

Figure 3-4. The effect of dispersion on a 10 second rectangular wave ........................... 33

Figure 3-5. Percent of lost emissions as a function of window size ............................... 34

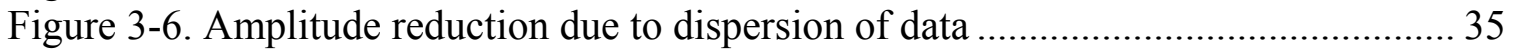

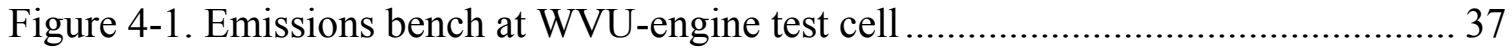

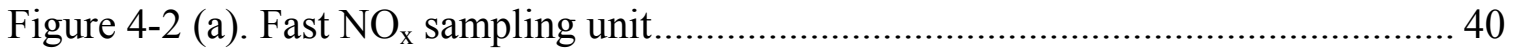

Figure 4-2 (b). Remote Sampling head of Fast $\mathrm{NO}_{\mathrm{x}}$ mounted on the dilution tunnel ...... 41

Figure 4-3. Speed (a) and torque (b) profiles of DDC Series 60 engine on FTP

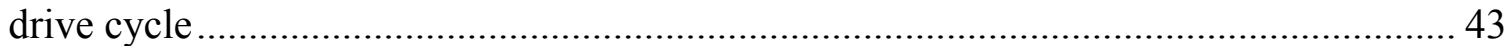

Figure 4-4. Speed profiles of different modes of HHDDT drive cycle .......................... 48

Figure 4-5. Speed profile of UDDS drive cycle ......................................................... 49

Figure 5-1. The effect of dispersion on the correlation between emission rate and

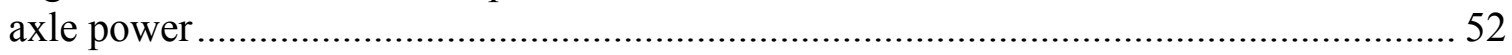

Figure 5-2 (a). Illustration of the time-invariance of a system ............................................5

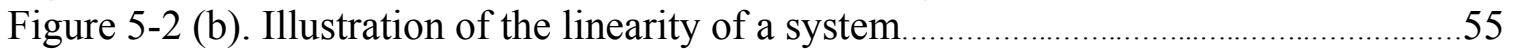

Figure 5-3. Reconstruction using SIT (a) continuous emission (b) parity plot ............... 58

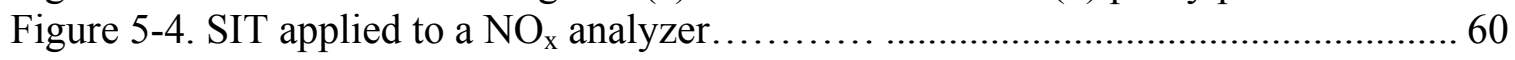

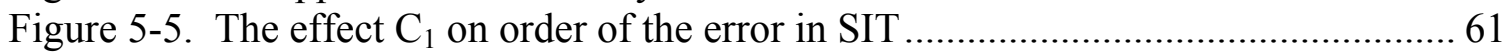

Figure 5-6. $\mathrm{NO}_{\mathrm{x}}$ reconstruction using DCM (a \& b) Continuous data (c) Parity plot ...... 65

Figure 5-7. $\mathrm{CO}_{2}$ reconstruction using DCM (a) Parity plot (b) Continuous data.............. 67

Figure 5-8. Representation of the system in time domain .......................................... 72

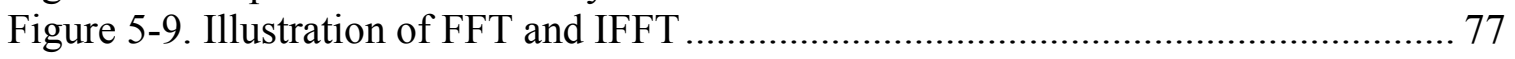

Figure 5-10. Comparison of DCM and IFFT in reconstruction of $\mathrm{CO}_{2}$ emissions from

Peterbilt truck with Caterpillar 3406E engine tested on TEST_D cycle .........................8 80

Figure 5-11. Comparison of DCM and IFFT in reconstruction of $\mathrm{NO}_{\mathrm{x}}$ emissions from

Peterbilt truck with Caterpillar 3406E engine tested on UDDS cycle............................ 83

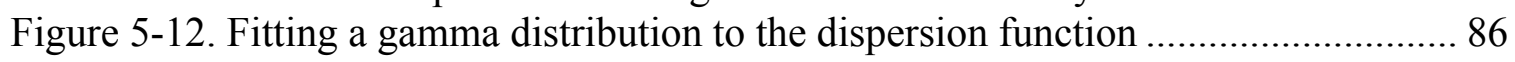

Figure 5-13 (a). MDT in reconstruction of $\mathrm{CO}_{2}$ emissions from Peterbilt truck with

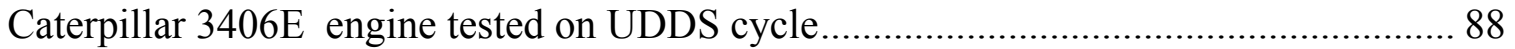

Figure 5-13 (b). MDT in reconstruction of $\mathrm{NO}_{\mathrm{x}}$ emissions from Peterbilt truck with

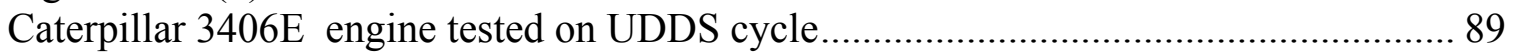

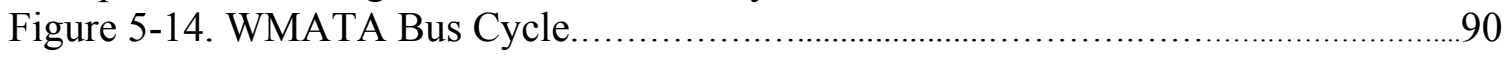

Figure 5-15 (a). The ratio of bin average of the reconstructed to measured emissions

for New Flyer 2006 Transit bus tested on UDDS drive cycle...........................94

Figure 5-15 (b). The ratio of bin average of the reconstructed to measured emissions

for New Flyer 2006 Transit bus tested on WMATA drive cycle ...............................................94

Figure 5-16 (a). Effect of reconstruction on bin with constant speed..................................95

Figure 5-16 (b). Effect of reconstruction on bin with constant acceleration................95 
Figure 5-17 (a). The ratio of percent standard deviation of the reconstructed to measured emissions for New Flyer 2006 Transit bus tested on UDDS drive

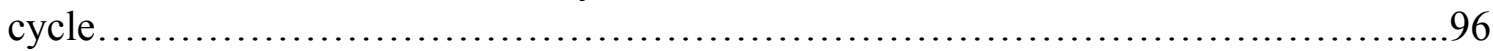

Figure 5-17 (b). The ratio of percent standard deviation of the reconstructed to measured emissions for New Flyer 2006 Transit bus tested on WMATA drive

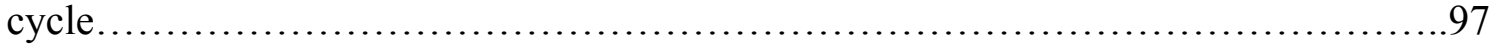




\section{LIST OF TABLES}

Table 2-1. Emission standards for heavy duty diesel engines

Table 4-1. Working principles of the analyzers for each of the exhaust gas

components. 38

Table 4-2. Details of the engines tested on the engine dynamometer

Table 4-3. Details of the vehicles tested.

Table 5-1. $\mathrm{R}^{2}$ values for the three FTP runs examined to test the validity of the DCM ... 65

Table 5-2. Errors in DCM with different numerical methods for computing the derivatives

Table 5-3. Errors in DCM with multiple derivatives

Table 5-4. Comparison of IFFT and DCM in reconstructing $\mathrm{CO}_{2}$.....

Table 5-5. Comparison of DCM and IFFT in reconstructing $\mathrm{NO}_{\mathrm{X}}$

Table 5-6 (a). Measured $\mathrm{CO}_{2}(\mathrm{~g} / \mathrm{s})$ for different combinations of speed and acceleration from a New Flyer 2006 Transit bus tested on UDDS drive cycle.

Table 5-6 (b) Reconstructed $\mathrm{CO}_{2}(\mathrm{~g} / \mathrm{s})$ for different combinations of speed and acceleration from a New Flyer 2006 Transit bus tested on WMATA drive cycle. 


\section{NOMENCLATURE AND ABBREVIATIONS}

$\Delta \mathrm{t}$

$\Delta \mathrm{t}_{\mathrm{av}}$

$\prod$

bsfc

${ }^{0} \mathrm{C}$

$\mathrm{C}_{\mathrm{i}}$

$\mathrm{C}(\mathrm{t})$

CARB

CAT

CFR

$\mathrm{CO}$

$\mathrm{CO}_{2}$

COPERT

$\mathrm{CRC}$

$\mathrm{D}$

d

$\mathrm{D} / \mathrm{uL}$

DCM

DDC

DOT

ECT

ECU

EERL

EGR

EPA

ESC

$\mathrm{E}_{\mathrm{j}}$

${ }^{0} \mathrm{~F}$

FFT

$\mathrm{fNO}_{\mathrm{x}}$

FTIR
Time shift

Average time shift

Correlation Coefficient

Brake-Specific Fuel Consumption

Degree Celsius

$\mathrm{I}^{\text {th }}$ element of the dispersion function

Emission rate

California Air Resources Board

Caterpillar

Code of Federal Regulations

Carbon Monoxide

Carbon Dioxide

Computer Program to Calculate Emissions from Road Transport

Coordinating Research Council

Axial dispersion coefficient

Coefficient of molecular dispersion

Vessel dispersion number

Differential Coefficients Method

Detroit Diesel Corporation

Department of Transportation

Engine Coolant Temperature

Engine Control Unit

Engine and Emissions Research Laboratory

Exhaust Gas Recirculation

Environmental Protection Agency

European Stationary Cycle

Emission at time $\mathrm{t}=\mathrm{t}_{\mathrm{j}}$

Degree Fahrenheit

Fast Fourier Transform

Fast $\mathrm{NO}_{\mathrm{x}}$

Fourier Transform Infrared 


$\begin{array}{ll}\text { FTP } & \text { Federal Test Procedure } \\ \text { g/bhp-hr } & \text { Grams per brake horsepower hour } \\ \text { g/mile } & \text { Grams per mile } \\ \text { g/sec } & \text { Grams per second } \\ \text { gal } & \text { Gallon } \\ \text { GVWR } & \text { Gross Vehicle Weight Rating } \\ \mathrm{H} & \text { Dispersion function } \\ \text { HC } & \text { Hydrocarbons } \\ \text { HDDE } & \text { Heavy-Duty Diesel Engine } \\ \text { HHDDT } & \text { Heavy Heavy-Duty Diesel Truck } \\ \mathrm{h}_{\mathrm{m}} & \text { Transfer function } \\ \mathrm{hp} & \text { Horsepower } \\ \mathrm{Hz} & \text { Hertz } \\ \mathrm{IFFT} & \text { Inverse Fast Fourier Transform } \\ \mathrm{IMP} & \text { Inlet Manifold Pressure } \\ \mathrm{IMT} & \text { Inlet Manifold Temperature } \\ \mathrm{K}, \theta & \text { parameters of the gamma distribution } \\ \mathrm{kg} & \text { Kilograms } \\ \mathrm{km} & \text { Kilometer } \\ \mathrm{kW} & \text { Kilowatts } \\ \mathrm{lb} & \text { Pounds } \\ \mathrm{lb}-\mathrm{ft} & \text { Foot-pound } \\ \mathrm{MDT} & \text { Modified De-convolution Technique } \\ \mathrm{MEMS} & \text { Mobile Emissions Measurement System } \\ \mathrm{MEP} & \text { Mean Effective Pressure } \\ \mathrm{mph} & \text { Miles per hour } \\ \mathrm{m} / \mathrm{s} & \text { Meters per second } \\ \mathrm{m} / \mathrm{s}^{2} & \text { Meters per second squared } \\ \mathrm{MVEI} & \text { Motor Vehicle Emission Inventory } \\ \mathrm{N} & \text { Size of the continuous data } \\ \mathrm{NDIR} & \text { Non-Dispersive Infrared } \\ \mathrm{NMHC} & \text { Non-Methane Hydrocarbons } \\ \mathrm{NO} & \text { Nitric Oxide } \\ & \end{array}$




$\begin{array}{ll}\mathrm{NO}_{2} & \text { Nitrogen dioxide } \\ \mathrm{NO}_{\mathrm{X}} & \text { Oxides of nitrogen } \\ \mathrm{NTE} & \text { Not-To-Exceed } \\ \text { PEMS } & \text { Portable Emissions Measurement System } \\ \mathrm{PM} & \text { Particulate Matter } \\ \mathrm{ppm} & \text { Parts Per Million } \\ \text { PREVIEW } & \text { Portable Real-Time Emission Vehicular Integrated Engineering } \\ & \text { Workstation } \\ \text { PSF } & \text { Point Spread Function } \\ \mathrm{P}_{\mathrm{i}} & \text { Power at time } \mathrm{t}=\mathrm{i} \\ \mathrm{R}^{2} & \text { Coefficient of regression } \\ \text { ROVER } & \text { Real-time On-road Vehicle Emissions Recorder } \\ \text { RPM } & \text { Revolutions per Minute } \\ \text { SAE } & \text { Society of Automotive Engineers } \\ \mathrm{SET} & \text { Supplemental Emissions Test } \\ \mathrm{SIT} & \text { Sequential Inversion Technique } \\ \text { std } & \text { standard deviation } \\ \mathrm{t} & \text { Time } \\ \theta_{\mathrm{i}} & \text { Non dimensional time } \\ \text { TRANS-LAB } & \text { Transportable Laboratory } \\ \text { UDDS } & \text { Urban Dynamometer Driving Schedule Chassis Dynamometer Cycle } \\ \mathrm{U}\left(\mathrm{t}_{\mathrm{i}}\right) & \text { Analyzer input at time } \mathrm{t}=\mathrm{i} \\ \mathrm{US} \text { EPA } & \text { United States Environmental Protection Agency } \\ \mathrm{UV} & \text { Ultra-Violet } \\ \text { VGT } & \text { Variable Geometry Turbocharger } \\ \text { WMATA } & \text { Washington Metropolitan Area Transit Authority } \\ \text { WVU } & \text { West Virginia University } \\ \mathrm{x}(\mathrm{t}) & \text { Analyzer input } \\ \mathrm{Y}\left(\mathrm{t}_{\mathrm{i}}\right) & \text { Analyzer output at time } \mathrm{t}=\mathrm{i} \\ \mathrm{Y}^{\prime}(\mathrm{t}) & \text { First time derivative of the analyzer output } \\ \mathrm{Y}^{\prime \prime}(\mathrm{t}) & \text { Second time derivative of the analyzer output } \\ \end{array}$




\section{Introduction, Overview \& Objectives}

\subsection{Introduction}

Internal Combustion (IC) engines produce exhaust that contains carbon monoxide (CO), nitrogen oxides $\left(\mathrm{NO}_{\mathrm{x}}\right)$, hydrocarbons $(\mathrm{HC})$ and particulate matter $(\mathrm{PM})$. These emissions deteriorate the quality of the atmospheric air and human health. The United States Environmental Protection Agency (USEPA) introduced Clean Air Act in 1963 and ever since the emissions have been regulated.

In spite of their high initial cost and cold start problems, diesel engines are a popular, if not, automatic choice in heavy-duty trucks mainly because of their fuel efficiency. In order to further improve fuel efficiency and reduce emissions, most of the onroad, heavy-duty trucks in the United States are equipped with direct injection diesel engines which are turbocharged and electronically controlled. The emissions from the diesel engine vary significantly from those from a gasoline engine. Particularly, $\mathrm{NO}_{\mathrm{x}}$ concentrations are much higher from diesel engines than from gasoline engines. $\mathrm{NO}_{\mathrm{x}}$ is a major contributor to photochemical smog, acid rain and low level ozone formation.

\subsection{Overview}

'Instantaneous' emissions are the actual emissions produced by the engine due to the combustion of the fuel. A measurement system can be used to record these instantaneous emissions, but the system will distort the signal that corresponds to the instantaneous emissions and produce an output signal, which represents the 'measured' emissions. For an ideal analyzer system, the measured emissions will be the same as the 
instantaneous emissions. However, any real analyzer system will report a distorted signal during the process of measurement. For example, the emissions reported by the analyzer may be delayed and dispersed relative to the instantaneous emissions.

By understanding the relationship between the measured and the instantaneous emissions, an attempt can be made to obtain the instantaneous signal from the measured signal. This procedure will be referred to as 'reconstruction' in this document. Transient dynamics of the analyzer need to be measured and understood through laboratory procedures. This enables verifying the accuracy of the reconstruction that can be applied to the measured data.

\subsection{Purpose and objective of the research}

EPA currently certifies engines for emissions in a thirty second NTE (Not-ToExceed) window. This involves driving the vehicle continuously for at least 30 seconds within the operating constraints associated with NTE certification. A more detailed description of the certification procedure is given in Chapter 2 and the effects of the window size are discussed in Chapter 3. Currently, the measured emissions are regulated and the analyzer systems must meet a specification. But the emissions that are measured are not in fact the true (instantaneous) emissions. Since the measurement systems distort the true emissions, there is a chance that some of the engines that could get certified for the measured emissions may not get certified if the true emissions are considered for certification. Reconstructed instantaneous emissions should be useful for the EPA in certification of engines. 
The objective of this research is to apply reconstruction techniques to estimate instantaneous heavy-duty instantaneous emissions. These techniques will take as the input, the continuous set of emissions data and approximate dispersion characteristics of the analyzer employed in measuring the continuous data.

\subsection{Plan to meet the objective}

In order to meet the objective, four different methods of reconstruction were presented and each of those methods was tested with the real-time emissions data. Some of the methods were slightly modified and adapted to help the reconstruction. Further, the transient response characteristics of the analyzers employed in the measurement were thoroughly understood and were verified using a forward transform.

\subsection{Organization of this document}

Chapter 2 provides information about the current legislated testing procedures for heavy-duty engines and acceptable emissions standards. An overview of work done on emission inventory modeling is presented.

Chapter 3 introduces the concepts of time delay and time dispersion of data. A brief literature review on the calculation and the correction of measurement time delays is presented. Further more, calculation of analyzer dispersion is presented, followed by the effects and significance of such dispersion on continuous emissions data measurement.

Chapter 4 discusses the details of the measurement equipment, the procedures followed in the laboratories to obtain the continuous emissions data and a detailed description of the drive cycles employed and the types of engines tested. 
Chapter 5 provides insight into the correlations of emissions with an operating variable such as power and how analyzer dispersion (discussed in Chapter 3) can be applied to real-time data. After verifying the forward transform, several methods of reconstruction (back transform) were presented and validated using the real-time emissions data.

Chapter 6 consists of conclusions drawn from the research and recommendations for extending the work. 


\section{$2 \quad$ Literature Review}

This chapter provides information about the current legislated testing procedures for heavy-duty engines and acceptable emissions standards. Further an overview of previous work done on emission inventory modeling is presented.

\subsection{Air quality and health effects of emissions}

The major components of diesel exhaust are carbon monoxide (CO), nitrogen oxides $\left(\mathrm{NO}_{\mathrm{x}}\right)$, hydrocarbons $(\mathrm{HC})$ and particulate matter $(\mathrm{PM})$. These diesel emissions are a complex mixture with majority (more than 90\%) of the particles less than $1 \mu \mathrm{m}$ and hence easily respirable [1]. The Health Effects Institute (HEI) Diesel Working Group has presented a comprehensive report about the adverse health effects of diesel exhaust [2]. According to the report, the risk of cancer increases with increasing exposure to the diesel exhaust. Carbon monoxide (CO) when inhaled mixes with the hemoglobin of the blood and reduces its oxygen-carrying capacity [3]. This could result in dizziness, and intake of higher concentrations of $\mathrm{CO}$ can result in death. Oxides of nitrogen $\left(\mathrm{NO}_{\mathrm{x}}\right)$ are formed when combustion takes place at high temperatures, and these oxides are one of the primary sources of ozone at the ground level. These oxides are a mixture of oxidizing gases capable of damaging cells lining the respiratory tract. A more detailed description of the health effects of emissions can be obtained elsewhere [4-6].

The United States Environmental Protection Agency (USEPA) monitors and reports on air quality in the United States. With assistance from the local air-quality control boards, the USEPA measures the level of pollution based on the Air Quality Index (AQI), which 
ranges from 0 to 500 [7]. If the index is over 100 , the quality of air is considered unhealthy. In order to minimize the dangers posed by these emissions on human health, the USEPA introduced the Clean Air Act for the first time in 1963. Ever since, the emissions have been monitored and regulated. As a result, the nation's air quality has greatly improved over the last 20 years [7].

\subsection{Significance of heavy-duty emissions}

Though heavy-duty diesel vehicles comprise of only $2 \%$ of the on-road vehicle population, they are driven for long hours and are loaded with more cargo than the majority of other on-road vehicles. Hence, their contribution to on-road $\mathrm{NO}_{\mathrm{x}}$ emissions is $45 \%$, as estimated by the California Air Resources Board (CARB) [8]. Another study indicates that

almost half of the on-road emissions of $\mathrm{NO}_{\mathrm{x}}$ are from heavy-duty diesel vehicles [9]. The 2010 standards for diesel emissions in the US allow a maximum $\mathrm{NO}_{\mathrm{x}}$ of 0.2 grams per brake horsepower hour (g/bhp-hr).

\subsection{Heavy-duty cycle development}

The US Federal Government introduced the first Clean Air Act in 1963 to improve ambient air quality [10]. Emissions regulations were imposed on all vehicles in California when the state established CARB in 1967. In 1970, the EPA introduced nationwide emissions regulations for heavy-duty diesel engines with amendments to the first Clean Air Act. A study named CAPE-21 was conducted in 1972 by the USEPA and the Coordinating Research Council (CRC) to develop a test cycle that represented the on-road heavy-duty 
driving in the country [11]. Data were collected from several trucks and buses in Los Angles and New York. From the observations made by the study, the chassis cycle (Urban Dynamometer Driving Schedule (UDDS)) and the engine dynamometer cycle (transient FTP) were developed in 1978. Except in California, the present-day inventory modeling for heavy-duty engines employs the emissions measurement from the transient Federal Test Procedure (FTP), which is an engine-based, speed-time and torque-time trace as specified in the Code of Federal Regulations (CFR) [12]. The FTP transient cycle (Figure 2-1) [13] comprises of four phases. The first phase is a New York Non Freeway (NYNF), which represents driving in light urban traffic. The second phase is Los Angeles Non Freeway (LANF), which represents driving in a crowded urban traffic with few stops. The third is a Los Angeles Freeway (LAFY), which is a typical busy expressway driving in Los Angeles. The final phase is the same as the first phase, NYNF. 


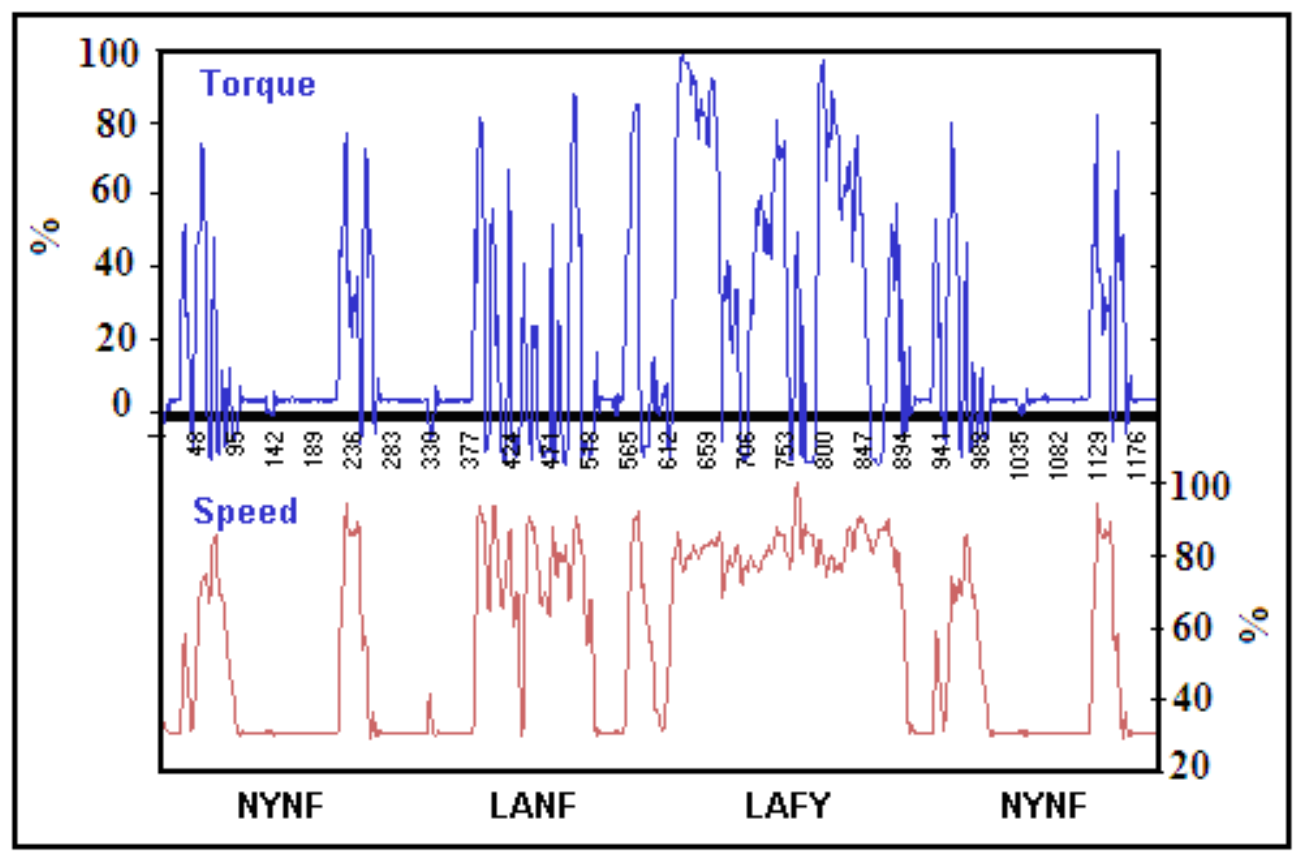

Figure 2-1. FTP Transient Cycle [13]

\subsection{Units for measurement of heavy-duty emissions}

The measurement systems in the heavy-duty emissions testing laboratories usually provide the cumulative emissions for the entire operating cycle and continuous emissions. In the case of engine testing, the emissions of each component of the exhaust for the whole cycle can be reported as mass of emissions per unit work. These emissions are expressed in grams of component per unit of mechanical energy delivered by the engine, such as $\mathrm{g} / \mathrm{kWh}$ or $\mathrm{g} / \mathrm{bhp}-\mathrm{hr}$. In case of chassis dynamometer testing, the mass emissions rate of each component of the exhaust is reported as mass of emissions per mile (g/mile) and mass of emissions per gallon of fuel intake (g/gal). 


\subsection{Steady state and transient emissions test cycles}

Heavy-duty diesel emissions measurements are performed either on an engine or a chassis dynamometer over a standardized emission test cycle. Each of the engine test cycles is a sequence of engine operating conditions. The emissions test cycles can be either steady-state or transient cycles. Steady state test cycles are comprised of sequences in which the engine has to be operated in modes of constant engine speed and load and the emissions are analyzed for each test mode. The overall emissions are calculated as a weighted average from all test modes. Transient test cycles, on the other hand, have a predetermined pattern, which comprises of variations of speed and load on the engine. Transient test emissions are continuously collected and analyzed over the duration of the operating cycle. Different test cycles used in this study are described in detail in Chapter 4.

\subsection{Need for continuous data of emissions}

Each component of emissions can be measured in units such as grams per cycle or grams per mile. While this total provides an overall estimate of emissions, it fails to provide information about the instantaneous emissions produced from the vehicle at any specific time during the drive cycle. Monitoring continuous data can be useful for researchers in analyzing the emissions as a function of other vehicle operating parameters such as torque and axle power. There is a need for continuous emissions data in order to optimize engine control strategies and to formulate the emissions inventory models. Moreover continuous emissions data help the researchers understand how the vehicle operating condition affects the emissions. 


\subsection{Heavy-duty emissions standards}

The EPA defines heavy-duty vehicles as vehicles with a gross vehicle weight rating (GVWR) higher than 8,500 lb. Heavy-duty vehicles are further divided into three categories based on the GVWR [14]. Light heavy-duty vehicles have a GVWR of at least $8,500 \mathrm{lb}$, but less than $19,500 \mathrm{lb}$; medium heavy-duty vehicles have a GVWR of at least $19,500 \mathrm{lb}$, but not more than $33,000 \mathrm{lb}$, while the heavy heavy-duty vehicles have a GVWR higher than 33,000 lb. The emissions standards [15 , 16] for heavy-duty diesel engines are shown in Table 2-1. The maximum permissible $\mathrm{PM}$ and $\mathrm{NO}_{\mathrm{x}}$ levels have been reduced significantly. Effective from October 2002, EPA introduced US 2004 standard of 2.5 $\mathrm{g} / \mathrm{bhp}$-hr for $\mathrm{NO}_{\mathrm{x}}$ and non-methane hydrocarbons (NMHC) combined [17]. In response to this standard, most of the manufacturers employed Exhaust Gas Recirculation (EGR). The 2010 emissions standard of $\mathrm{NO}_{\mathrm{x}}+\mathrm{NMHC}$ for all the heavy-duty diesel engines is 0.2 g/bhp-hr.

Table 2-1 Emission standards for heavy duty diesel engines [16] 


\begin{tabular}{|c|c|c|c|c|}
\hline Model year & HC (g/bhp-hr) & NO (g/bhp-hr) & CO (g/bhp-hr) & PM (g/bhp-hr) \\
\hline \multicolumn{5}{|c|}{ Heavy-duty diesel truck engines } \\
\hline 1988 & 1.3 & 10.7 & 15.5 & 0.6 \\
\hline 1990 & 1.3 & 6.0 & 15.5 & 0.6 \\
\hline 1991 & 1.3 & 5.0 & 15.5 & 0.25 \\
\hline 1994 & 1.3 & 5.0 & 15.5 & 0.10 \\
\hline 1998 & 1.3 & 4.0 & 15.5 & 0.10 \\
\hline 2004 & 1.3 & $\begin{array}{c}2.4 \\
\left(\text { or } \mathrm{NO}_{\mathrm{x}}+\mathrm{NMHC} \leq 2.5\right. \\
\text { and } \mathrm{NMHC} \leq 0.5)\end{array}$ & 15.5 & 0.10 \\
\hline 2007 & 1.3 & $\begin{array}{c}\text { Family Emission Limit of } \\
1.2<\left(\mathrm{NO}_{\mathrm{x}}+\mathrm{NMHC}\right) \leq 1.5\end{array}$ & 15.5 & 0.01 \\
\hline 2010 & 1.3 & $\begin{array}{l}\left(\mathrm{NO}_{\mathrm{x}}+\mathrm{NMHC} \leq 0.2\right. \\
\text { and } \mathrm{NMHC} \leq 0.14)\end{array}$ & 15.5 & 0.01 \\
\hline \multicolumn{5}{|c|}{ Urban bus engines } \\
\hline 1991 & 1.3 & 5.0 & 15.5 & 0.25 \\
\hline 1993 & 1.3 & 5.0 & 15.5 & 0.10 \\
\hline 1994 & 1.3 & 5.0 & 15.5 & 0.07 \\
\hline 1996 & 1.3 & 5.0 & 15.5 & 0.05 \\
\hline 1998 & 1.3 & 4.0 & 15.5 & 0.05 \\
\hline 2004 & 1.3 & $\begin{array}{c}2.4 \\
\text { (or } \mathrm{NO}_{\mathrm{x}}+\mathrm{NMHC} \leq 2.5 \\
\text { and } \mathrm{NMHC} \leq 0.5 \text { ) }\end{array}$ & 15.5 & 0.05 \\
\hline 2007 & 1.3 & $\begin{array}{l}\text { Family Emission Limit of } \\
1.2<\left(\mathrm{NO}_{\mathrm{x}}+\mathrm{NMHC}\right) \leq 1.5\end{array}$ & 15.5 & 0.01 \\
\hline 2010 & 1.3 & $\begin{array}{l}\left(\mathrm{NO}_{\mathrm{x}}+\mathrm{NMHC} \leq 0.2\right. \\
\text { and } \mathrm{NMHC} \leq 0.14)\end{array}$ & 15.5 & 0.01 \\
\hline
\end{tabular}




\subsection{Consent decrees}

In 2000, Yanowitz et al. [18] argued that, over the last two decades, the emissions of particulate matter from heavy-duty diesel engines have decreased, but $\mathrm{NO}_{\mathrm{x}}$ emissions have not. This is because some engine manufacturers operated the engines differently during certification than they would be operating during normal use [19]. The difference between the real-world operation and the certification was significant when the vehicle was at high speed or cruising. The EPA identified these manufacturers and introduced additional testing requirements for engines manufactured by them. Hence, the EPA, the United States Department of Justice, CARB, and the engine manufacturers (Caterpillar, Cummins, Detroit Diesel, Volvo, Mack Trucks, Renault, and Navistar) reached a settlement [20] in October 1998 to limit $\mathrm{NO}_{\mathrm{x}}$ emissions from heavy-duty diesel engines. The consent decree settlements required that the engines manufactured should be meeting within four years from then (by October 2002) the new US 2004 standard of $2.5 \mathrm{~g} / \mathrm{bhp}-\mathrm{hr}$ for $\mathrm{NO}_{\mathrm{x}}$ and non-methane hydrocarbons (NMHC) combined. To meet these standards, most of the engine manufacturers have employed exhaust gas recirculation (EGR) for reducing $\mathrm{NO}_{\mathrm{x}}$ emissions to acceptable levels. In addition to these standards, several additional testing requirements were introduced in 1998. These include Supplemental Emissions Test (SET) and Not-to-Exceed (NTE) limits.

\subsection{The SET limits}

The purpose of SET was to control the heavy-duty engine emissions during steadystate driving. The test [21] consists of 13 modes and is based on the 13 mode Euro III 
cycle. Each of the 13 modes has duration of 2 minutes and is specified by various speed and load points. Each mode is assigned a weighing factor, and the emissions are averaged over the entire cycle using those weighing factors.

\subsection{NTE limits}

The EPA has introduced the "Not to Exceed" (NTE) zone to control and monitor emissions. The NTE defines an engine operating envelope [22]. The NTE zone was introduced to account for the speed and torque points that the vehicle experiences in the real world. NTE takes into account speed values higher than $15 \%$ of the maximum ESC (European Stationary Cycle) speed, and torque and power values higher than $30 \%$ of the maximum ESC values. The ESC speed is calculated as follows:

$$
\mathrm{S}_{15 \% \text { ESC Speed }}=\mathrm{S}_{\mathrm{lo}}+0.15\left(\mathrm{~S}_{\mathrm{hi}}-\mathrm{S}_{\mathrm{lo}}\right)
$$

where $\mathrm{S}_{\mathrm{lo}}$ is the lowest engine speed corresponding to $50 \%$ of the maximum power and $\mathrm{S}_{\mathrm{hi}}$ is the highest engine speed that corresponds to $70 \%$ of the maximum power. The NTE zone [23] is shown in Figure 2-2.

The NTE test is defined in the Code of Federal Regulations, CFR 86.1370-2007. The NTE test procedure establishes a zone of operation with torque and speed boundaries (the NTE zone) where emissions must not exceed a specified value for any regulated pollutants. NTE testing does not involve a specific driving cycle, but it involves driving of any type that could occur within the bounds of the NTE control area. The emissions from this NTE testing are averaged for at least thirty seconds and are compared to the applicable NTE emission limits. The standards were created by EPA in accordance with the consent 
decree between the EPA and several major diesel engine manufacturers. The NTE limit is 1.25 times the FTP limit. For 2005 model year heavy-duty engines, the NTE limit for NMHC plus $\mathrm{NO}_{\mathrm{x}}$ is 3.125 grams per brake horsepower-hour. For 2007 engines, the corresponding NTE limit is 0.25 grams per brake horsepower-hour.

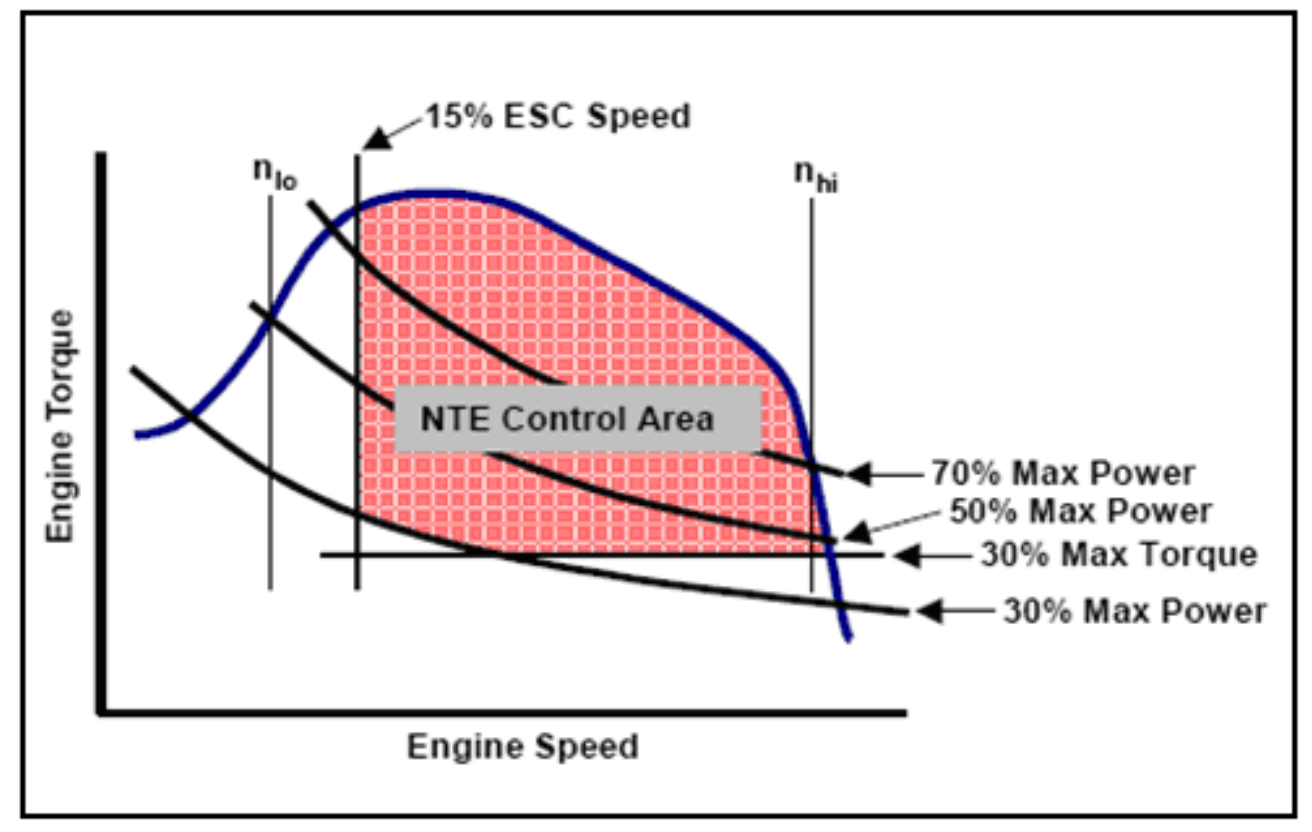

Figure 2-2. NTE torque and speed boundaries [23]

\subsection{Definition and requirements of the NTE event}

For an engine to be operating in the NTE zone, some additional criteria need to be verified. These criteria include conditions based on altitude, ambient temperature, engine brake-specific fuel consumption (bsfc), inlet manifold temperature and pressure (IMT, IMP), and engine coolant temperature (ECT). The additional criteria for an engine to be operating in the NTE zone are as follows:

"1. Vehicle altitude $\leq 5500 \mathrm{ft}$

2. Ambient temperature $\leq 100^{\circ} \mathrm{F}$ at sea level to $86^{\circ} \mathrm{F}$ at $5500 \mathrm{ft}$ 
3. bsfc $\leq 105 \%$ of the minimum bsfc if an engine is not coupled to a multi-speed manual or automatic transmission

4. Engine operation must be outside of any engine manufacturer petitioned exclusion Zone.(operating zone in which the engine is not capable of operating in real-world conditions for

5. Engine operation must be outside of any NTE region where an engine manufacturer declares that less than $5 \%$ of in-use operation occurs

6. For EGR-equipped engines, IMT $\geq 86^{\circ} \mathrm{F}$ to $100^{\circ} \mathrm{F}$, depending on IMP

7. For EGR-equipped engines, ECT $\geq 125^{\circ} \mathrm{F}$ to $140^{\circ} \mathrm{F}$, depending on IMP

8. If equipped, an engine's after-treatment system's or systems' temperature $(\mathrm{s}) \geq 482^{\circ} \mathrm{F}$

If all of these conditions are satisfied simultaneously for a 30 second window, then that window is considered a 30 second NTE event. [24]"

\subsection{Problems with NTE operation}

While the EPA clearly specified the above requirements to be achieved by the engine while operating in the NTE zone, a controversy remains as to the applicability of the NTE limits in real-world driving. While the engine is required to be in the NTE zone for at least 30 seconds, in real-world driving conditions, there is a chance that the engine may operate outside the NTE zone for a few seconds [25-27]. Then such an operation may not be considered as an NTE event according to the definition. When the engines are highpowered, it is highly likely that the power required for the cruising speed is around $30 \%$ of the engine power, and that might fluctuate below the minimum power envelope [28]. 
Moreover, when the engine is operating in the NTE zone, it could emit elevated $\mathrm{NO}_{\mathrm{x}}$ at power levels just outside the NTE zone, or at idle.

\subsection{NTE Window Size}

In the NTE zone, the emissions are measured and averaged at least for thirty seconds and are compared to the applicable NTE emission limits. But some of the emissions that correspond to the NTE operation may not be even measured in the NTE zone. These could be due to time dispersion in measurement, which are explained in Chapter 3. One reason for using windows at least 30 seconds wide is to account for signal dispersion. In fact, the window size is like a confidence interval. The larger the window size, the better are the chances of getting an accurate estimate of total emissions within the window. With smaller windows, the chances of the emissions not being measured completely are higher (than with larger windows). These emissions are referred to as 'lost emissions,' in this document and this concept is introduced in Chapter 3. There is also a chance that the measured emissions are more than the actual emissions for a given window, which are introduced as 'gained' 'emissions.

\subsection{Motivation to improve measurement accuracy}

The EPA faced lawsuits from the engine manufacturers regarding the technological feasibility of the engine emission control strategies in EPA regulations pertaining to the NTE limits [22]. But the testing in the NTE zone is not a standardized emissions laboratory test like the FTP. The EPA resolved this matter by proposing a well-described emissions 
test known as "Heavy-Duty In-Use NTE Testing" (HDIUT) for diesel engines and vehicles. One section of that outline stated: "The NTE Threshold will be the NTE standard, including the margins built into the existing regulation, plus an additional margin to account for in-use measurement accuracy. This additional margin shall be determined by the measurement processes and methodologies to be developed and approved by EPA/CARB. The margin will be structured to encourage instrument manufacturers to develop more and more accurate instruments in the future. [29]" This emphasizes the need to obtain more accurate emissions measurement techniques.

\subsection{On board measurement}

Engine manufacturers were found to have installed various defeat devices that electronically altered the engine's performance to minimize emissions during standard offroad procedures and increase economy (at the expense of higher emissions) when in normal use [19]. Hence, it became vital to obtain accurate estimate of exhaust emissions over a certain driving route. The most realistic solution seems to be on board measurement. Several portable emissions measurement systems (PEMS) were developed by various research facilities. Ford Motor Company and WPI-Microprocessor Systems, Inc. together developed PREVIEW [30] (Portable Real-Time Emission Vehicular Integrated Engineering Workstation) that samples water-laden exhaust. Horiba [31], Honda [32] and Ford [33] also developed several other on-board systems for emissions measurement. Some of these systems were large and not conveniently portable. However, none of the mobile emissions measurement systems developed over the past two decades was fully capable of meeting the requirements of measuring exhaust emissions from a heavy-duty vehicle 
during its in-use, on-road operation. In order to achieve accurate in-use brake-specific mass emissions, as required by the Consent Decrees, it is imperative that a viable PEMS be capable of accurately measuring several parameters in a repeatable manner with the highest level of precision. These include engine speed, engine torque, exhaust mass flow rates, and exhaust constituent concentrations.

In 2000, West Virginia University developed an on-board measurement system known as Mobile Emissions Measurement System (MEMS) [34-36] by evaluating PEMS and available technologies and completed the integration and testing of the Mobile Emissions Measurement System (MEMS). MEMS is capable of measuring in-use brakespecific $\mathrm{NO}_{\mathrm{x}}$ and $\mathrm{CO}_{2}$ emissions from heavy-duty diesel-powered vehicles driven over the road under real-world conditions. Also, MEMS allows the calculation of brake-specific mass emissions over 30 second windows within the NTE zone. Since March 2004, MEMS had been used to measure in-use emissions from 50 pre-consent decree vehicles and 170 post-consent decree vehicles [37].

\subsection{Emission inventory models}

Continuous data can also help formulate the emissions inventory models. For example, the EPA model, 'MOVES', (Motor Vehicle Emission Simulator) [38, 39] employs emissions as a function of vehicle specific power, while there is another approach [40] which uses speed-acceleration matrices. 


\subsubsection{Traffic situation models}

CARB developed emissions models known as MVEI. The model is composed of four computer models namely CALIMFAC, WEIGHT, BURDEN and EMFAC [41]. The CALIMFAC model produces emission rates for each model year when the vehicle is new and as it accumulates mileage and emission controls deteriorate. The WEIGHT model calculates the relative weighting each model year should be given in the total inventory, and each model year's accumulated mileage. The EMFAC model uses these pieces of information, along with correction factors and other data, to produce fleet composite emission factors. Finally the BURDEN model combines the emission factors with the county specific activity data to produce emission inventories.

The USEPA developed MOBILE [42], a vehicle emission factor model, which is a software tool for predicting emissions in grams per mile from cars, trucks, and motorcycles under various conditions. Base emission rates are estimated for each vehicle type based on the model year and they represent the emissions of an average vehicle of that type when used in average urban driving. Several correction factors are then applied to produce an emissions rate that simulates real-world conditions.

These models are supposed to estimate and model emissions based on the assumption that the exhaust emissions can be represented solely by the integrated values of a specific driving cycle. The estimation of emissions by these models involve determination of a set of emission factors that specifies the rate at which the emissions are generated and generation of an estimate of vehicle activity. However, there are several studies which concluded that the actual vehicle emissions and the emissions predicted using such models are significantly different [43-45]. 


\subsubsection{Average speed model}

A model known as the COPERT computer program [46] was developed by the Corinair work group. This model was based on speed-related emissions and fuel consumption. The emission and fuel rates were generated from cassis dynamometer measurements for different cycles and different average speed levels. This model is very simple, but is not sensitive to vehicle's operating modes.

\subsubsection{Physical models}

A generic physical model was presented by Barth et al. [47, 48]. The model consisted of an instantaneous power demand function, which estimates traction power through the sum-total of inertial load, frictional load and air-resistance. Then the engine power was obtained from the estimated traction power and the power absorbed by the accessories and the combined efficiency of transmission and final drive. This physical model also involved developing emissions rates by the estimation of fuel consumption rate and air/fuel ratio. This physical model can be combined very effectively with the vehicle operating parameters for a better time-resolved emission rates. These predicted rates can be compared to the measured rates iteratively for a better estimate by the model.

\subsubsection{Modal emissions model}

Aggregate modal emissions model was developed using statistical techniques [49]. The model was developed by closely analyzing a large database of emissions certification. 
The variations were then embedded into the model with the vehicle technologies, operating characteristics, test age and odometer of the vehicle being the variables. This technique determines the variables that have the greatest effect on overall emissions values. This modal model is aggregate in the sense that it predicts a single integrated emissions value given any particular driving cycle.

\subsubsection{Instantaneous emissions models}

Some instantaneous emissions models such as MOVES, estimate emissions based on the operating condition of the vehicle. Speed-acceleration look up tables have stored values for majority of the combinations of vehicle speed and acceleration. Each combination has a predetermined value of emissions and some of the emissions will be interpolated based on the known values. These tables can be created for each vehicle, or a group of vehicles, based on common vehicle attributes such as model year, engine type and technology [50].

The instantaneous emissions models predict emissions by relating emissions signals to vehicle operating variables such as vehicle speed, acceleration, etc. Some models used neural networks [51], which mimic the relationship between the emissions and different parameters related to the vehicle and then update the network based on the most recent data. A few other examples of instantaneous models can be found elsewhere [52-55]. These instantaneous models can be slightly modified to account for the data dispersion associated with the emissions measurement systems. The algorithms of MOVES can also be altered to accommodate data dispersion. This could enable a better emissions estimate. 


\section{$3 \quad$ Theory of Delay and Dispersion of Data}

This chapter introduces the concepts of time delay and time dispersion of data. A brief literature review on the calculation and the correction of measurement time delays is presented. Further more, calculation of analyzer dispersion is presented, followed by the effects and significance of such dispersion on continuous emissions data measurement.

\subsection{Measurement and compensation of delay}

\subsubsection{Measurement delay}

When the steady state condition of the engine changes, the corresponding engineout emissions levels also change. There is a time delay between the point when engine/vehicle experiences an operating condition and the point when the corresponding analyzer measures the emissions related to that operating condition. The time delay is a combination of transport time taken by the exhaust to reach the appropriate gas analyzer and the response time of the analyzer. The sum total of these two measurement delay times should account for the time shift between the instantaneous (actual) at the tail pipe and measured emissions. Messer [56] has presented a mathematical model that takes into account the heat transfer and the mass flow rate of the exhaust to accurately measure the delay time between the engine transients and emissions measurement. 


\subsubsection{Compensation for delay and brief review of literature}

To compensate for the delay, the emissions data should be shifted back in time to align with the engine operating variables like power and speed. It is accepted by the research community that the $\mathrm{CO}_{2}$ increases with increase in power because it represents the fuel consumption. Also $\mathrm{NO}_{\mathrm{x}}$ usually correlates with power, but if there are two engines operating at the same power, the engine operating at high speed and low load may produce a lesser amount of $\mathrm{NO}_{\mathrm{x}}$ than the engine operating at low speed and high load [57]. The importance of time-alignment was addressed in detail by Hawley [58]. There are several ways in which the emissions data can be time-aligned. Some researchers prefer visual timealignment, which is usually done by matching the crests and troughs of the continuous emissions data set with that of an engine or vehicle operating parameter such as power. The most widely followed procedure for time alignment is known as cross-correlation, where two data sets are compared against a common variable and the time shift that best matches the two sets is calculated. It is based on the assumption that a correlation exists between the two data sets. This method is widely used to calculate the measurement time delays involved in the emissions sampling train by comparing emissions with power. Ramamurthy [59] has used this cross correlation for modeling heavy-duty vehicle emissions inventory. The correlation coefficients involving two sets of data can be calculated using the Eq.3.1.

$$
\Pi_{\Delta t}=\frac{\sum_{\Delta t=-t_{\max }}^{t_{\max }-\Delta t}\left[P(t) C\left(t+\Delta t_{a v}\right)\right]}{\sum_{\Delta t=-t_{\max }}^{t_{\max }-\Delta t}[P(t) C(t)]}
$$


Where $\Pi_{\Delta t}$ is the correlation coefficient, $\mathrm{P}(\mathrm{t})$ is the power, $\mathrm{C}(\mathrm{t})$ is the emission rate of the gas the $\Delta \mathrm{t}_{\mathrm{av}}$ is the time shift between power and emissions rate. This time shift is the average response time for the exhaust collection system to detect a change in emission gas levels.

For all the data analysis in this document, the following procedure was followed for cross-correlating emissions data with power. Let the data of an operating variable be represented by $P_{i}$ (where $i=1$ to $N$, which is the size of the discrete time data under analysis) and those of an emissions component be represented by $E_{j}$, where $j$ also runs from 1to N. It is known that the E lags P. Let the dimensionless time shift (the number of time intervals) between the two sets of data be $\mathrm{s}$. If both $\mathrm{P}$ and $\mathrm{E}$ are aligned, the area under the product curve represented by the integral sum for continuous data $\int_{\mathrm{i}=1}^{\mathrm{N}-\mathrm{s}}\left(\mathrm{P}_{\mathrm{i}} \mathrm{E}_{\mathrm{i}+\mathrm{s}}\right) \mathrm{ds}$ should be maximized. In practical applications, a simple trial and error method was employed to determine the shift to maximize $\sum_{\mathrm{i}=1}^{\mathrm{N}-\mathrm{s}}\left(\mathrm{P}_{\mathrm{i}} \mathrm{E}_{\mathrm{i}+\mathrm{s}}\right)$, which is a cumulative sum of the product of $\mathrm{P}$ and $\mathrm{E}$ over the entire range of the data set. Some other algorithms were also developed which cross-correlate the derivatives of the two variables, while most of the algorithms cross-correlate only the variables $[\mathbf{6 0}, \mathbf{6 1}]$.

\subsection{Time dispersion of data and earlier work related to data dispersion}

Apart from the time delay, response can be dispersed over a period of time when measured by the analyzer, i.e. the specific operating condition experienced by the engine may be instantaneous, but the measured response (in same units as the operating condition) 
may spread over a period of time. The measured response also experiences amplitude reduction, i.e., the amplitude of a peak or a dip in measured response is smaller than the one actually experienced by the engine. This phenomenon is called attenuation in signal processing terms. Hence, the emissions as measured by the analyzers may not be the same as the instantaneous emissions at the tailpipe.

A brief illustration of dispersion is as follows. Consider a unit impulse input injected into an analyzer at time $\mathrm{t}=0$. The response in the first four successive time intervals starting from the first is $0.2,0.3,0.4$ and 0.1 units respectively. It is assumed that such an analyzer is used in measurement. Now, it is assumed that the analyzer is fed with an input pulse of $(1,3,2,1,4,0,1)$, which means 1 unit of emissions is injected in the first time interval, 3 units in the second and so on. The input $\mathrm{U}(\mathrm{t})$ is represented as a function of time. All the input of a species prior to the first interval is assumed to be zero in concentration. The analyzer diffuses the above input, $\mathrm{U}(\mathrm{t})$, according to a time dispersion function [0.2, $0.3,0.4,0.1]$ and generates the following output, say $\mathrm{Y}(\mathrm{t})$ of emissions in ppm in each interval, as follows. $(0.2,0.9,1.7,2.1,2.2,1.8,1.9,0.7,0.4,0.1)$. This is referred to as the diffused or dispersed output throughout this study. It is simply a convoluted product of the input $U(t)$ with the dispersion function. It should also be noted that for constant flow rate, it is immaterial whether one discusses concentration or mass flow of a species.

\subsubsection{Theory of dispersion}


According to Levenspiel's dispersion model [62-64], applicable for non-ideal fluid flow through a reactor, there will be a difference in time taken by elements of fluids that follow different paths through the reactor. The distribution of these times for the streams exiting the vessel is known as Residence Time Distribution (RTD) of the fluid. While the fluid molecules travel through the reactor, they get redistributed due to turbulence thus resulting in molecular dispersion. Molecular dispersion can be represented by Fick's law as

$$
\partial \mathrm{C} / \partial \mathrm{t}=\mathrm{d}\left(\partial^{2} \mathrm{C} / \partial \mathrm{x}^{2}\right)
$$

Eq 3.2

where $\mathrm{C}$ is the concentration and $\mathrm{d}$ is the coefficient of molecular dispersion. The above equation is non-dimensionalized. The concentration $\mathrm{C}_{\mathrm{i}}$ as a function of non dimensional time $\theta_{\mathrm{i}}$ can be given by the following model:

$$
\mathrm{C}_{\mathrm{i}}=\frac{1}{2 \sqrt{\pi \theta_{i}(\mathrm{D} / \mathrm{uL})}} \exp \left[-\frac{\left(1-\theta_{i}\right)^{2}}{4 \theta_{i}(\mathrm{D} / \mathrm{uL})}\right]
$$

In the above equation, $\theta_{i}=t_{i} u / L, D$ is the tunnel diameter, $u$ is the average velocity of the fluid and $\mathrm{L}$ is the length of the tunnel. D/uL represents the non dimensional form of the axial dispersion coefficient through the tunnel.

\subsubsection{Earlier work related to dispersion of data}

This dispersion model was adopted by Ramamurthy and Clark [65] in their effort to correlate the transient emissions with power. In their work, instead of back-transforming the emissions to correlate with power, the power was dispersed using the above model. 
Then, the dispersion model was approximated using a Gaussian distribution. The problem of dispersion was again later addressed by Ganesan and Clark [66]. Real-time transient $\mathrm{CO}_{2}$ emissions were predicted by developing a relationship between measured emissions and dispersed power. This distortion of emissions data calls for techniques which compensate for the delay and dispersion associated with emissions measurement. Some such techniques for compensating the transport dynamics were presented by Weilenmann et al. [67]. These techniques involve modeling the measurement system by understanding the transient dynamics of the analyzers and the transport of the emissions to the analyzer

\subsubsection{Understanding the transient dynamics of the analyzers}

Estimating the transient response of the measurement system is vital in reconstructing the actual engine-out emissions from the measured emissions [68]. The dispersion of the emissions in the sampling system is assumed to be negligible compared to that in the analyzer. The researchers examined the response characteristics of two analyzers (with the sampling system) used to collect the data that were processed in this study. $\mathrm{NO}_{\mathrm{x}}$ was measured using a Rosemount 955 analyzer and $\mathrm{CO}_{2}$ was measured using Horiba AIA 210 analyzer. All the data analyzed in this study were measured only by these analyzers.

The response of a Rosemount $955 \mathrm{NO}_{\mathrm{x}}$ analyzer to an instantaneous pulse input of $\mathrm{NO}_{\mathrm{x}}$ is shown in the Figure 3-1 (a). The response was obtained through the following experiment conducted with the help of the research staff and engineers at the engine test cell at West Virginia University. A balloon was filled with approximately one liter of $\mathrm{NO}_{\mathrm{x}}$ with a concentration of 1000 parts per million (ppm) and inserted in the dilution tunnel. 
The balloon was burst to simulate an instantaneous pulse. The pulse traveled via the sampling lines and the output of the Rosemount 955 was collected. The time delay due to transport of the pulse through the tunnel depends on the length of the tunnel. Since we assumed that the pulse does not lose its amplitude while traveling through the tunnel, all the dispersion takes place only in the analyzer.

The time delay showed in the Figure 3-1 (a) is a function of the length of the sampling lines and speed of the exhaust gas travel through the lines. Only the dispersion of the instantaneous pulse is of interest in this analysis. The response was found to be dispersed over a period of 6 seconds. The response was of 5 hertz and the fraction of the response in each one interval ( 0.2 second) is represented by a point. The shape of the response in Figure 3-1 (a) is obtained by connecting all such points with simple straight lines. If the fractions of the response are less than $0.05 \%$, all such fractions were considered insignificant and were added as one fraction on either side of the response. In other words, if there were a negligible response from $t=7$ to $t=9$ as in Figure 3-1 (a), the sum of all those small responses were shown in $\mathrm{t}=9$. Moreover, the area under the curve is unity since the response is normalized.

A similar response for the Horiba AIA 210 analyzer for $\mathrm{CO}_{2}$ is shown in Figure 3-1 (b). A comprehensive description of the analyzers and operating procedures employed in the laboratory are provided in Chapter 4. 


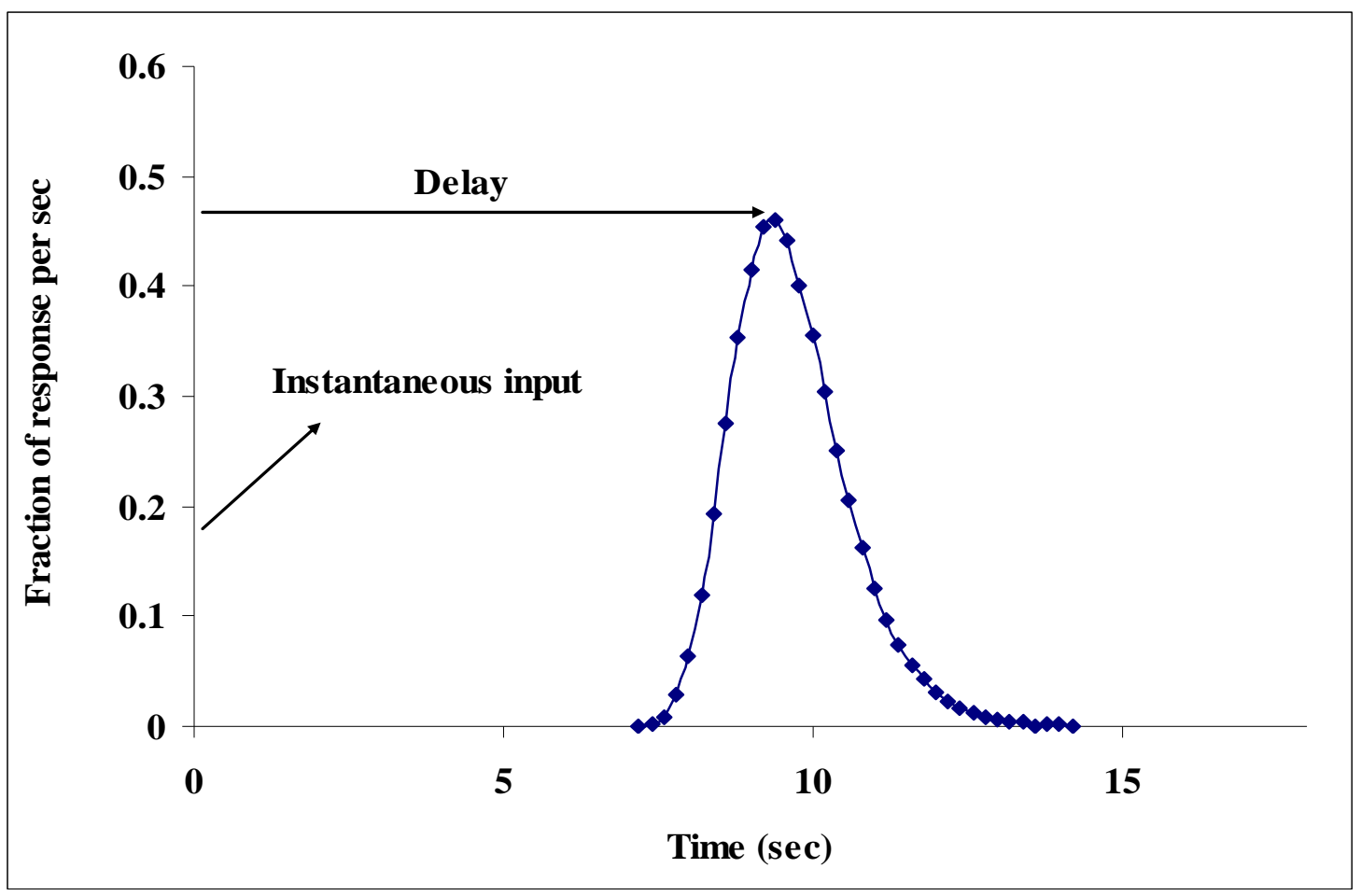

Figure 3-1 (a). Impulse response of Rosemount $955 \mathrm{NO}_{\mathrm{x}}$ analyzer to an instantaneous input of $\mathrm{NO}_{x}$ at time $\mathrm{t}=\mathbf{0}$

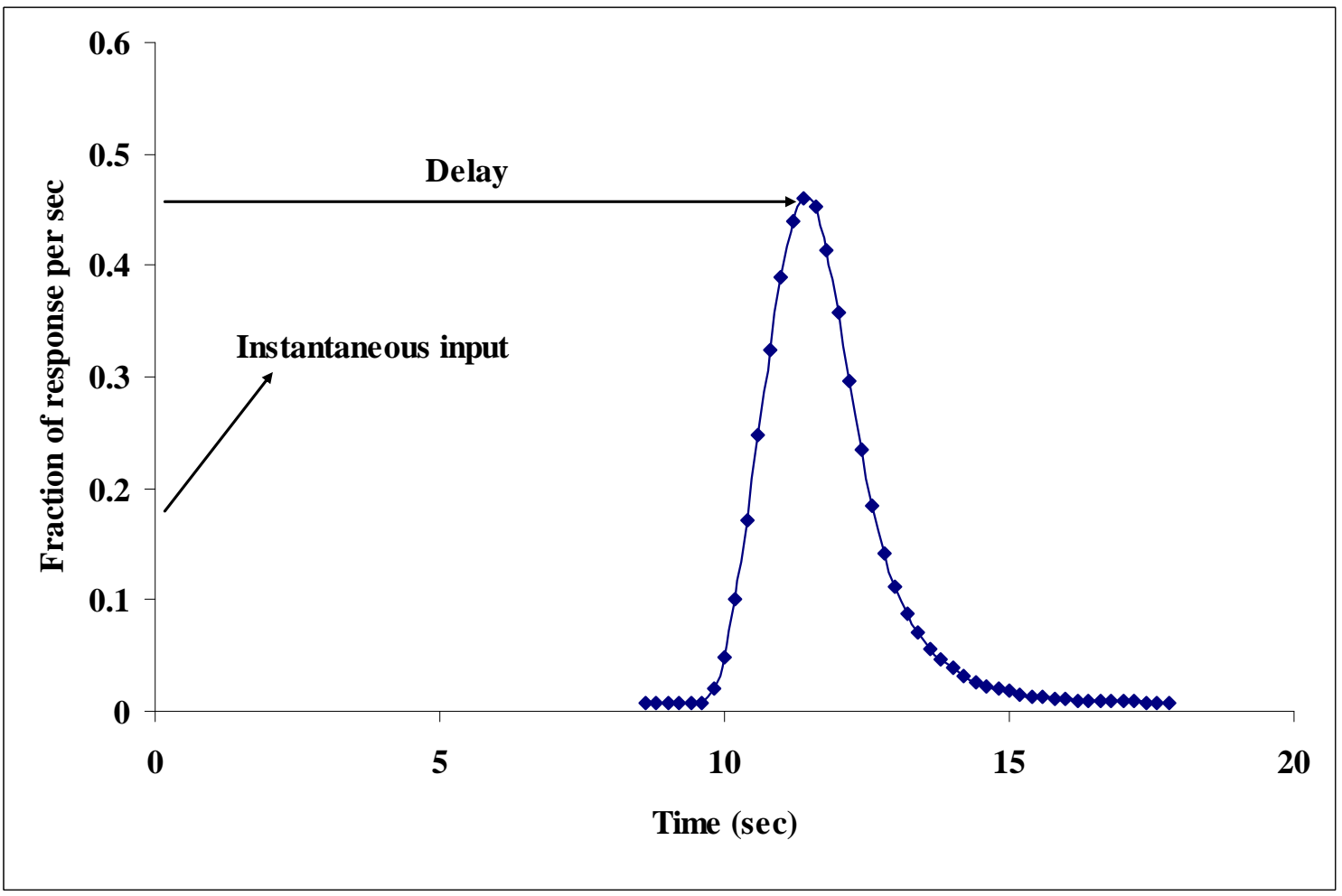

Figure 3-1 (b). Impulse response of Horiba AIA 210 analyzer to an instantaneous input of $\mathrm{CO}_{2}$ at time $\mathrm{t}=0$ 


\subsubsection{Understanding the effects of dispersion on a step input}

The dispersion function of an analyzer is by definition, the analyzer's response to a unit instantaneous impulse. Hence, the set of fractions shown as points in Figure 3-1 (a) was in fact, the dispersion function for the Rosemount $955 \mathrm{NO}_{\mathrm{x}}$ analyzer. To understand the effect of such a dispersion function on instantaneous data, a hypothetical step was input to the analyzer. The step input is dispersed using the dispersion function (the unit impulse response) in Figure 3-1 (a). The step input and the dispersed output were shown in Figure 3-2. The response values are connected with simple straight lines in Figure 3-2. The response takes time to reach steady state value, which is indicative of the dispersion characteristics of the analyzer. The $10-90 \%$ response time was 2.3 seconds for this analyzer. The $10-90 \%$ response time specified by the manufacturer for this analyzer was in the range of 1.5 to 2 seconds. 


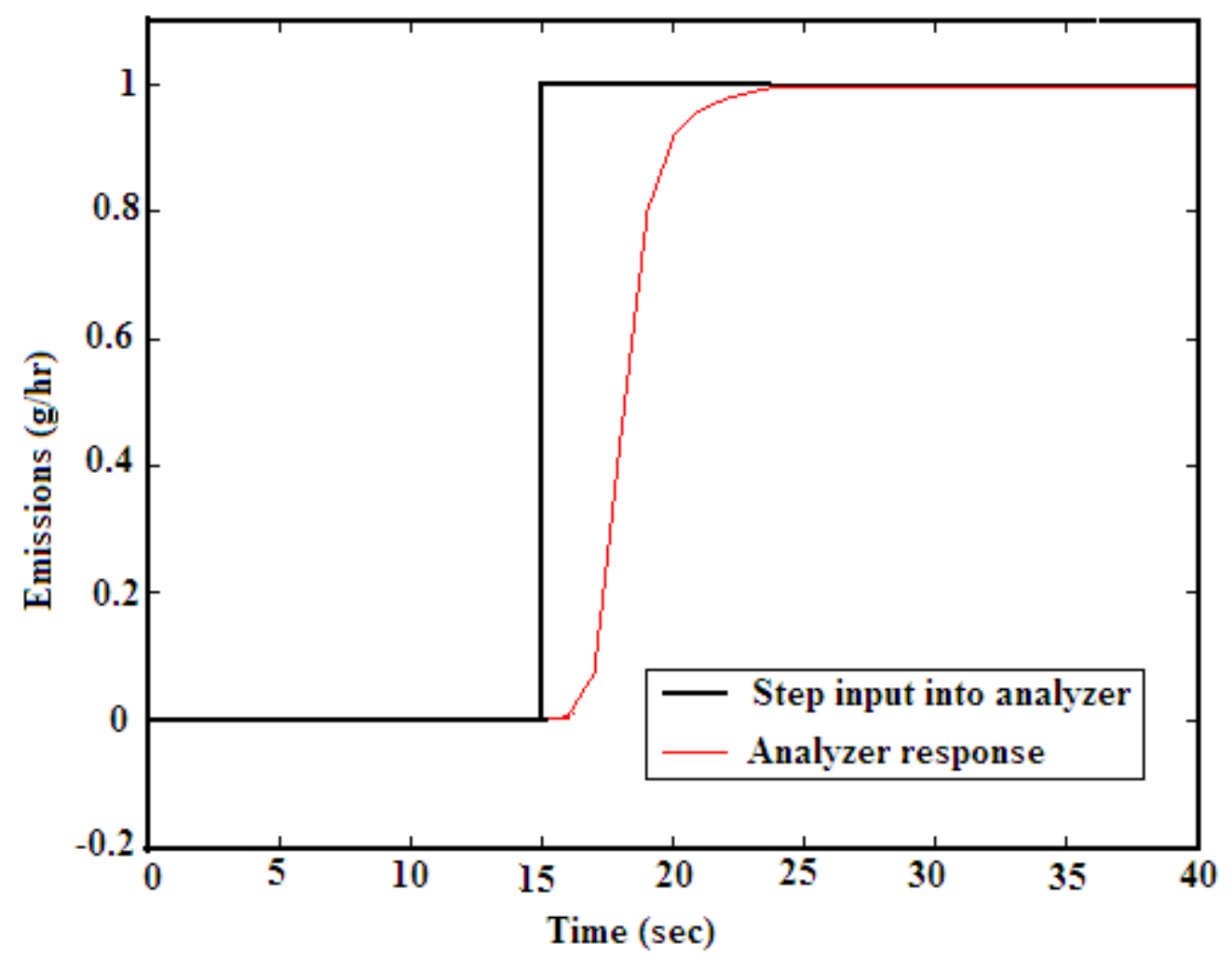

Figure 3-2. The effect of dispersion on a step input

\subsubsection{Emissions 'lost' in measurement due to dispersion}

It was of interest to numerically examine the effect of dispersion function on 30 second windows like the NTE windows. To illustrate this effect, a rectangular wave of input 30 seconds wide and unit amplitude was considered. This operating input can be either power or 'instantaneous' emissions input. This instantaneous input was diffused using the instantaneous impulse response shown in Figure 3-1 (a) and 'analyzer response' was thus generated. This was time-shifted using cross-correlation method and the result is shown in dotted line in Figure 3-3. In this particular case, 3.29\% of the emissions are not measured within the 30 second window. They are referred to as "lost" emissions in this document. For a similar dispersion by the analyzer, if the considered window size was only 
10 seconds, then $10.03 \%$ of total emissions would be lost as shown in Figure 3-4. Figure 35 shows the effect of window size on lost emissions.

It should be noted that different analyzers have different response characteristics and the responses shown in Figures 3-3, 3-4 and 3-5 are specific to the Rosemount 955 $\mathrm{NO}_{\mathrm{x}}$ analyzer with impulse response discussed in Figure 3-1 (a). However, if an analyzer slower (or faster) than the Rosemount 955 were used, more (or less) emissions would have been lost as shown in Figure 3-5.

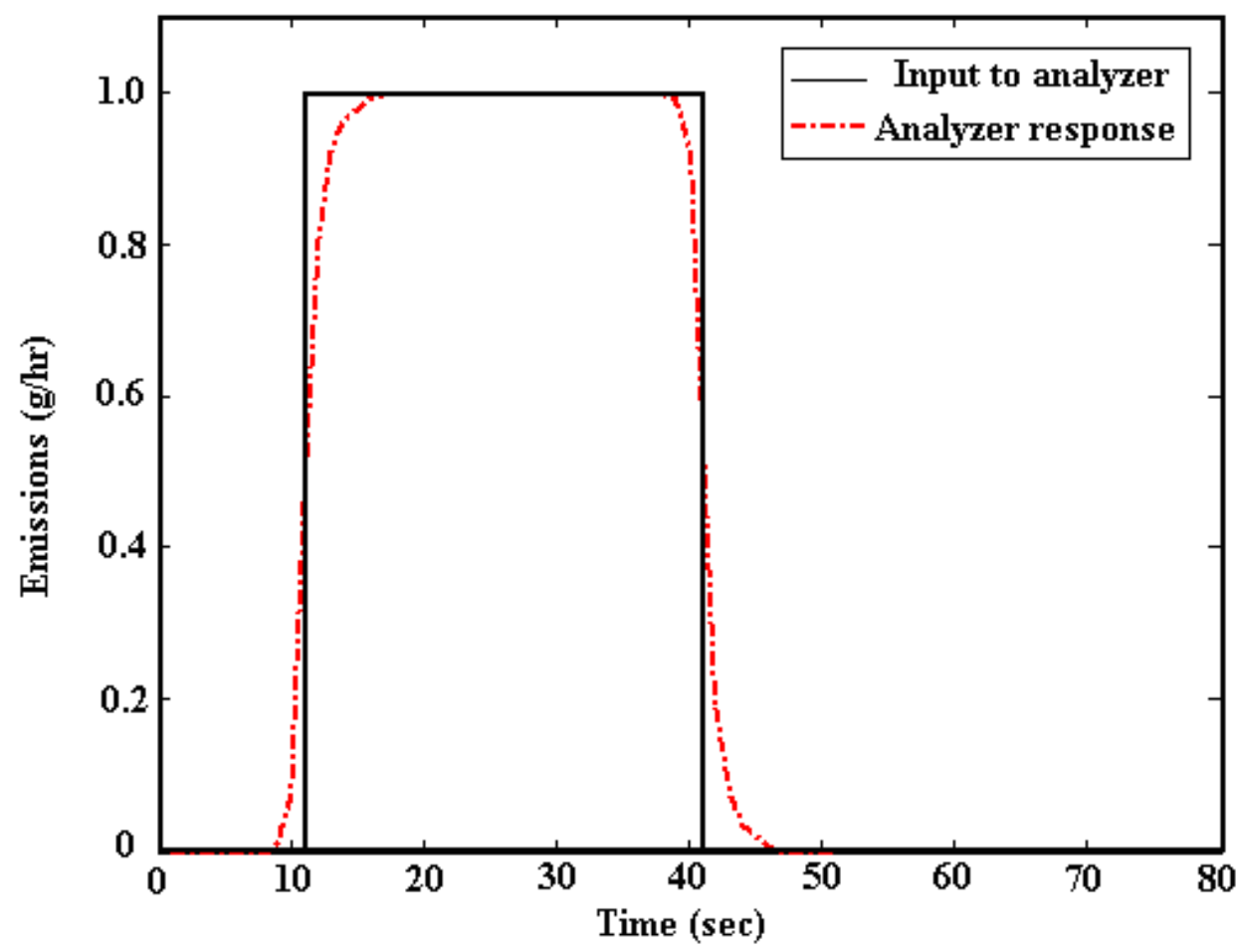

Figure 3-3. The effect of dispersion on a 30-second rectangular wave 


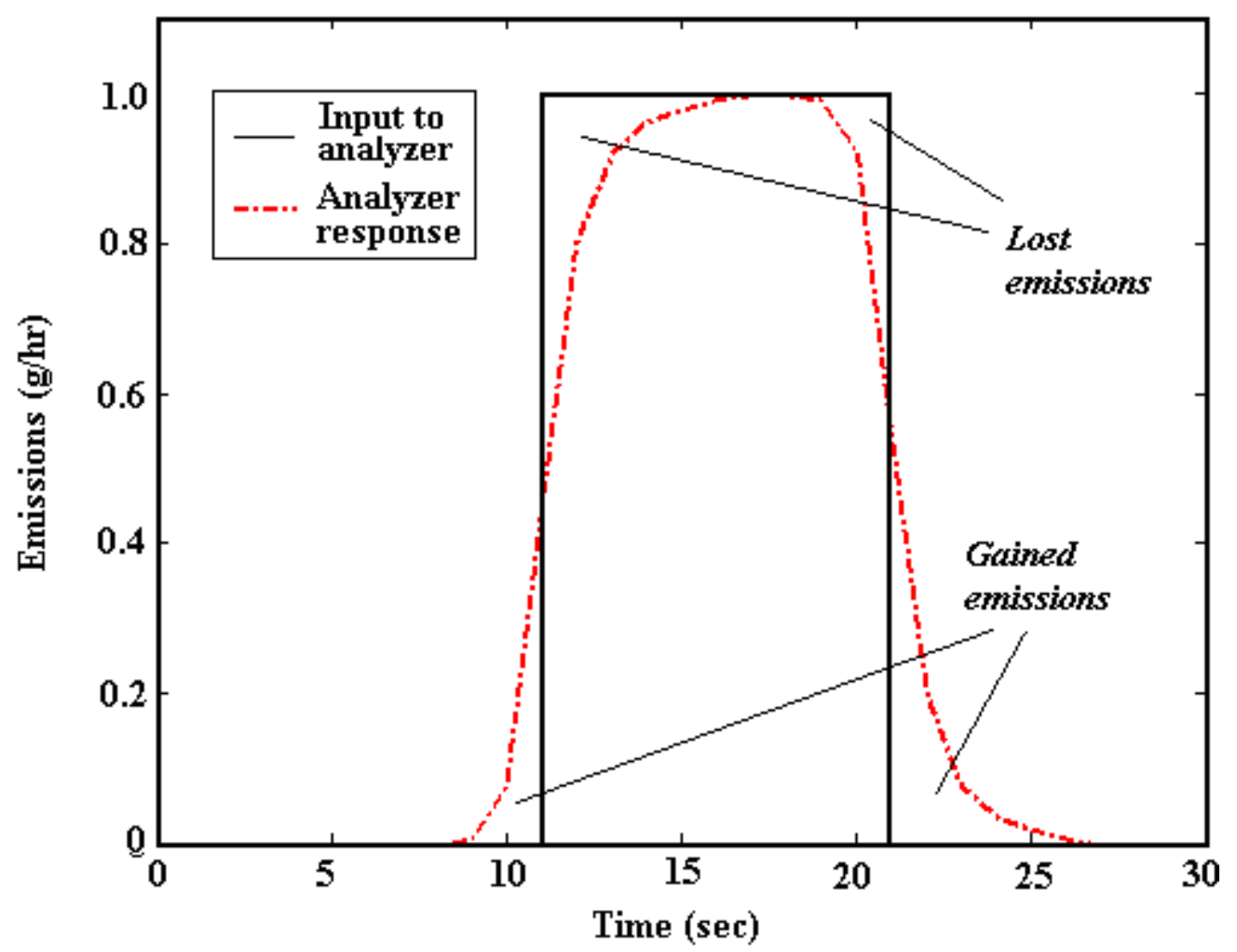

Figure 3-4. The effect of dispersion on a 10 second rectangular wave 


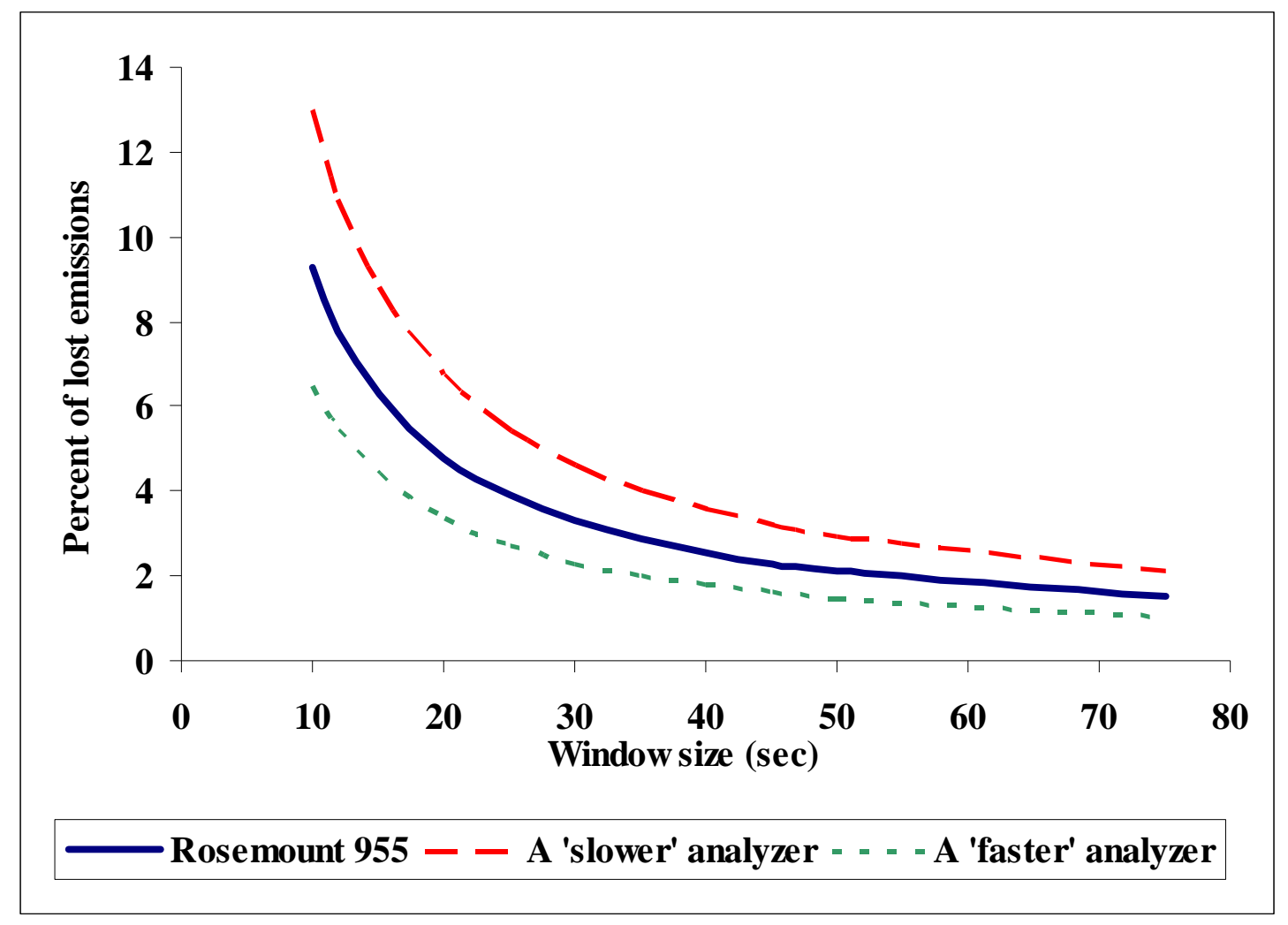

Figure 3-5. Percent of lost emissions as a function of window size

\subsubsection{The 'gain' of emissions that corresponds to the 'loss' of emissions}

Since the analyzer dispersion function is normalized, i.e., all the elements of the dispersion function add up to unity, there are actually no emissions lost during the total time of measurement. In other words, the sum total of the emissions lost in all the windows should be gained totally in some other windows. 


\subsubsection{Amplitude reduction due to dispersion of data}

When the data are dispersed by the analyzer, the maximum amplitude is under-read and the minimum amplitude is over-read. To illustrate this effect, a sine wave is considered and the amplitude of sine wave before and after the dispersion is measured. The frequency of the dispersion function (the same as in Figure 3-1 (a)) was kept the same for this analysis. When the data has a low frequency, the reduction in amplitude is lesser than for high frequency data as shown in Figure 3-6.

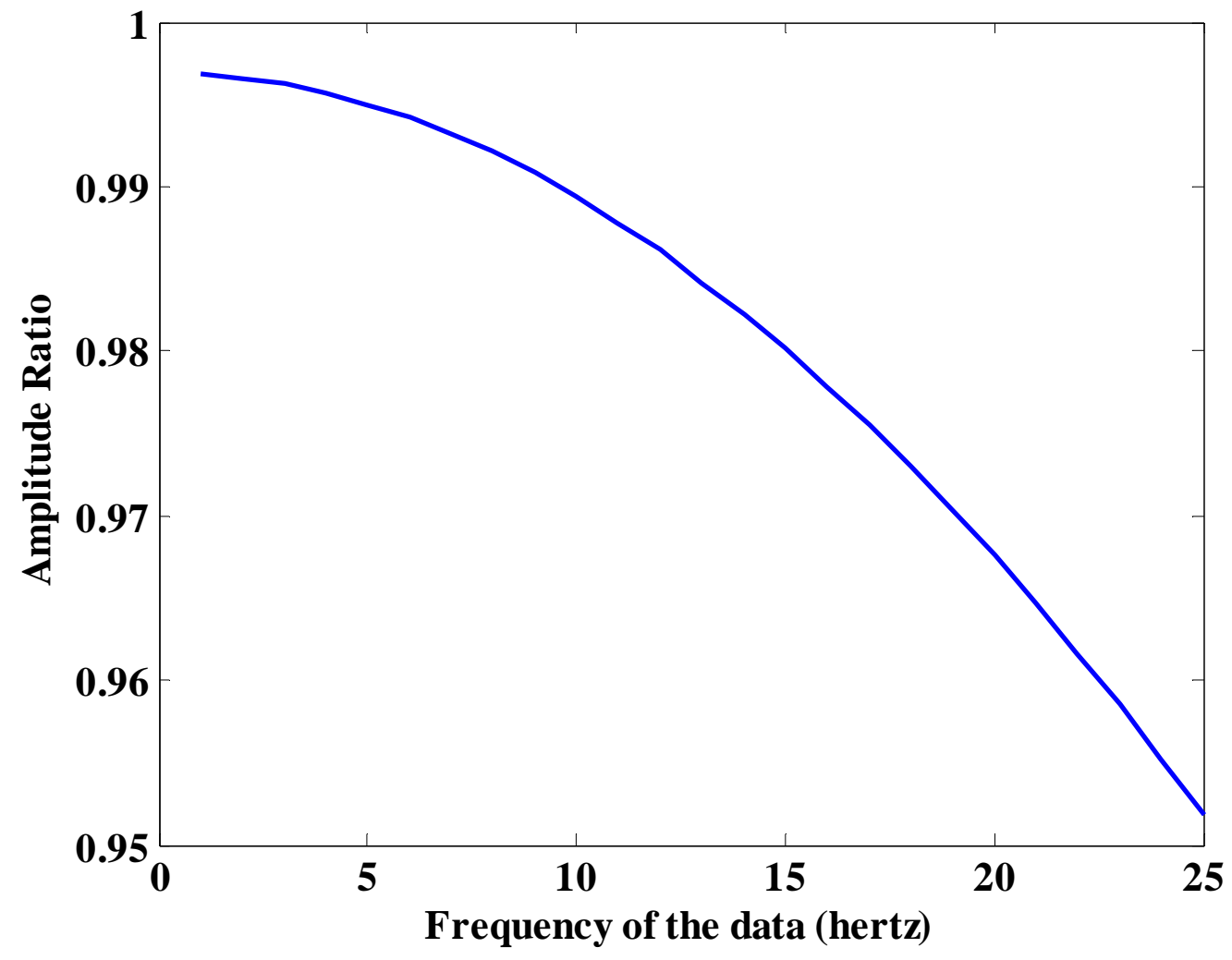

Figure 3-6. Amplitude reduction due to dispersion of data 


\section{Experimental Equipment, Procedures and Available Data}

This chapter discusses the details of the measurement equipment, the procedures followed in the laboratories to obtain the continuous emissions data and a detailed description of the drive cycles employed and the types of engines tested.

\subsection{Operation of the engine test cell}

The experimental data used for analysis in this research were obtained from research efforts of the engineers and the technical staff who conducted engine tests at West Virginia University Engine and Emissions Research Laboratory (WVU-EERL). A detailed description of the test cell set up and the operation of the dynamometer and exhaust gas sampling systems can be obtained elsewhere [69, 70]. However, a brief description of the operation of the test cell is as follows. The engine was coupled to a dynamometer to simulate the real world operation. The dynamometer was a DC General Electric model DYC-243 engine dynamometer. Torque on the engine was measured by a load cell, attached to an arm of known length, which measured force. Engine speed was recorded with a digital encoder inside the dynamometer. The exhaust from the engine was diluted in a full scale dilution tunnel where it was mixed with ambient air. The mass flow rate of the diluted exhaust was measured and metered by a critical flow venturi. Sample probes were inserted into the dilution tunnel at about 10 tunnel diameters downstream and the heated sample lines were connected to them. The heated lines were maintained at about $235^{\circ} \mathrm{F}$ to prevent any possible condensation of water vapor in the exhaust. The diluted exhaust was 
then carried to the analyzer sample bench shown in Figure 4-1 for analysis of exhaust components.

\subsection{Analyzers used for emissions measurement}

The analyzer bench at the WVU engine test cell is shown in Figure 4-1. Further, a brief description of the working principles for each of the analyzers is given in Table 4-1. A more elaborate description of the working principles of all these analyzers can be found elsewhere [71, 72].

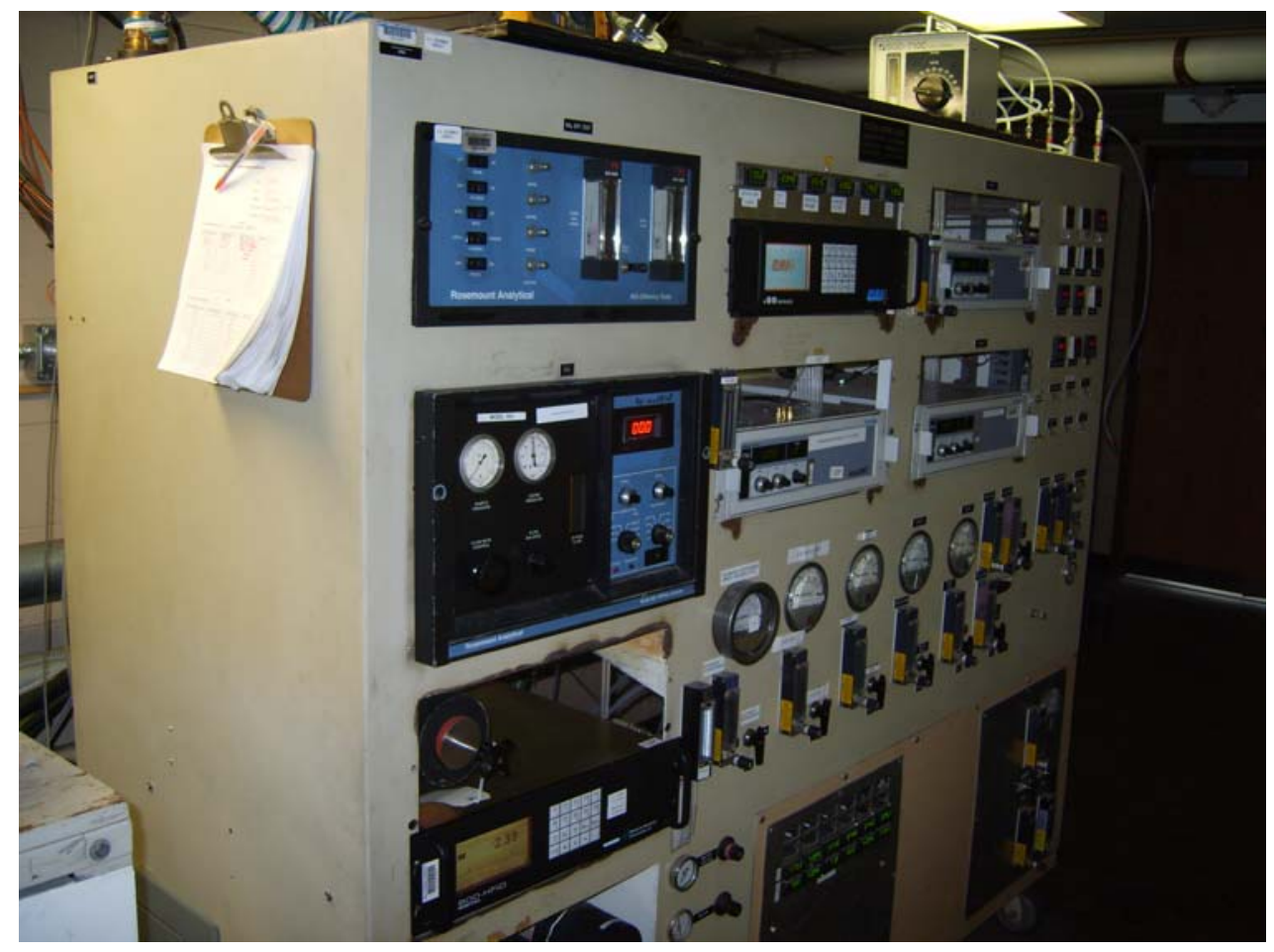

Figure 4-1. Emissions bench at WVU-engine test cell 
Table 4-1. Working principles of the analyzers for each of the exhaust gas components

\begin{tabular}{|c|c|c|c|}
\hline Component & Analyzer & Principle of detection & $\begin{array}{l}10-90 \% \\
\text { response time }\end{array}$ \\
\hline $\mathrm{CO}$ & $\begin{array}{l}\text { HORIBA AIA } \\
210 \text { LE }\end{array}$ & $\begin{array}{l}\text { Non-dispersive Infrared } \\
\text { Detector (NDIR) }\end{array}$ & 2 to $5 \mathrm{sec}$ \\
\hline $\mathrm{CO}_{2}$ & $\begin{array}{l}\text { HORIBA } \\
\text { AIA-210 }\end{array}$ & NDIR & 2 to $5 \mathrm{sec}$ \\
\hline $\mathrm{HC}$ & Rosemount 402 & $\begin{array}{l}\text { Heated Flame Ionization } \\
\text { Detector (HFID) }\end{array}$ & 1 to $2 \mathrm{sec}$ \\
\hline Regular NOx & Rosemount 955 & Chemiluminescent Detector & 1.5 to $2 \mathrm{sec}$ \\
\hline Fast NOx & $\begin{array}{l}\text { Cambustion } \\
\mathrm{fNO}_{\mathrm{x}} 400\end{array}$ & Chemiluminescent Detector & $0.012 \mathrm{sec}$ \\
\hline
\end{tabular}

\subsection{1 $\mathrm{CO}$ and $\mathrm{CO}_{2}$ analyzers}

To analyze $\mathrm{CO}$ and $\mathrm{CO}_{2}$, Horiba's non-dispersive infra-red (NDIR) analyzers were employed. Before the exhaust gas sample enters the analyzer, the sample is dried to avoid moisture. There is a particular wave length of the infrared energy at which each of the gaseous components is absorbed. The amount of energy absorbed at a wavelength corresponding to $\mathrm{CO}$ (or $\mathrm{CO}_{2}$ ) could be measured and is directly proportional to the concentration of $\mathrm{CO}\left(\right.$ or $\left.\mathrm{CO}_{2}\right)$ in the exhaust. 


\subsubsection{HC analyzer}

An internal pump was used to draw the diluted exhaust into a Rosemount Analytical 402 heated flame ionization detector (HFID) which was used to analyze hydrocarbons. The hydrocarbons in the diluted exhaust were ionized to produce a current proportional to the number of hydrocarbons.

\subsubsection{Regular $\mathrm{NO}_{\mathrm{x}}$ analyzer}

A Rosemount 955 chemiluminescent analyzer was used to measure $\mathrm{NO}_{\mathrm{x}}$. The analyzer worked on a phenomenon called chemiluminescence in which photons of light were produced by a chemical or electrochemical reaction. The analyzer is capable of measuring either $\mathrm{NO}$ or total $\mathrm{NO}_{\mathrm{x}}$.

To determine $\mathrm{NO}$, the sample $\mathrm{NO}$ is converted to $\mathrm{NO}_{2}$ by oxidation using molecular ozone. During this reaction, about $10 \%$ of $\mathrm{NO}_{2}$ molecules get elevated to an excited state and then when the molecules come back to non-excited state, photon emission takes place. The emitted photons are detected and the response of the analyzer is proportional to the total NO in the converted sample.

To determine the total $\mathrm{NO}_{\mathrm{x}}$, a similar procedure was followed, except that the gas stream was passed through a converter which converts all the $\mathrm{NO}_{2}$ into $\mathrm{NO}$. The instrument response in this case, is proportional to the NO present in the original sample plus the NO produced by the dissociation of $\mathrm{NO}_{2}$. 


\subsubsection{Fast $\mathrm{NO}_{\mathrm{x}}$ analyzer}

Regular $\mathrm{NO}_{\mathrm{x}}$ analyzers are most suited for an accurate estimate of the integrated emissions collected over an entire test cycle. However, fast $\mathrm{NO}_{\mathrm{x}}$ analyzer is tailor-made for measurement of instantaneous emissions under changing operating conditions. The fundamental advantage of the fast $\mathrm{NO}_{\mathrm{x}}$ analyzer is that it has a rapid response $\left(\mathrm{T}_{10-90 \%}=12\right.$ milliseconds). This response time is the summation of the time taken by the gas to flow into the system and the electronic delay in measurement. The fast $\mathrm{NO}_{\mathrm{x}}$ analyzer employed in the WVU test cell was manufactured by Cambustion Ltd, Cambridge, UK [73]. The instrument is designated as $\mathrm{NOO}_{\mathrm{x}}$ 400, and the sampling unit is shown in Figure 4-2 (a). This analyzer is capable of measuring only NO. A comprehensive working manual [74] was provided by Cambustion Ltd.

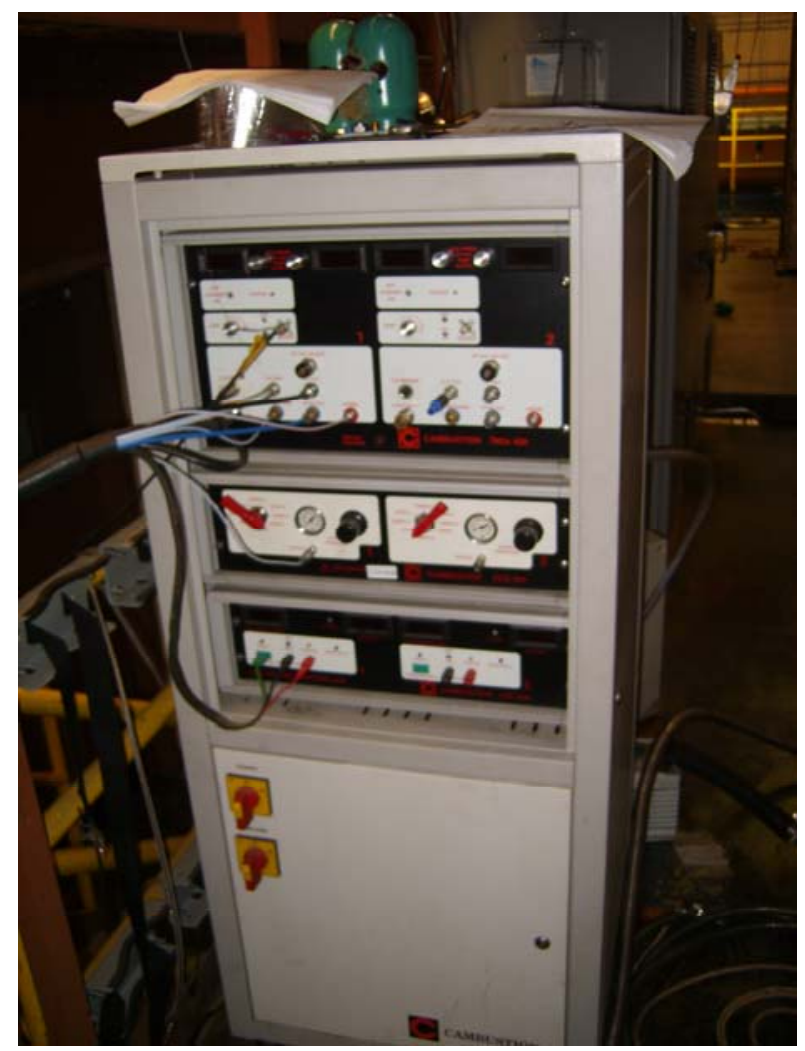

Figure 4-2 (a) Fast $\mathrm{NO}_{\mathrm{x}}$ sampling unit 
The fast $\mathrm{NO}_{\mathrm{x}}$ analyzer consists of a sampling head, which was mounted close to the dilution tunnel, as shown in Figure 4-2 (b). A sampling probe was used to connect the sampling head to the dilution tunnel. The sampling head also consists of a constant pressure chamber in order to stabilize the pressure fluctuations. A portion of the sample flow was drawn into the reaction chamber of the sampling head, where it is mixed with a controlled flow of ozone. This light was collected with the help of a fiber optic cable and measured at the Main Control Unit (MCU) by a photo-multiplier. The MCU contained two main subsystems: A gas handling system that provided ozone to the sample head and an electronic system that detected and amplified the chemiluminescence signal. The light emission was proportional to the concentration of $\mathrm{NO}$ in the sample. Since the fast $\mathrm{NO}_{\mathrm{x}}$ sample was not dried before entering the analyzer, it may have water vapor. The sampling line was heated by a line heater controller (LHC) to avoid condensation of water vapor.

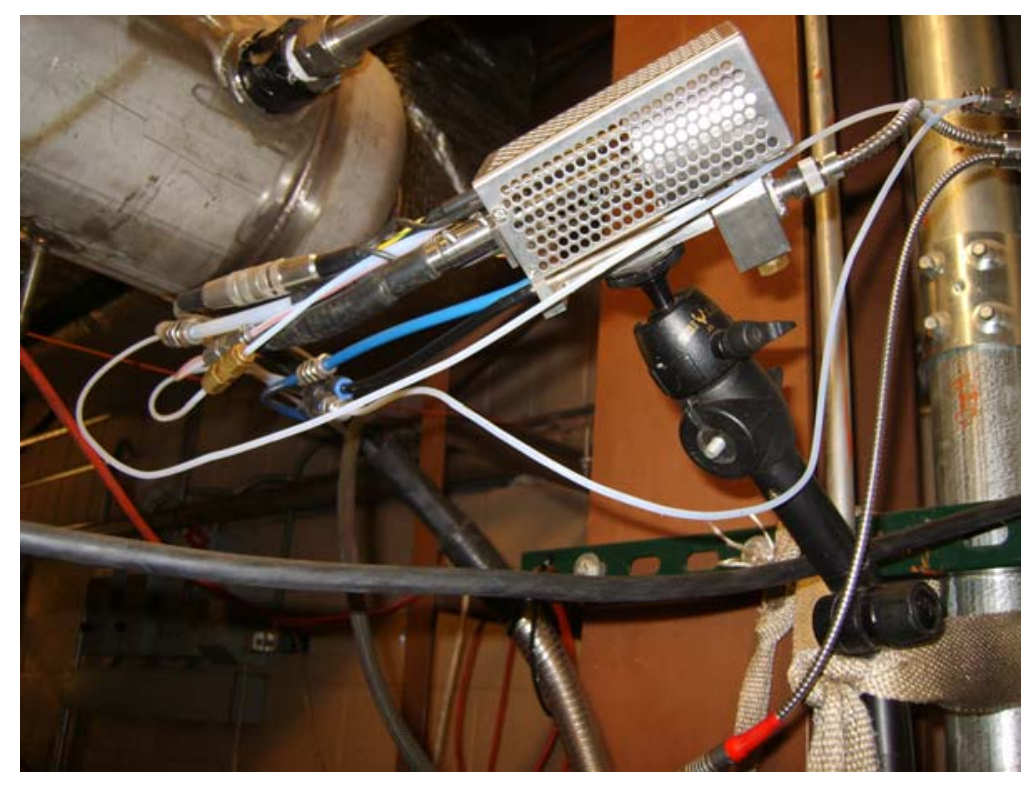

Figure 4-2 (b). Remote Sampling head of Fast $\mathrm{NO}_{\mathrm{x}}$ mounted on the dilution tunnel 


\subsection{Engine data used in the analysis}

The data were obtained from the engines that were tested on Federal Transient Procedure (FTP) at the engine test cell. The specifications of the engines are given in Table 4-2, while the cycle speed and torque of the engine are shown in Figure 4-3.

Table 4-2. Details of the engines tested on the engine dynamometer

\begin{tabular}{|c|c|c|c|}
\hline $\begin{array}{c}\text { Engine } \\
\text { Manufacturer }\end{array}$ & $\begin{array}{c}\text { Detroit Diesel } \\
\text { Corporation (DDC) }\end{array}$ & $\begin{array}{c}\text { Cummins } \\
\text { Engine Inc. }\end{array}$ & Caterpillar \\
\hline Engine Model & Series 60 & ISM 370 ESP & $3406 \mathrm{E}$ \\
\hline Model Year & 2000 & 2004 & 1996 \\
\hline Displacement & 12.7 liters & 10.8 liters & 14.6 liters \\
\hline Power Rating & $500 \mathrm{hp} @ 2100 \mathrm{rpm}$ & $370 \mathrm{hp} @ 2100 \mathrm{rpm}$ & $475 \mathrm{hp} @ 2100 \mathrm{rpm}$ \\
\hline Torque Rating & $1735 \mathrm{lb}-\mathrm{ft} @ 1450 \mathrm{rpm}$ & $1350 \mathrm{lb}-\mathrm{ft} @ 1200 \mathrm{rpm}$ & $1650 \mathrm{lb}$-ft @ $1200 \mathrm{rpm}$ \\
\hline Configuration & Inline 6 cylinder & Inline 6 cylinder & Inline 6 cylinder \\
\hline Bore X Stroke & 5.1 in X 6.3 in & 4.9 in X 5.8 in & 5.4 in X 6.5 in \\
\hline
\end{tabular}




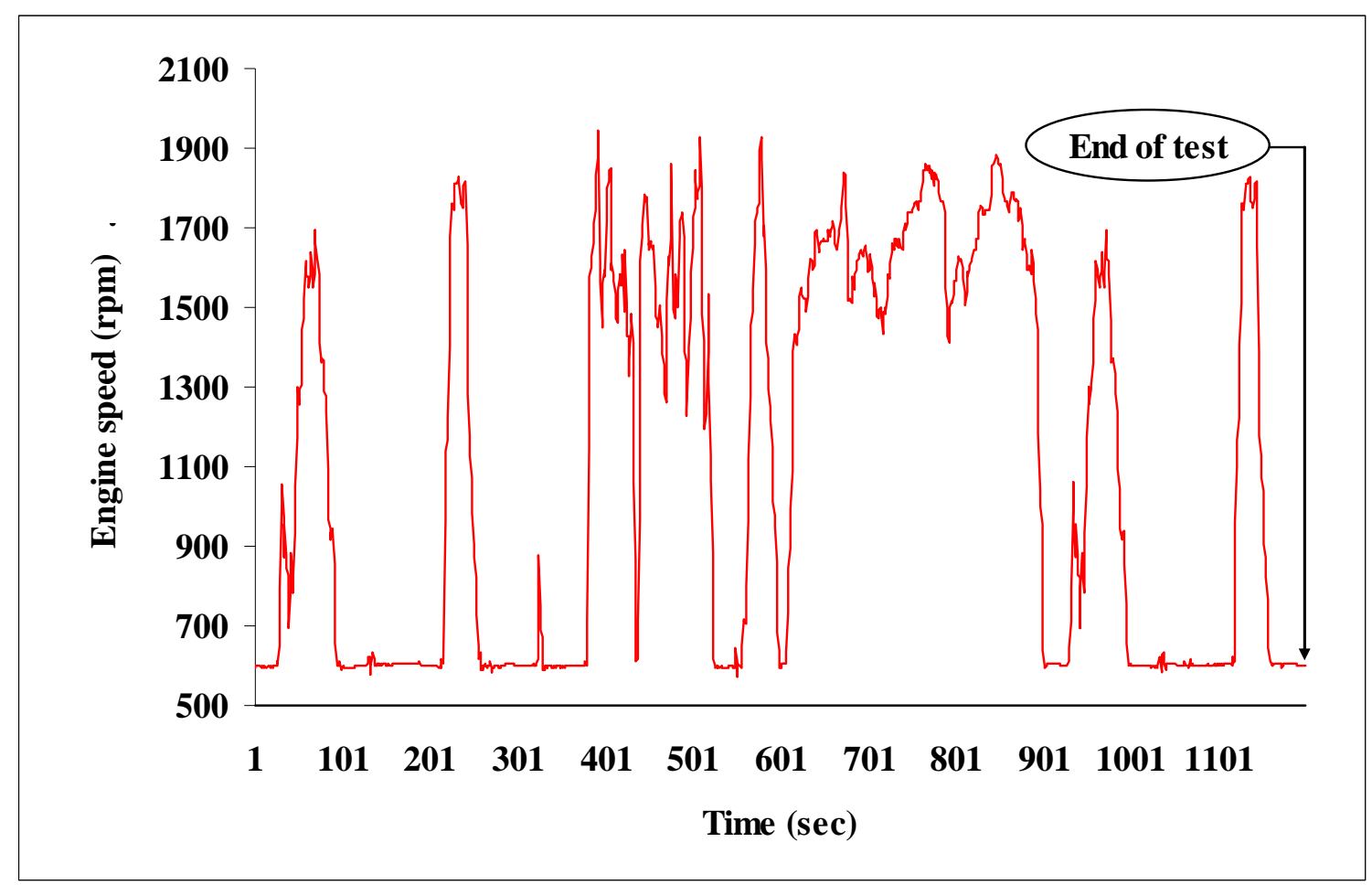

(a)

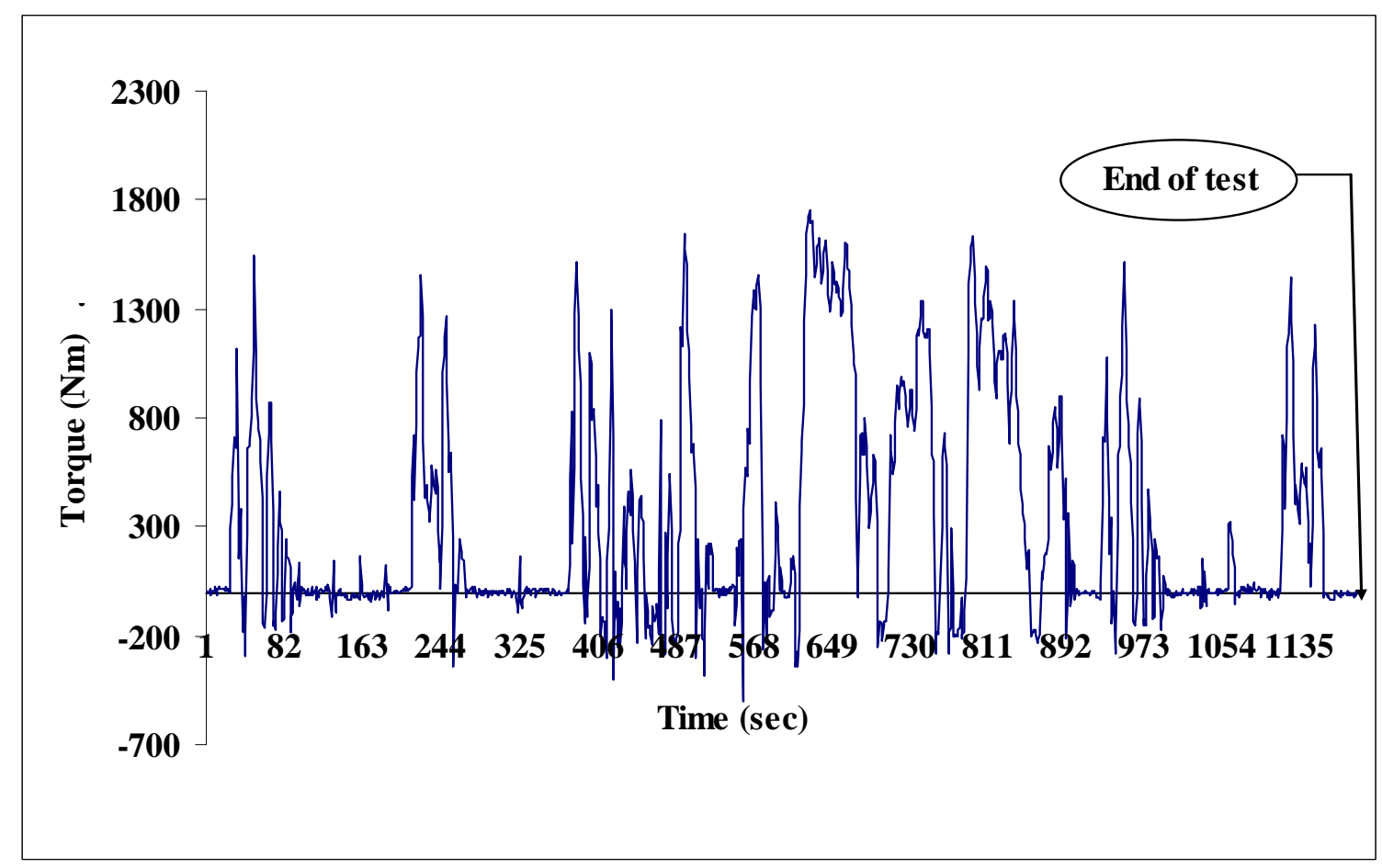

(b)

Figure 4-3. Speed (a) and torque (b) profiles of DDC Series 60 engine on FTP cycle 


\subsection{Chassis dynamometer testing procedure}

Some of the data analyzed in this work were obtained from the research efforts of the engineers and the technical staff who conducted chassis dynamometer testing at the West Virginia University Transportable Heavy-Duty Vehicle Emissions Testing Laboratories (TRANSLAB). While a comprehensive explanation of the experimental procedures can be found in some earlier work [75-79], a brief description of the experimental set up is as follows. The dynamometer was a platform with flywheels, power absorbers and rollers. The vehicle was mounted on a test bed with the drive wheels on four rollers, two on each side. The rear wheels were allowed to rotate freely on the rollers. The power was absorbed from the vehicle hubs by the power absorbers mounted on either side of the chassis bed, simulating the load on the vehicle. The power absorbers simulate realworld driving conditions by accounting for the aerodynamic and the frictional load. The flywheels were connected to the vehicle hubs and the vehicle load was established using a coast down procedure on the dynamometer. The torque produced by the vehicle was translated to the sensors through shafts and gear boxes. The sum of the readings of the sensors on either side should be equivalent to the axle torque. The vehicle was driven to follow the speed-time trace of the desired drive cycle. The target speed was provided on the computer screen to the driver while the test was running and the vehicle was driven to meet that speed which simulates the drive cycle used. The emissions were measured with exhaust gas analyzers and a data acquisition system which consists of control system computer, driver's interface computer, data acquisition boards, dynamometer controllers, sensors and calibration and testing software. The losses associated with the tire-roller interaction have been discussed elsewhere [80]. 


\subsection{Chassis data used for analysis}

\subsubsection{Vehicles tested on the chassis dynamometer}

Some of the chassis data used in this study were obtained from the testing conducted in the WVU Transportable Heavy-Duty Vehicle Emissions Testing Laboratory on E55/59 CRC heavy-duty trucks [81]. The vehicles were loaded at three possible test weights of $30,000,56,000$, and $66,000 \mathrm{lbs}$. The trucks that were tested were identified as CRC-34, CRC-38, CRC-39 and CRC-40. Two of these trucks, CRC-34 and CRC-40, had engines manufactured by Detroit Diesel, and two others, CRC-38 and CRC-39, had engines manufactured by Cummins. All these engines were equipped with a cooled EGR to reduce the emissions of $\mathrm{NO}_{\mathrm{x}}$ [82-85]. EGR is considered most effective in reducing $\mathrm{NO}_{\mathrm{x}}$ at high loads of engine operation [86]. Chassis data were also collected from the chassis testing conducted in on a Peterbilt Truck with a Caterpillar 3406E engine fitted to a 19-speed Eaton Fuller transmission with $550 \mathrm{hp}$. The specifications of the trucks are presented in the Table 4-3. Data were also collected from chassis testing conducted on a New Flyer transit bus with 2006 Cummins ISM engine. 
Table 4-3. Details of the vehicles tested

\begin{tabular}{|c|c|c|c|}
\hline $\begin{array}{c}\text { Vehicle } \\
\text { Identity }\end{array}$ & $\begin{array}{c}\text { Vehicle } \\
\text { Model } \\
\text { year }\end{array}$ & Engine & $\begin{array}{c}\text { Engine hp \& } \\
\text { Displacement }\end{array}$ \\
\hline CRC-34 & 2004 & DDC Series 60 & $500 \mathrm{hp} \mathrm{\&} 12.7$ liters \\
\hline CRC-38 & 2004 & Cummins ISX & $530 \mathrm{hp} \mathrm{\&} 15$ liters \\
\hline CRC-39 & 2004 & Cummins ISX & $530 \mathrm{hp} \mathrm{\&} 15$ liters \\
\hline CRC-40 & 2004 & DDC Series 60 & $500 \mathrm{hp} \mathrm{\&} 14$ liters \\
\hline Peterbilt & 2006 & Cat 3406E & $475 \mathrm{hp} \mathrm{\&} 15.1$ liters \\
\hline $\begin{array}{l}\text { New Flyer } \\
\text { Transit bus }\end{array}$ & 2006 & Cummins ISM & $280 \mathrm{hp} \mathrm{\&} 10.9$ liters \\
\hline
\end{tabular}

\subsubsection{Drive cycles used for the chassis dynamometer data}

The drive cycles suitable for trucks and buses for chassis dynamometer testing have been presented previously [87]. The chassis testing was performed on the several modes of the Heavy Heavy-Duty Diesel Truck (HHDDT) drive schedule [Figure 4-4] and Urban Dynamometer Driving Schedule (UDDS) [Figure 4-5]. The development and examination of HHDDT schedule was presented in detail else where $[\mathbf{8 8}, \mathbf{8 9}]$. The HHDDT schedule consists of five modes (Idle, Creep, Transient, Cruise and High-speed Cruise). The creep 
mode represents very low speed truck operation with a maximum speed of $8.24 \mathrm{mph}$. The transient mode of HHDDT is a ten-minute drive that mimics the vehicle stopping and going at an average speed of $20 \mathrm{mph}$. It involves sharp accelerations and decelerations with a peak speed of less than $50 \mathrm{mph}$. The cruise mode of HHDDT cycle, which is representative of truck driving on the interstate, is a 2000 second cycle with a speed around $60 \mathrm{mph}$ continuously for about 1400 seconds. The high-speed cruise mode is represented by HHDDT_S. It had an average speed of $50 \mathrm{mph}$ and a maximum speed of $67 \mathrm{mph}$ and it represents expressway truck driving. The UDDS (also known as Test_D drive cycle) is a seventeen minute cycle with a peak speed of $60 \mathrm{mph}$. For the data analysis in this study, transient, cruise and high speed cruise modes of HHDDT were used. The speed-time traces of these three modes are shown in Figure 4-4.

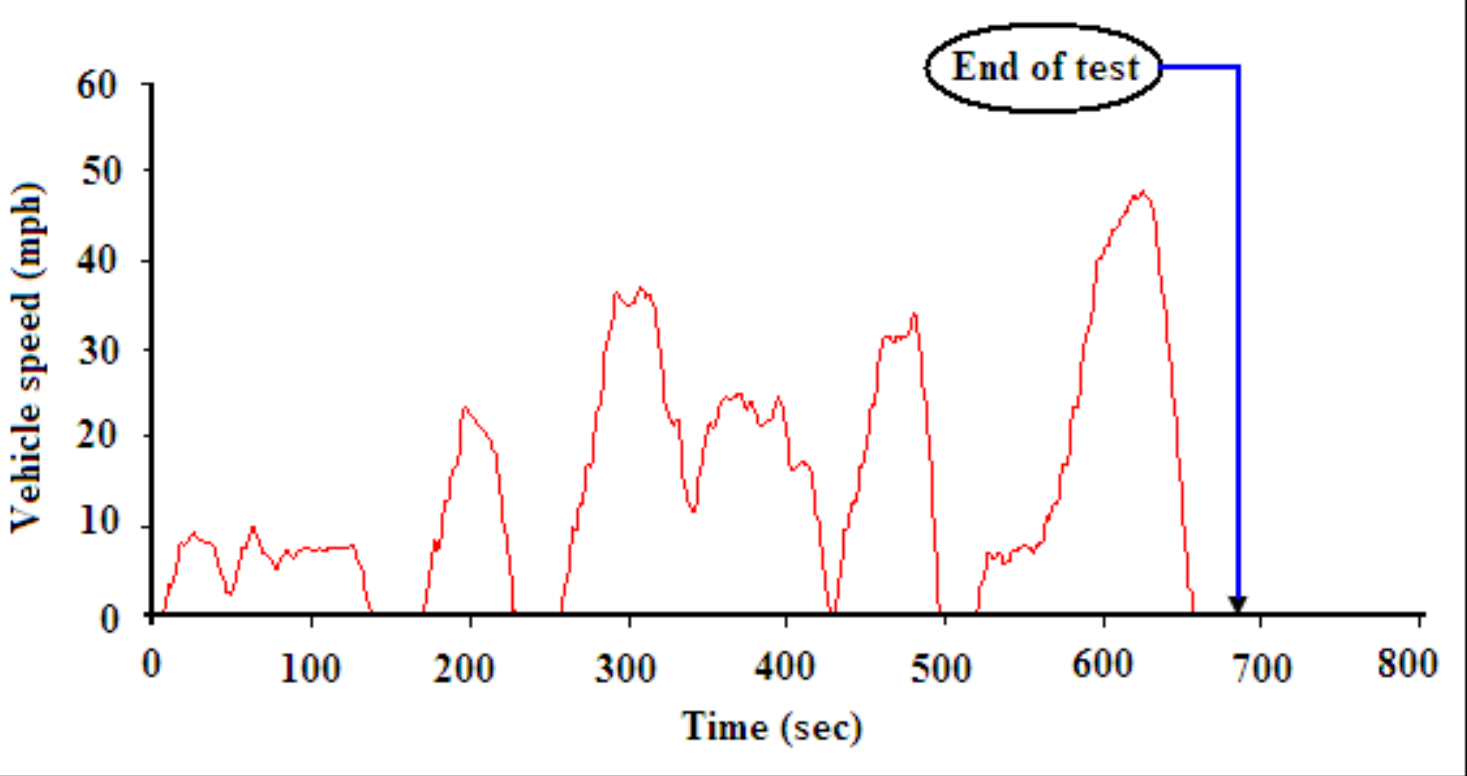

(a) Transient mode 


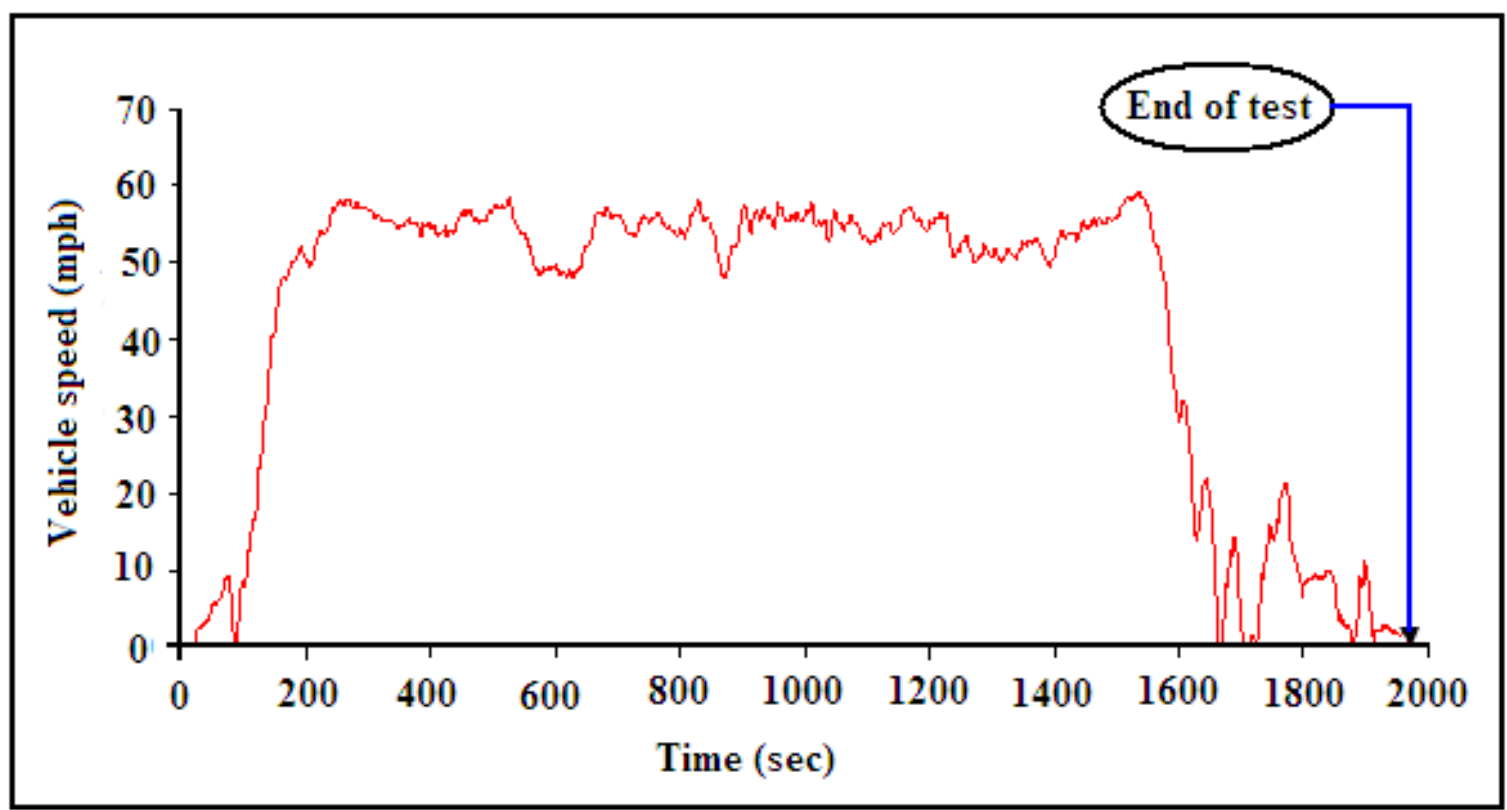

(b) Cruise mode

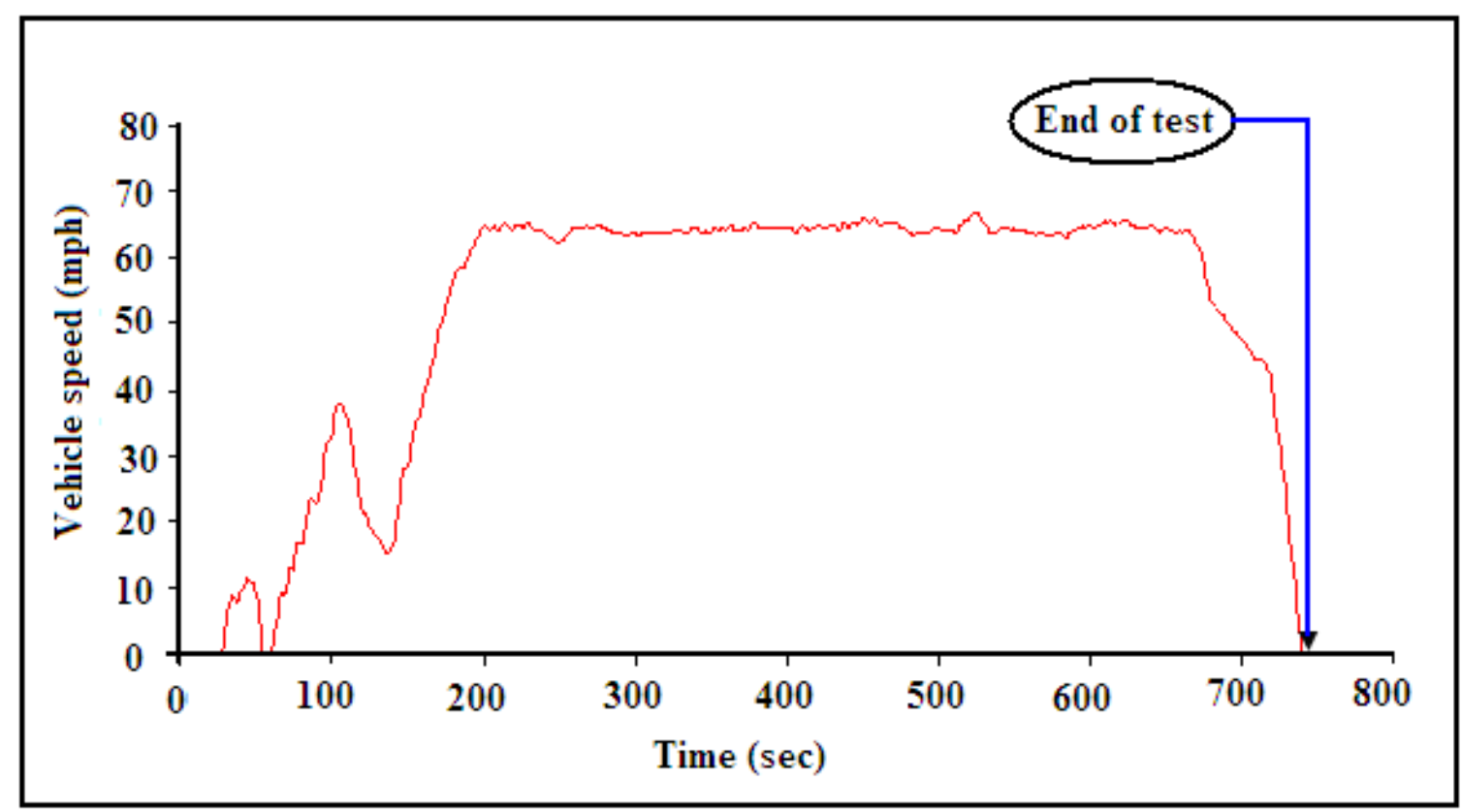

(c) High speed cruise mode

Figure 4-4. Speed profiles of different modes of HHDDT drive cycle 


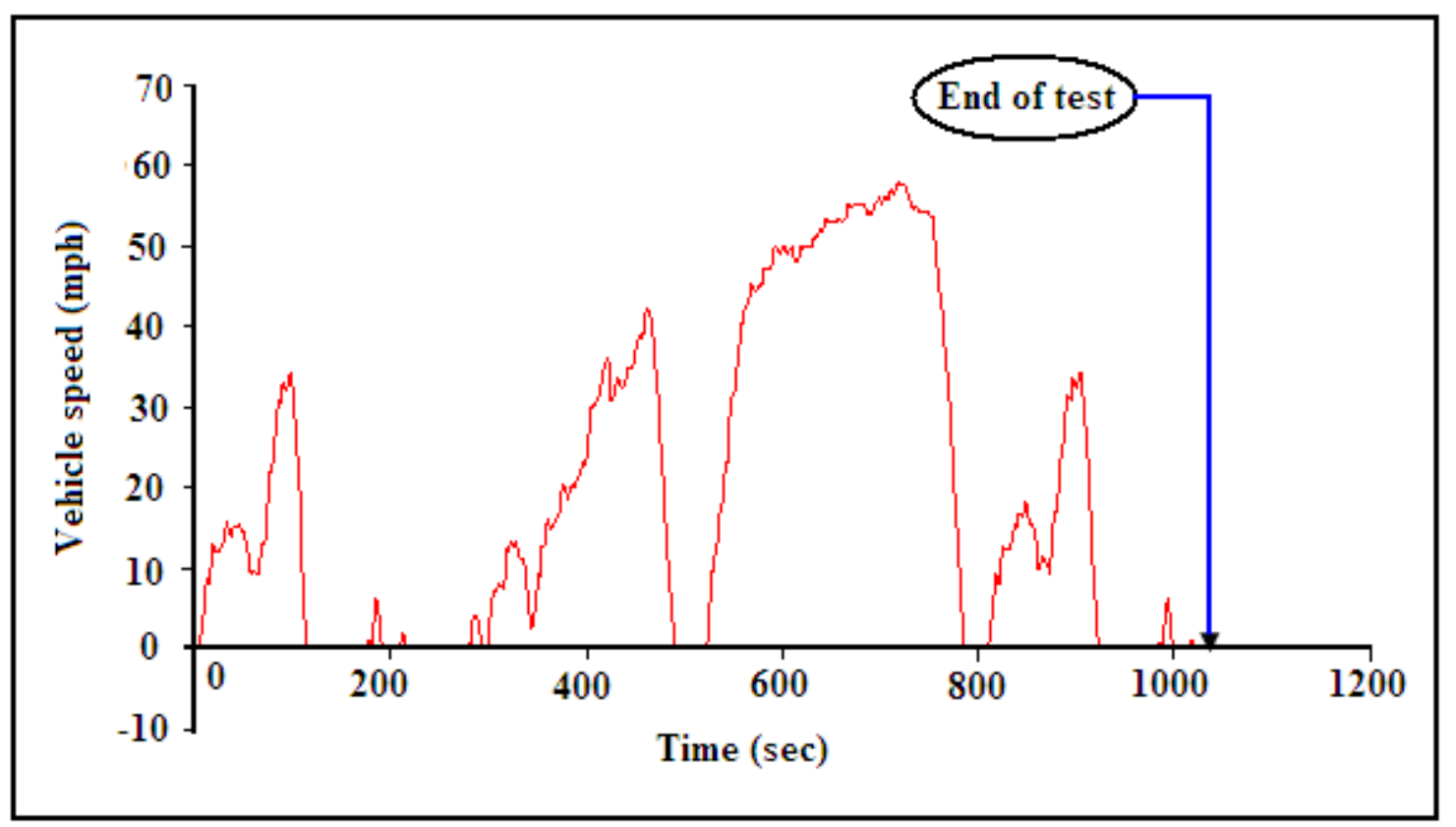

Figure 4-5. Speed profile of UDDS drive cycle 


\section{$5 \quad$ Data Analysis and Results}

In this chapter, first, the 'forward transform' was introduced and then verified by applying the dispersion function to an operating variable, the axle power. Later, several methods of reconstruction (back transform) were presented and validated using the realtime emissions data.

\subsection{Applying the forward transform}

A 'forward transform' is simply an application of dispersion to an instantaneous data. In other words, if any instantaneous data is forward transformed, it generates corresponding dispersed data. In order to reconstruct the true instantaneous emissions, the measured emissions of the analyzer need to be back-transformed based on the dispersion characteristics of the analyzer system employed. The dispersion characteristics were obtained from the laboratory testing as described earlier in Chapter 3. Before attempting a back-transformation, the dispersion characteristics were tested with a simple forward transform. In order to achieve that, a reliable instantaneous data were required.

\subsubsection{Operating variables that can simulate instantaneous data}

Several studies were conducted to determine the most significant vehicle operating parameter that can estimate the emission levels [90]. Some studies [91] concluded that vehicle speed and acceleration could account for the emission estimation. Since acceleration rates are very low in heavy-duty trucks, it was suggested that "instead of using 
both acceleration and speed as independent variables, power can be used as a single independent variable to model the $\mathrm{NO}_{\mathrm{x}}$ and $\mathrm{CO}_{2}$ " [92]. Some of the emissions prediction models involve only axle power as an operating parameter that could affect emissions. Ramamurthy and Clark have developed models which predict emissions based on axlepower as a single independent variable [93]. These models could predict $\mathrm{NO}_{\mathrm{x}}$ and $\mathrm{CO}_{2}$ for one driving cycle on the basis of the model developed for another driving cycle. According to their study, axle power as a lone parameter provided a good estimate of instantaneous $\mathrm{NO}_{\mathrm{x}}$. For this study, axle power was considered instantaneous and forward transform was tested by dispersing the axle power.

\subsubsection{Applying the forward transform to axle power}

Before attempting a backward transform from the measured emissions which could have several constraints on emissions data and issues such as numerical instabilities [94], the dispersion of the emission data was simulated by dispersing the axle power [95]. The dispersion function (discussed earlier in Chapter 2) represents the response of the analyzer to a unit instantaneous pulse. Since the emissions measured by the analyzer are dispersed, when they are compared against power, the power needs to be dispersed to negate the effect of dispersion. The dispersion function of the analyzer system was used to disperse the axle power. Even though 'dispersed axle power' does not have any significance, dispersing the axle power can account for the dispersion associated with the emissions data. 


\subsubsection{The effect of dispersion of axle power}

Figure 5-1 shows the effects of dispersion for the data collected from CRC-34 truck loaded at 56,000 lb and tested on the HHDDT cycle. The correlation between the timeshifted $\mathrm{CO}_{2}$ and dispersed axle power was found to be better than the correlation between the time-shifted $\mathrm{CO}_{2}$ and un-dispersed axle power. In both the above cases, the data were time-aligned using the cross correlation method mentioned earlier. This was done to isolate the effect of dispersion. Without the dispersion of axle power, the idle intercept was high and the idle emissions had multiple values along the emissions axis. But if the power were dispersed, most of the zero power values were eliminated leading to a smaller intercept.

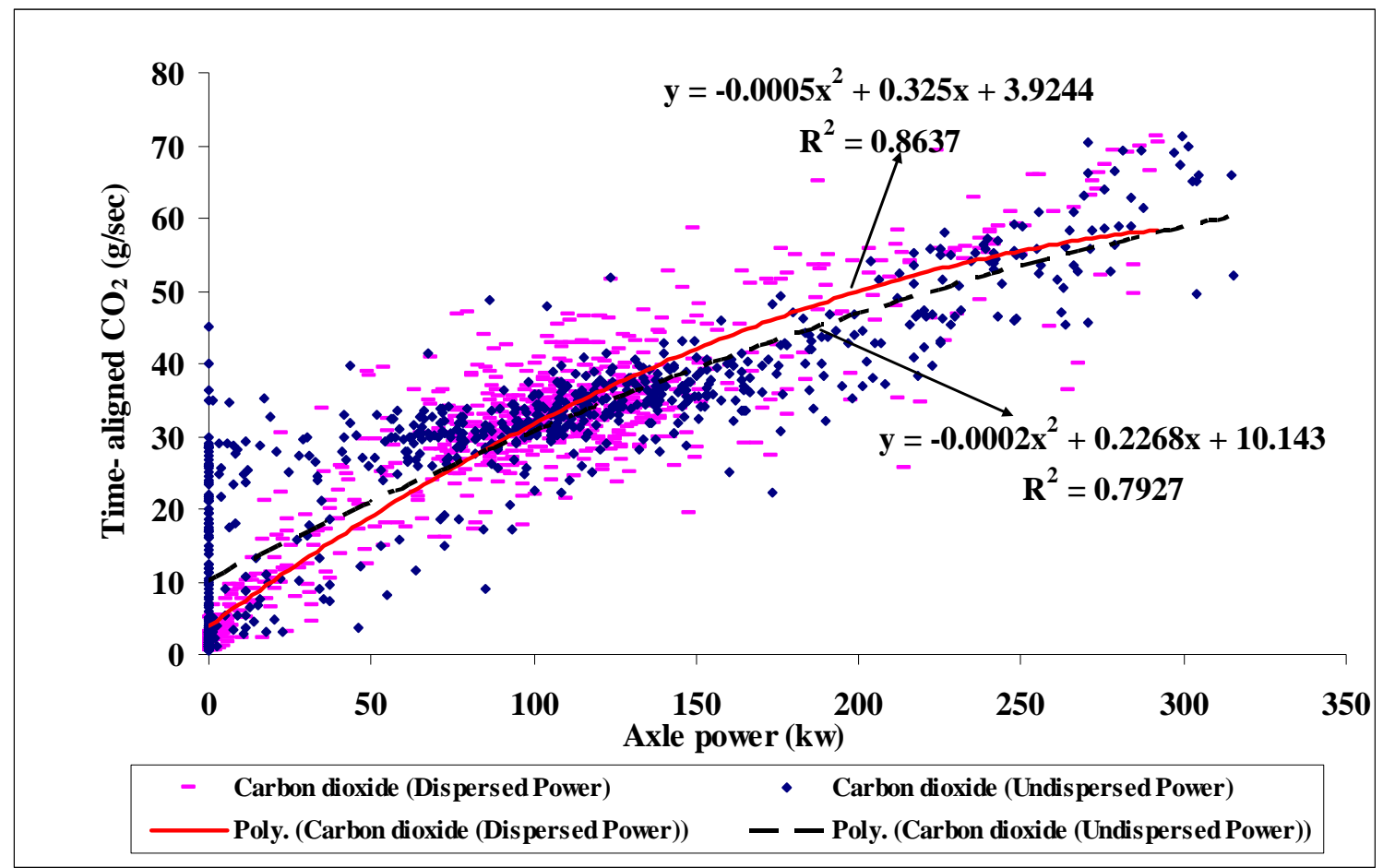

Figure 5-1. The effect of dispersion on the correlation between emission rate and axle power for CRC-34 loaded with 56,000 lb and tested on HHDDT_S 
The forward transform was tested in section 5.1.2 and 5.1.3. The emissions correlated better when the axle power (assumed instantaneous) was dispersed. Hence, if the emissions were back-transformed, they will correlate better with axle power i.e., they will become instantaneous.

\subsubsection{Constraint on emissions data for back-transformation}

Continuous data from heavy-duty testing usually stretch for about 1000 seconds and the reconstruction was stable up to around 1000 computations. But when a 5 hertz data were considered, the number of computation in the back transform will be 5000 , thereby causing numerical errors that made the methods unstable. The criterion for stability of each of the methods was described in section 5.2. Hence, to ensure stability and all the data and the dispersion functions were reduced to 1 hertz.

\subsubsection{Assumptions for the analyzer system}

For all the analysis in this study, the analyzer system is assumed to be timeinvariant and linear. The time-invariance of a system is illustrated in Figure 5-2 (a). For a given input at time $t_{1}$, the corresponding input is at $t_{2}$. For a system to be time-invariant, the following condition should be met. If the input is shifted by dt, then the output should retain its earlier shape, but should shifted by dt. The linearity of the system is illustrated in Figure 5-2 (b). $\mathrm{Y}_{1}(\mathrm{t})$ and $\mathrm{Y}_{2}(\mathrm{t})$ are the corresponding outputs for the inputs $\mathrm{X}_{1}(\mathrm{t})$ and $\mathrm{X}_{2}(\mathrm{t})$. If the input is the summation of the two inputs $X_{1}(t)+X_{2}(t)$, then the output should be the summation of the two outputs $Y_{1}(t)+Y_{2}(t)$ for the system to be linear. 

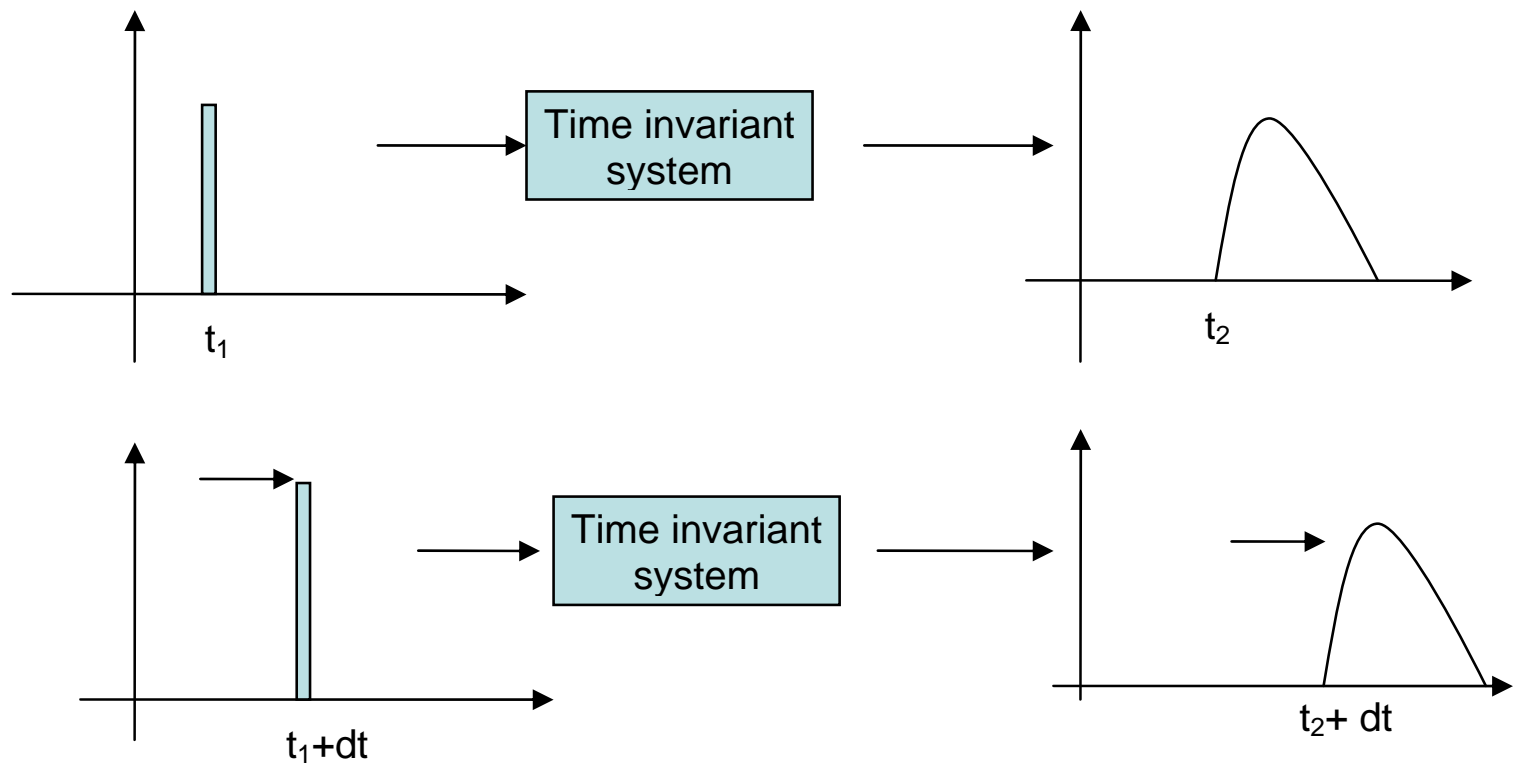

Figure 5-2 (a) Illustration of time-invariance of the system 

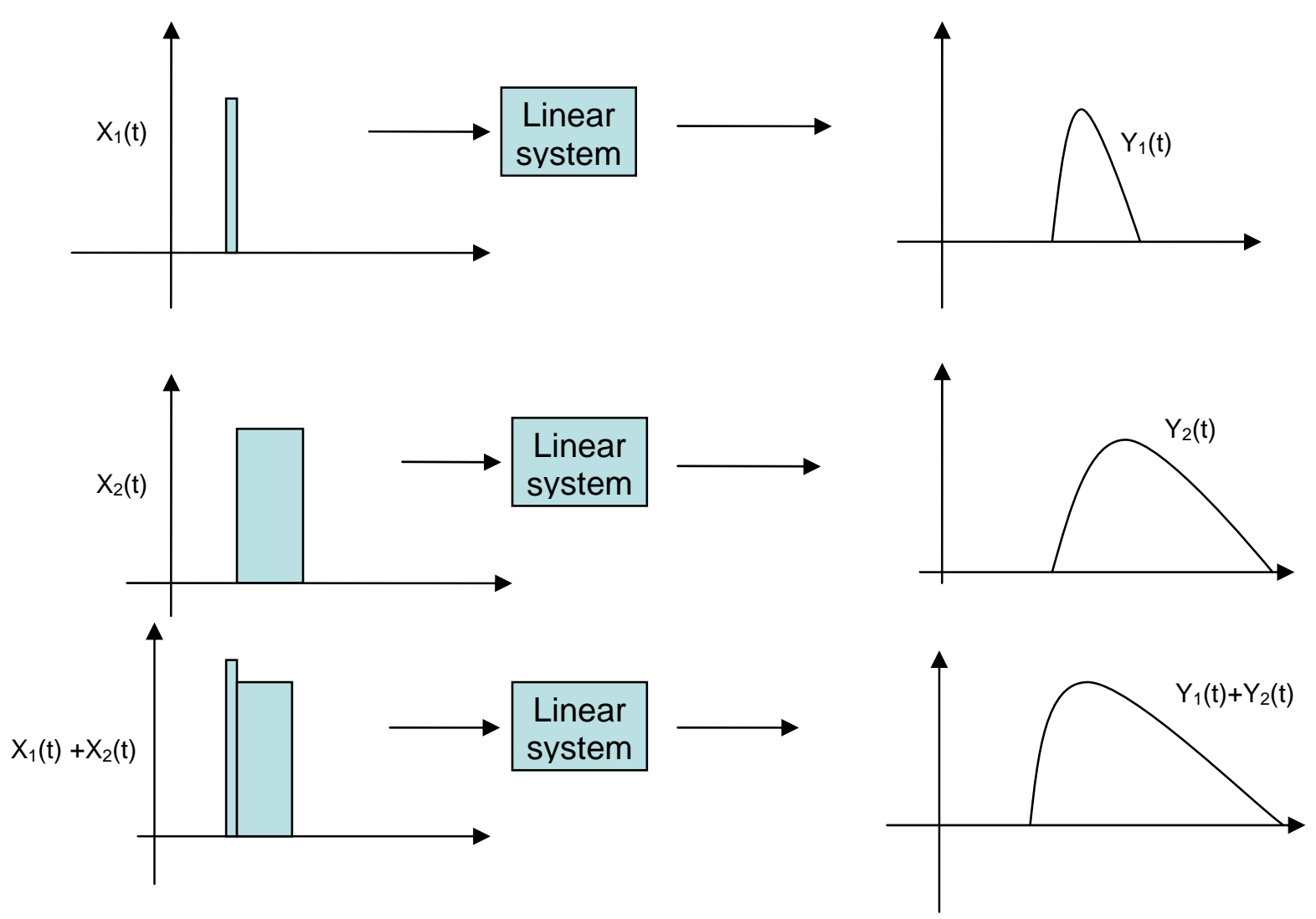

Figure 5-2 (b) Illustration of linearity of the system

\subsection{Introduction and application of back-transformation techniques}

Four different back-transformation (reconstruction) techniques are presented in this study. They are

1. Sequential Inversion Technique (SIT)

2. Differential Coefficients Method (DCM)

3. Inverse Fast Fourier Transform (IFFT)

4. Modified Deconvolution Technique (MDT) 


\subsubsection{Sequential inversion technique (SIT) [96]}

\subsubsection{Theory of SIT}

Let $U\left(t_{j}\right)$ and $Y\left(t_{j}\right)$ be the input and the output in the $\mathrm{j}^{\text {th }}$ second respectively. Let the elements in the dispersion function be $C_{1}, C_{2}, C_{3}$ and so on. The dispersion function relates the input and output at each second as follows.

$$
\begin{aligned}
& \mathrm{Y}\left(\mathrm{t}_{1}\right)=\mathrm{C}_{1} \mathrm{U}\left(\mathrm{t}_{1}\right) \\
& \mathrm{Y}\left(\mathrm{t}_{2}\right)=\mathrm{C}_{1} \mathrm{U}\left(\mathrm{t}_{2}\right)+\mathrm{C}_{2} \mathrm{U}\left(\mathrm{t}_{1}\right) \\
& \mathrm{Y}\left(\mathrm{t}_{3}\right)=\mathrm{C}_{1} \mathrm{U}\left(\mathrm{t}_{3}\right)+\mathrm{C}_{2} \mathrm{U}\left(\mathrm{t}_{2}\right)+\mathrm{C}_{3} \mathrm{U}\left(\mathrm{t}_{1}\right)
\end{aligned}
$$

In short, the set of equations can be represented by a system as shown in Eq. 5-1.

$$
\mathrm{Y}\left(\mathrm{t}_{\mathrm{j}}\right)=\mathrm{C}_{1} \mathrm{U}\left(\mathrm{t}_{\mathrm{j}}\right)+\mathrm{C}_{2} \mathrm{U}\left(\mathrm{t}_{\mathrm{j}-1}\right)+\mathrm{C}_{3} \mathrm{U}\left(\mathrm{t}_{\mathrm{j}-2}\right)+\ldots+\mathrm{C}_{\mathrm{k}} \mathrm{U}\left(\mathrm{t}_{\mathrm{j}-\mathrm{k}+1}\right)
$$

where $\mathrm{j}$ takes values from 1 to $\mathrm{n}$ (where $\mathrm{n}$ is the number of seconds of the output data considered) and $\mathrm{k}$ represents the number of elements in the dispersion function. The set of equations can be solved in sequence starting from the first equation when $j=1$. Since the computation of the input at any time interval, $\mathrm{U}\left(\mathrm{t}_{\mathrm{j}}\right)$ from the output, $\mathrm{Y}\left(\mathrm{t}_{\mathrm{j}}\right)$ depends on the input at the previous time interval, $\mathrm{U}\left(\mathrm{t}_{\mathrm{j}-1}\right)$, numerical errors will be propagated throughout the computation. The computational error includes the loss of significant digits due to truncation and the magnitude of the error increases with the number of data points or time intervals. 


\subsubsection{The role of dispersion function on SIT}

For a dispersion function $\left\{\mathrm{C}_{1} \mathrm{C}_{2} \mathrm{C}_{3} \mathrm{C}_{4}\right\}$, the role played by the size of $\mathrm{C}_{1}$ was examined keeping the other elements $\mathrm{C}_{2}, \mathrm{C}_{3}$ and $\mathrm{C}_{4}$ equal. (It should be noted that still $\mathrm{C}_{1}$ $+\mathrm{C}_{2}+\mathrm{C}_{3}+\mathrm{C}_{4}=1$ to achieve mass balance.) To start with, the fast $\mathrm{NO}_{\mathrm{x}}$ (from Cambustion $\mathrm{fNO}_{\mathrm{x}}$ analyzer, introduced in Chapter 3) data were collected from the testing conducted on 1992 DDC Series 60 on $2 / 28 / 2005$ at the WVU engine test cell. These data were considered as instantaneous $\mathrm{NO}_{\mathrm{x}}$. The data were dispersed in time using a dispersion function to obtain the diffused data. Before considering the realistic dispersion characteristic of an analyzer, the reconstruction of the emission signal for a simple dispersion function such as $\left\{\begin{array}{llll}0.4 & 0.2 & 0.2 & 0.2\end{array}\right\}$ was examined. For this dispersion function, the computation involved division by a large value of $\mathrm{C}_{1}$, and the input in the first time interval was computed accurately. Consequently, the reconstruction was accurate in the subsequent time intervals. As can be seen in Figure 5-2 (a), the reconstructed input values (asterisks) appear to lie on the analyzer input data line. The diffused output when plotted

against the original fast $\mathrm{NO}_{\mathrm{x}}$ data was scattered as shown in Figure 5-2 (b), but the reconstructed input agreed well $\left(\mathrm{R}^{2}\right.$ of 0.999$)$ with the fast $\mathrm{NO}_{\mathrm{x}}$ data. 


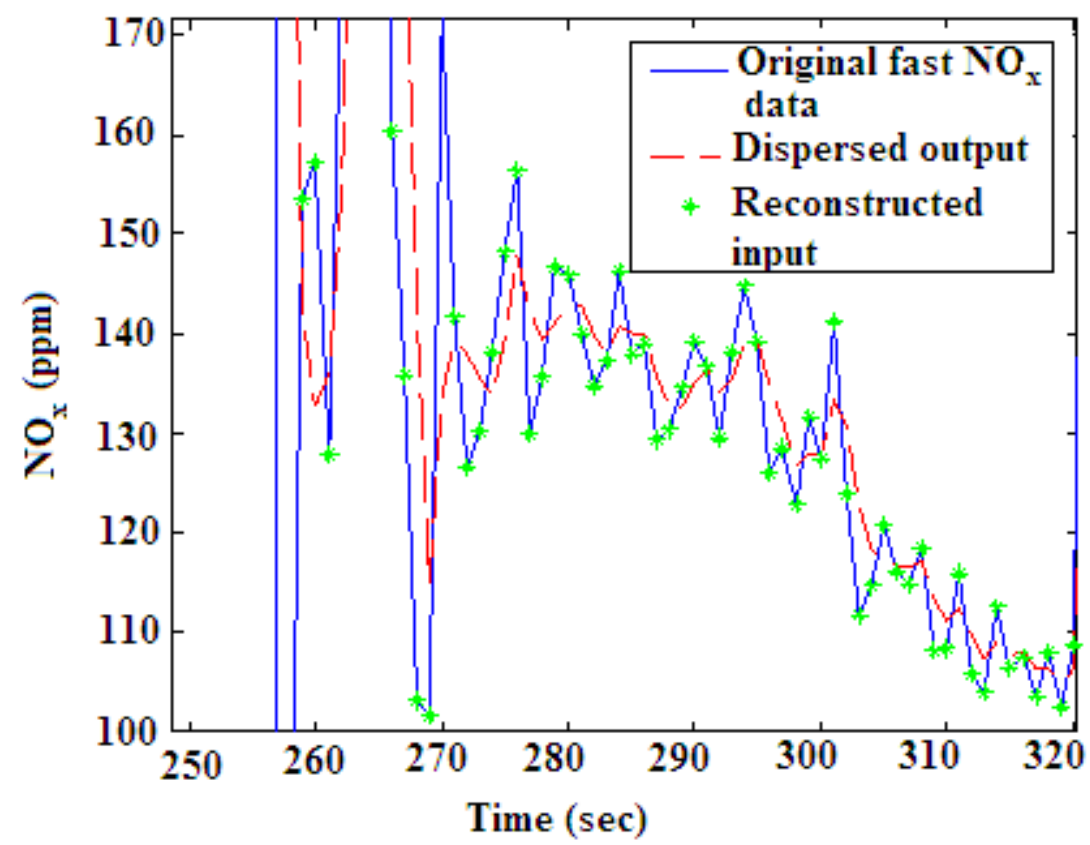

(a)

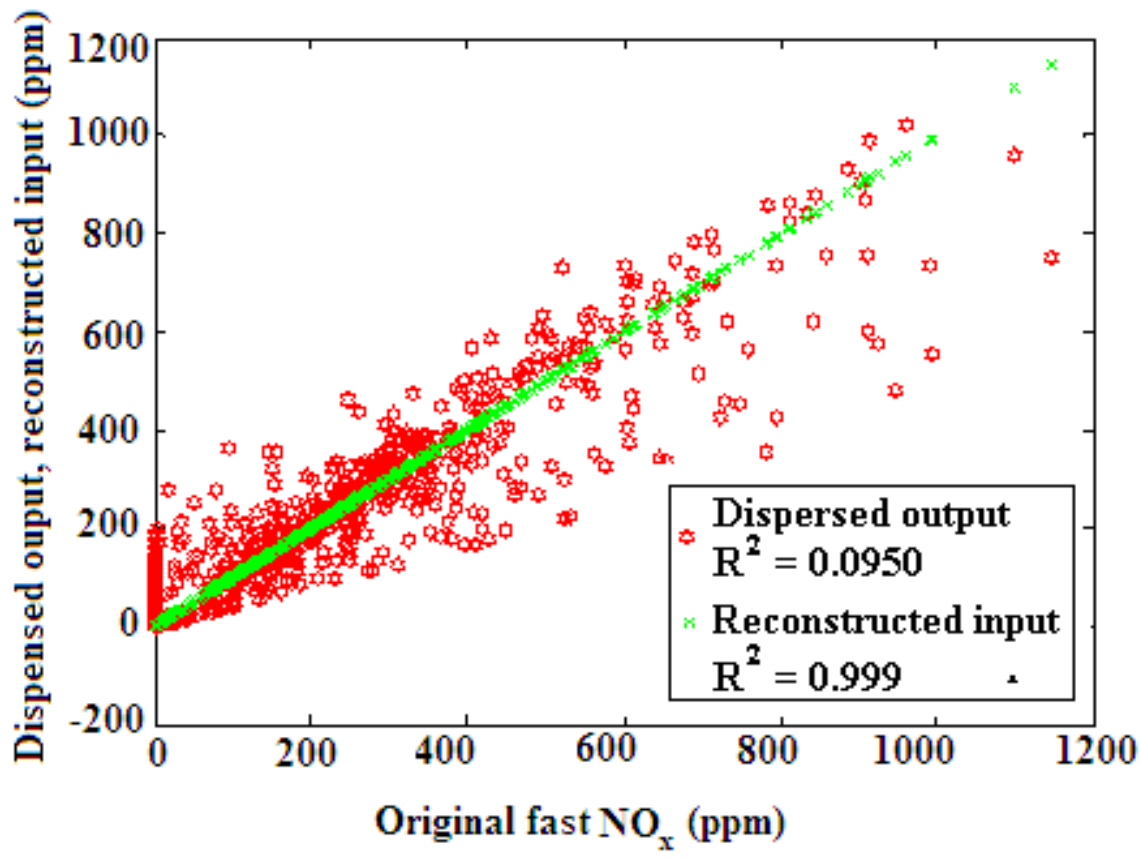

(b)

Figure 5-3. Reconstruction using SIT (a) continuous emission (b) parity plot

The original Fast $\mathrm{NO}_{\mathrm{x}}$ data and the corresponding dispersed data were presented in Figure 5-4 (a). However, it was observed that when the value of $\mathrm{C}_{1}$ was decreased, the technique 
failed. To find the value of $\mathrm{C}_{1}$ at which this technique begins to fail, the first element was gradually decreased. When it was reduced to 0.137 , a deviation was of the order of $10^{10}$ as shown in Figure 5-4 (b). The deviation was noted to be oscillatory. By further reducing the first element $C_{1}$ to 0.130 , the size of the deviation increased to the order of $10^{13}$.

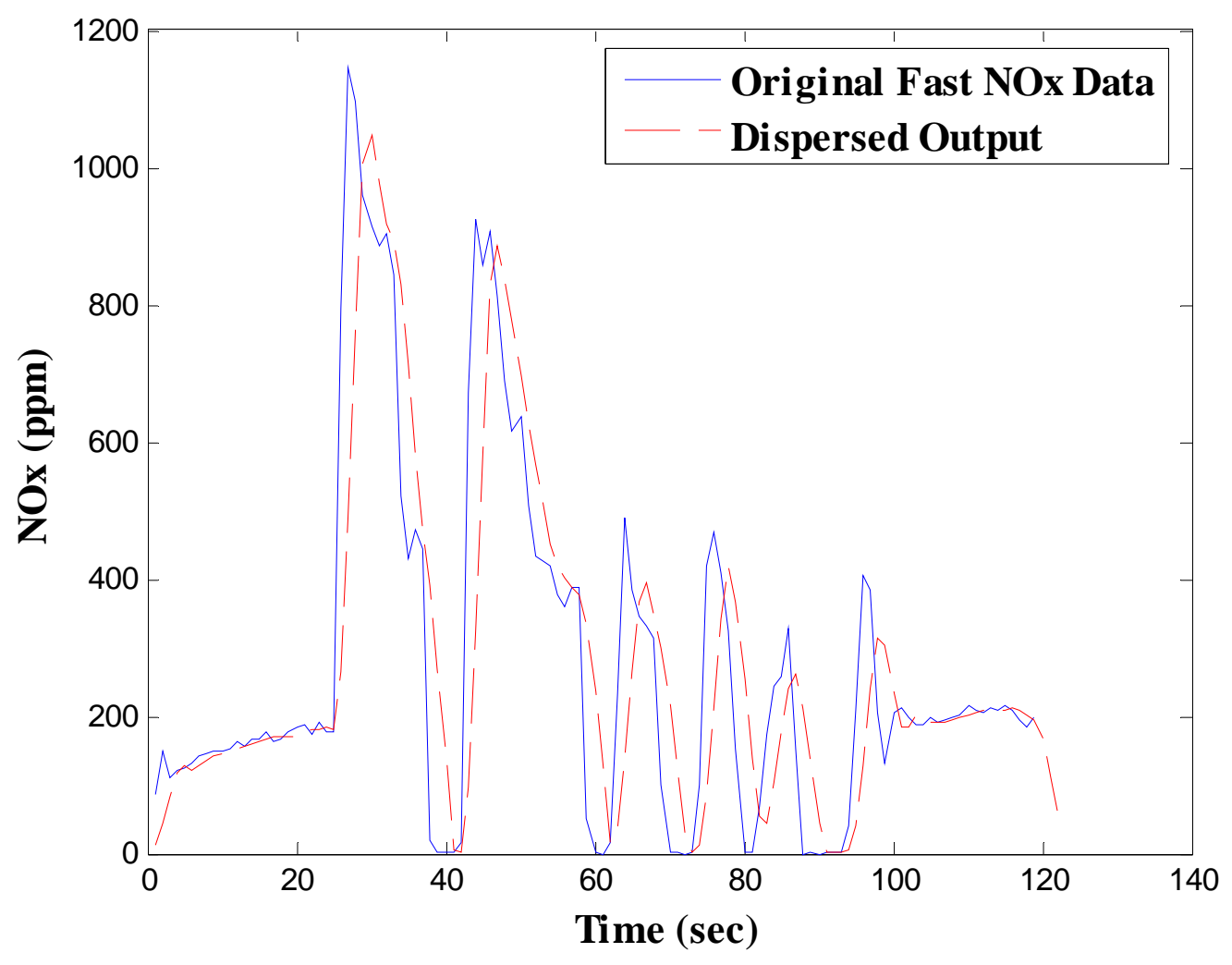

(a) 


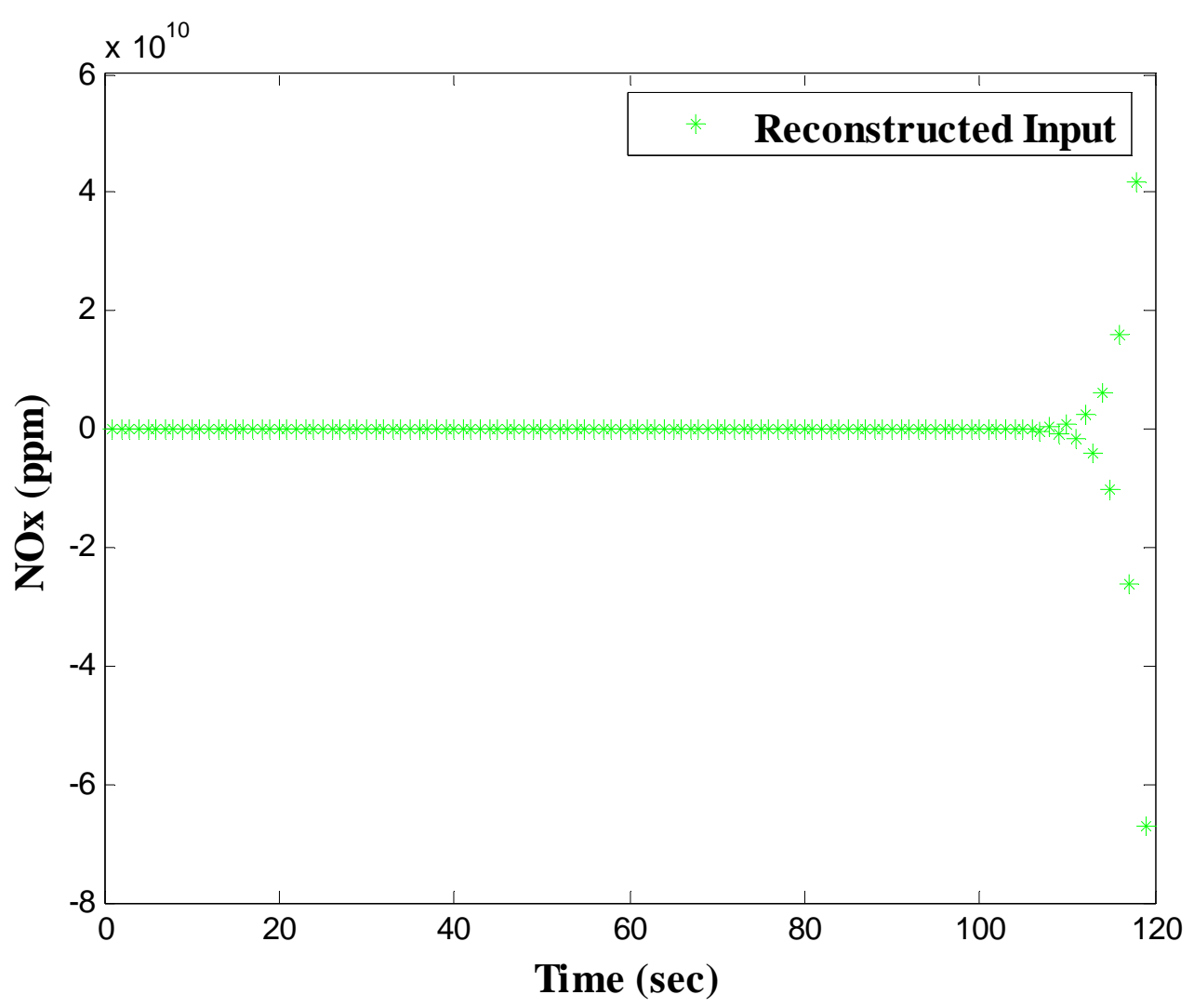

(b)

Figure 5-4. SIT applied to a $\mathrm{NO}_{\mathrm{x}}$ analyzer (a) Original data and dispersed data (b) Reconstructed data

If the first element $\left(\mathrm{C}_{1}\right)$ of the diffusion function were 0.6 , the magnitude of the error (which is the difference in the amplitude of the reconstructed signal and the real signal) was found to be of the order of $10^{-15}$, but with the decrease of the first element, the order of the error increased exponentially. The logarithm to the base ten of the error was computed and was plotted against the magnitude of the first element in Figure 5-5. The order of the error also increased with the time interval at which the error was computed. This was because the number of computations for the reconstruction increased the error sequentially. 


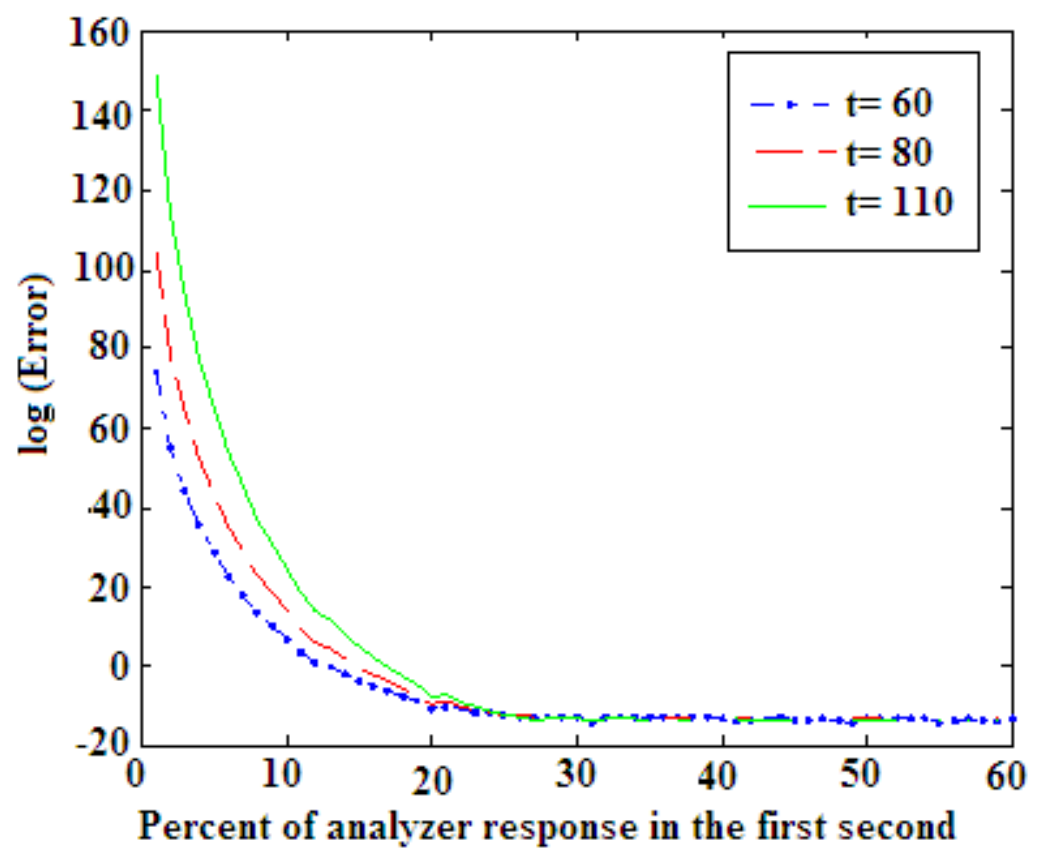

Figure 5-5. The effect $C_{1}$ on order of the error in SIT

Hence, for the SIT to predict the true engine-out emissions accurately, it is necessary that the first element of the dispersion function should be higher than the rest of the elements. This requires that the response of the analyzer in the first time interval should be bigger than or at least comparable to the response in the following time intervals. As this is not the case for most dilution and analyzer systems, the examination of the cases with the realistic dispersion function is unnecessary. Since the numerical error increases exponentially for every computation, this method is not practical for reconstructing the emission signal from the data measured by the current analyzer systems. Hence an effort to reconstruct the instantaneous emissions using SIT, for the realistic diffusion function is not warranted. In other words, since SIT failed for simple diffusion function, it will fail for a realistic diffusion function as well. 


\subsubsection{Differential coefficients method (DCM)}

Ajtay and Weilenmann have presented and discussed a mathematical approach [97] to reconstruct the true emission signals from the measured output of the analyzer.

\subsubsection{Definition and implementation of DCM}

Following their analysis, let $\mathrm{U}(\mathrm{t})$ be the input to the analyzer and $\mathrm{Y}(\mathrm{t})$ be the output and $Y^{\prime}(t)$ and $Y^{\prime /}(t)$ be the first and second derivatives of the output. The method assumes that the input can be expressed as the sum of the output and some linear combinations of the first and second derivatives of the output. The input $U(t)$ and output $\mathrm{Y}(\mathrm{t})$ and its derivatives are related by the following expression.

$$
\mathrm{U}(\mathrm{t})=\mathrm{Y}(\mathrm{t})+\mathrm{a}_{1} \mathrm{Y}^{\prime}(\mathrm{t})+\mathrm{a}_{2} \mathrm{Y}^{\prime /}(\mathrm{t})
$$

Eq.5-2 is subject to a constraint that the integrated input is the same as the integrated output over the duration of observation as it is assumed that the analyzer accounts for all of the data even though the data are delayed and diffused. This dispersion function was considered as the output $Y(t)$ and was differentiated numerically to obtain $Y^{\prime}(t)$ and $Y^{\prime \prime}(t)$ over a period of the dispersion. These time steps for the numerical differentiation can be one second, half a second or one tenth of a second, but a one second time step was considered. The numerical derivatives for this study were computed using backward differences in one second time intervals. Then the derivatives were mapped with the unit impulse input and the time sequence was fit over the dispersion period and the error was then computed at each second as the absolute value of $\left[U(t)-Y(t)-a_{1} Y^{\prime}(t)-\right.$ 
$\left.a_{2} Y^{\prime \prime}(t)\right]$. The least squares error was computed as the sum of the squares of the computed errors at all points and this was minimized for the best fit that generated the values of $a_{1}$ and $a_{2}$, the coefficients of the derivatives of the output. The values of $a_{1}$ and $a_{2}$ were then used to obtain the input $\mathrm{U}$ of the analyzer from the output $\mathrm{Y}$ of any given data from the analyzer. The inherent assumption in the method was that the analyzer was consistent in its dispersion behavior and that its behavior will not change in the long run.

\subsubsection{Validating DCM}

\subsection{Validating $\mathrm{DCM}$ in reconstructing $\mathrm{NO}_{\mathrm{x}}$ data}

The fast $\mathrm{NO}_{\mathrm{x}}$ data (from the DDC Series 60) were again considered as instantaneous $\mathrm{NO}_{\mathrm{x}}$, representing the values of $\mathrm{U}(\mathrm{t})$ and were dispersed in time to generate the diffused $\mathrm{NO}_{\mathrm{x}}, \mathrm{Y}(\mathrm{t})$. Then the procedure described above was used to reconstruct the $\mathrm{NO}_{\mathrm{x}}$. The reconstructed input and the original fast NOx data were plotted on a time-wise plot in Figure 5-6 (a). A portion of the 5-6 (a) is magnified in Figure 5-6 (b). The diffused data were smoother and had lost some high frequency detail, but the reconstructed data points lie close to the fast $\mathrm{NO}_{\mathrm{x}}$ curve, regaining the detail.

The correlation of the original input with the diffused output (with $\mathrm{R}^{2}$ of 0.9007 )

is shown in Figure 5-6 (c). After reconstruction, the correlation $\left(\mathrm{R}^{2}\right.$ of 0.976$)$ with the original fast $\mathrm{NO}_{\mathrm{x}}$ data improved. 


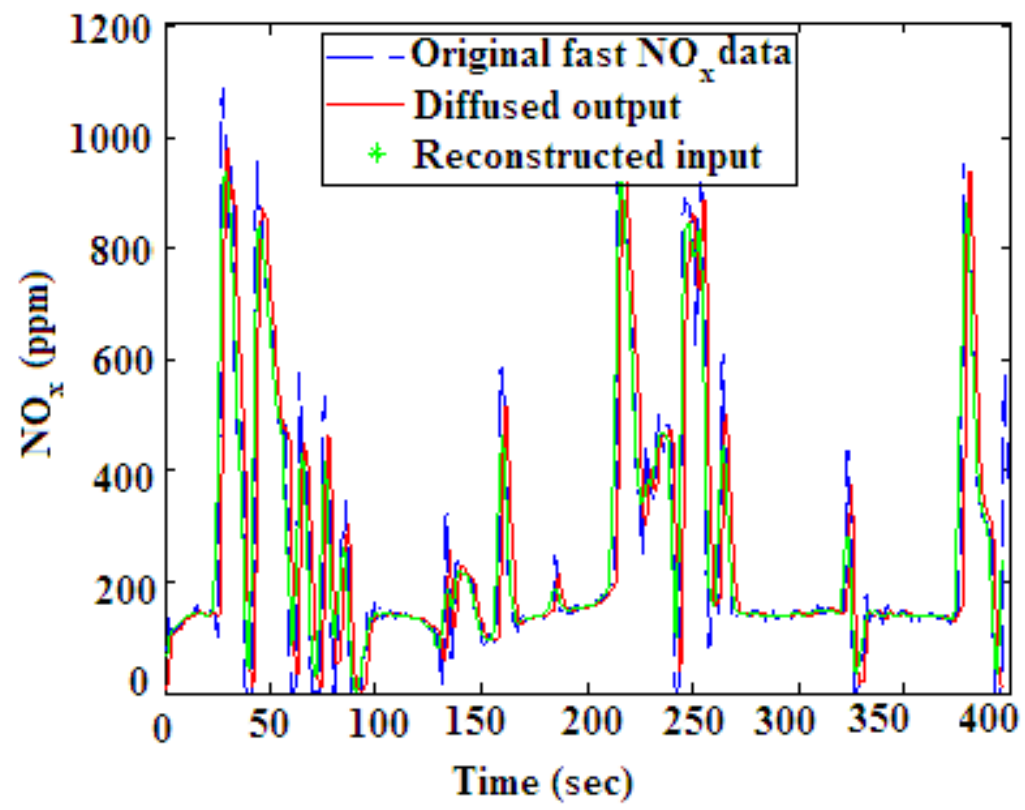

(a)

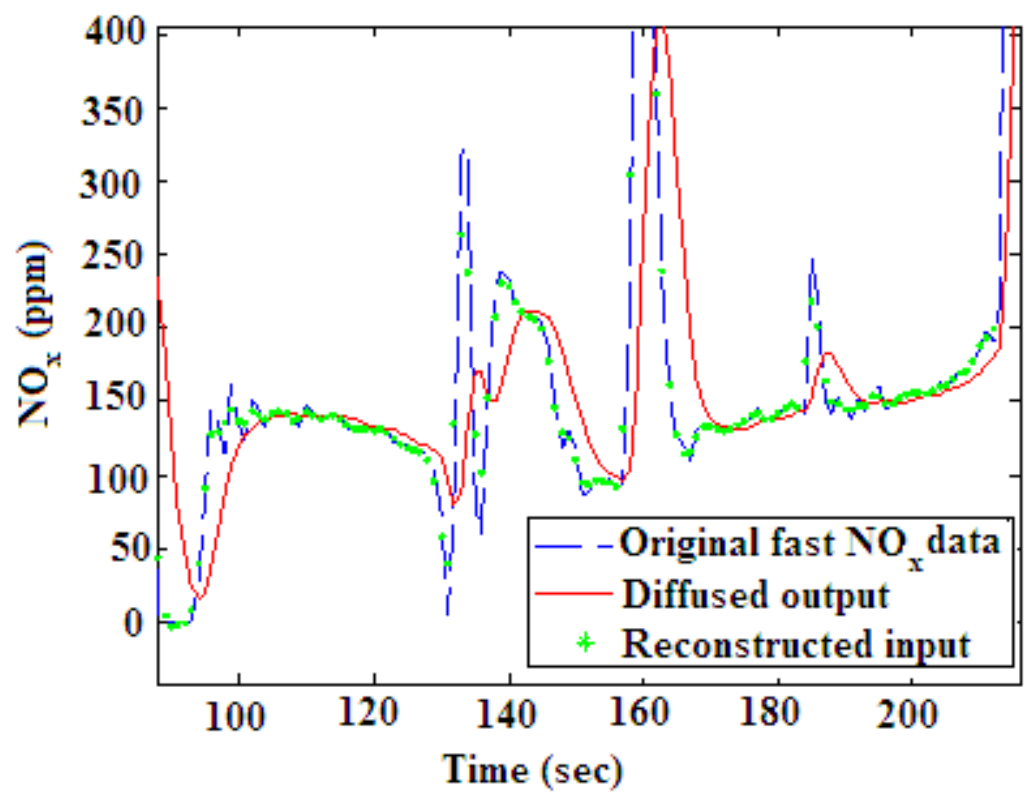

(b) 


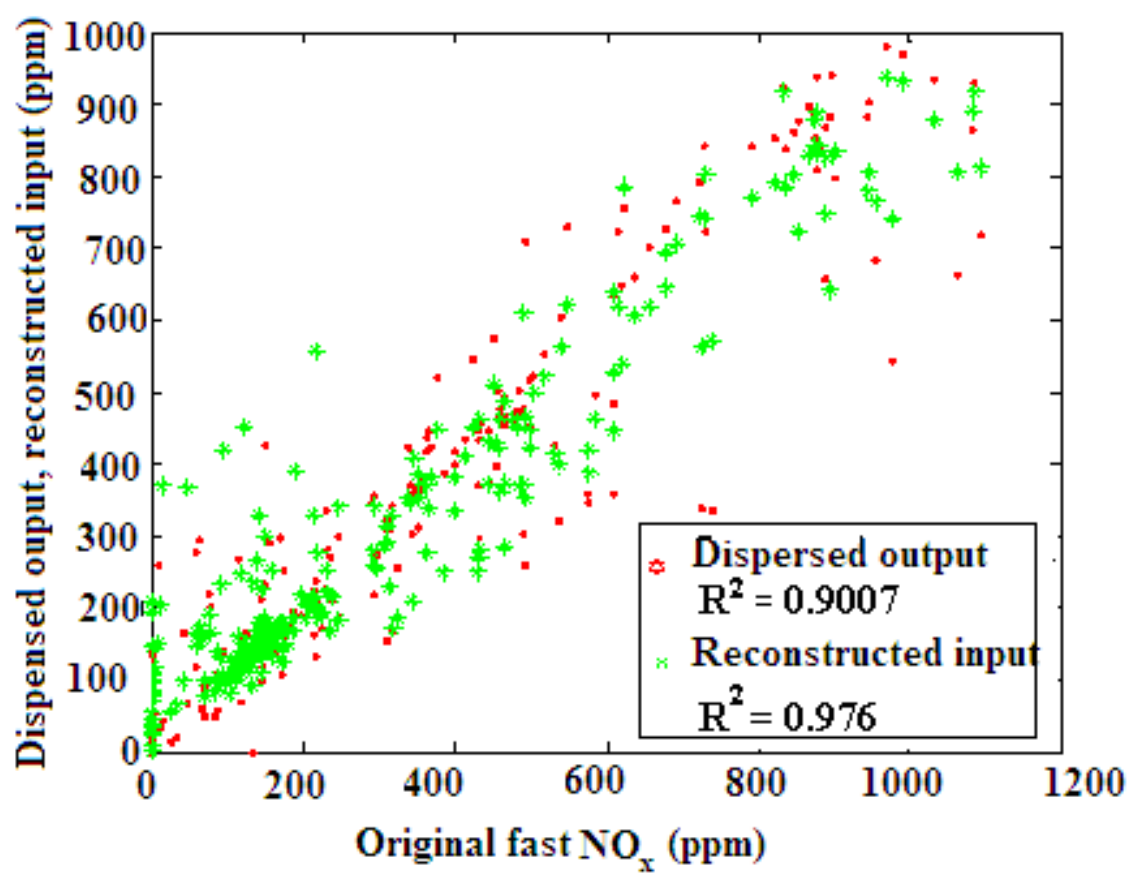

(c)

Figure 5-6. $\mathrm{NO}_{\mathrm{x}}$ reconstruction using DCM (a \& b) Continuous data (c) Parity plot

\subsection{Validating DCM in reconstructing $\mathrm{CO}_{2}$ data}

One way to evaluate the high frequency detail in emissions data is to correlate $\mathrm{CO}_{2}$ with power. For diesel engines, the $\mathrm{CO}_{2}$ corresponds closely to the fuel consumed, and brake specific fuel consumption is fairly constant over much of the engine operating envelope. The engine power data are not diffused in time, so that a high correlation of $\mathrm{CO}_{2}$ with power (particularly within the NTE, or at high power levels) suggests that the $\mathrm{CO}_{2}$ data are not excessively diffused.

The power was dispersed according to the dispersion function presented in Section 3.2.3 and then $\mathrm{CO}_{2}$ was time-aligned and expressed as a function of dispersed power. The $\mathrm{CO}_{2}$ was better correlated $\left(\mathrm{R}^{2}\right.$ of 0.978$)$ with the dispersed power than with the un- 
dispersed power ( $\mathrm{R}^{2}$ of 0.890 ), which was expected because of the dispersion associated with the measurement of the emissions. Then the continuous data were considered again and the data were reconstructed using the DCM. The reconstructed data correlated better $\left(R^{2}\right.$ of 0.950$)$ with the un-dispersed axle power than the measured data $\left(R^{2}\right.$ of 0.890$)$ as can be seen in Figure 5-7 (a). Moreover, the correlation of reconstructed (instantaneous) data with the un-dispersed (instantaneous) power $\left(\mathrm{R}^{2}\right.$ of 0.950$)$ was almost as good as (about $97 \%$ of) the correlation of the measured data with the dispersed power $\left(\mathrm{R}^{2}\right.$ of 0.978$)$. A section of the reconstruction is magnified in Figure 5-7 (b) and both the delay and the dispersion of the data can be clearly observed. This suggested that the reconstruction brought back the lost transient detail from the measured $\mathrm{CO}_{2}$ data. All the three FTP runs from the DDC Series 60 engine showed similar results and the correlation coefficients between the $\mathrm{CO}_{2}$ emissions and power are tabulated in Table 5-1. In all the three cases, the reconstructed $\mathrm{CO}_{2}$ correlated better with the power than the measured $\mathrm{CO}_{2}$.

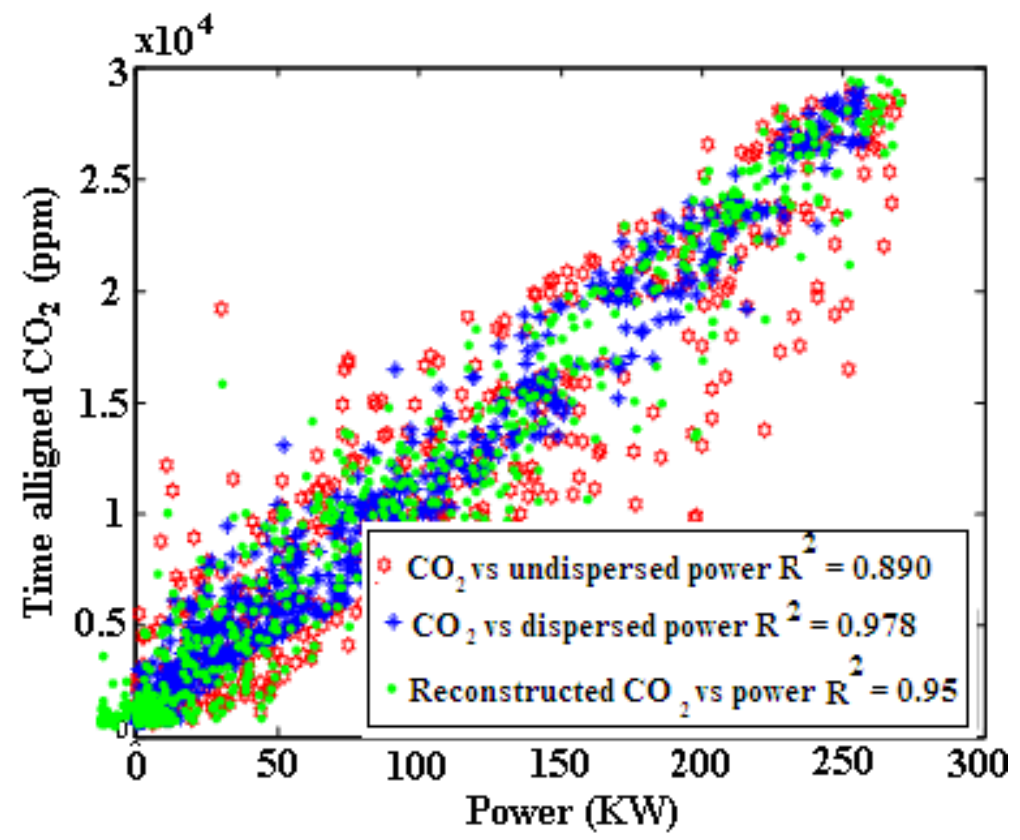

(a) 


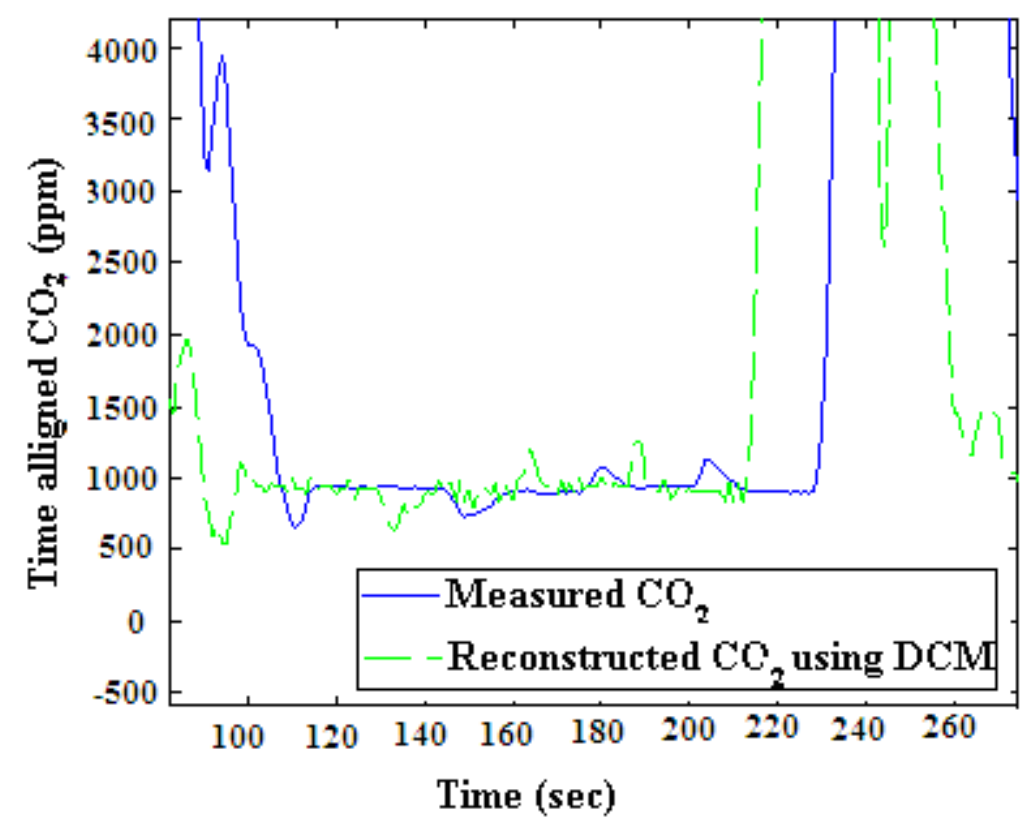

(b)

Figure 5-7. $\mathrm{CO}_{2}$ reconstruction using DCM (a) Parity plot (b) Continuous data

Table 5-1. $\mathbf{R}^{2}$ values for the three FTP runs examined to test the validity of the DCM

\begin{tabular}{|l|l|c|c|}
\hline $\begin{array}{l}\text { Correlating } \\
\text { Variables }\end{array}$ & $\begin{array}{l}\mathrm{CO}_{2} \\
\text { vs } \\
\text { Power }\end{array}$ & $\begin{array}{l}\mathbf{C O}_{2} \text { vs Dispersed Power } \\
\text { (Forward transform) }\end{array}$ & $\begin{array}{l}\text { Reconstructed } \mathbf{C O}_{2} \\
\text { vs Power } \\
\text { (Backward transform) }\end{array}$ \\
\hline Run 1 & 0.890 & 0.978 & 0.950 \\
\hline Run 2 & 0.899 & 0.974 & 0.957 \\
\hline Run 3 & 0.887 & 0.979 & 0.947 \\
\hline
\end{tabular}




\subsubsection{Improvement of DCM}

\subsection{Effect of forward, central and backward differences}

The DCM method suggested by Ajtay and Weilenmann $[67,97]$ involved the first two differentials numerically computed using the backward differences. It was of interest to check if the results can be varied if different methods of computing the derivatives can be used.

A few cases were examined to understand the effect of the way in which numerical derivatives were computed. The forward, central and backward differences were independently used while computing the differentials. The DCM was used to reconstruct the original data from the dispersed data and in each of the cases, the percent error was computed as follows. If $U(t)$ is the original input and $Y(t)$ is dispersed output and if $U^{\prime}(t)$ represents the reconstructed input, then the percent error is computed according to Eq.5-3.

$$
\text { Percent Error }=\frac{\sqrt{\sum\left(U(t)-U^{\prime}(t)\right)^{2}}}{\sqrt{\sum(U(t))^{2}}}
$$

In each of the cases, the root mean square (RMS) value of the error (error is the difference between the reconstructed input and the original input) was computed, and the RMS value of the original input was computed. The ratio of the RMS of the error to the RMS of the original input was expressed as a percentage and the results when more derivatives were used are shown in Table 5-2. The errors in all the cases were tabulated (Table 5-2). Since the backward differences showed better results than the central and 
forward differences, they were used for computing the derivatives for all the cases examined in this study.

Table 5-2. Errors in DCM with different numerical methods for computing the derivatives

\begin{tabular}{|c|c|c|c|}
\hline $\begin{array}{c}\text { Numerical Method } \\
\text { for computing the } \\
\text { derivatives }\end{array}$ & $\begin{array}{c}\text { Forward } \\
\text { differences }\end{array}$ & $\begin{array}{c}\text { Central } \\
\text { differences }\end{array}$ & $\begin{array}{c}\text { Backward } \\
\text { differences }\end{array}$ \\
\hline DDC-1 & $2.45 \%$ & $1.91 \%$ & $2.03 \%$ \\
\hline DDC-2 & $2.65 \%$ & $1.93 \%$ & $2.04 \%$ \\
\hline DDC-3 & $2.42 \%$ & $1.96 \%$ & $2.07 \%$ \\
\hline CUMMINS-1 & $4.03 \%$ & $4.38 \%$ & $3.55 \%$ \\
\hline CUMMINS-2 & $4.16 \%$ & $4.32 \%$ & $3.58 \%$ \\
\hline CUMMINS-3 & $4.39 \%$ & $4.25 \%$ & $3.95 \%$ \\
\hline
\end{tabular}

\subsection{Effect of multiple derivatives on DCM}

Instead of using just two derivatives in Eq. 5-2 by DCM, multiple derivatives were used (Eq. 5-3).

$\mathrm{U}(\mathrm{t})=\mathrm{Y}(\mathrm{t})+\mathrm{a}_{1} \mathrm{Y}^{\prime}(\mathrm{t})+\mathrm{a}_{2} \mathrm{Y}^{\prime \prime}(\mathrm{t})+\mathrm{a}_{3} \mathrm{Y}^{3}(\mathrm{t})+\mathrm{a}_{4} \mathrm{Y}^{4}(\mathrm{t})+\mathrm{a}_{5} \mathrm{Y}^{5}(\mathrm{t})+\mathrm{a}_{6} \mathrm{Y}^{6}(\mathrm{t})$

Several cases were examined for reconstruction using DCM with more derivatives. In each of the cases, the percent error was computed as follows. If $U(t)$ was the original input and $Y(t)$ was dispersed output and $U^{\prime}(t)$ represented the reconstructed input, then the percent error was again computed according to Eq.5-3 and the results were shown in Table 5-3. The marginal 
advantage of using more derivatives was neglected and hence while applying DCM, only the first two derivatives were considered as suggested originally in the method.

Table 5-3. Percent errors in DCM with multiple derivatives

\begin{tabular}{|c|c|c|c|c|c|c|}
\hline $\begin{array}{c}\text { Derivatives } \\
\text { Used }\end{array}$ & $\begin{array}{c}\text { First two } \\
\text { Derivatives } \\
\text { 'suggested by } \\
\text { Ajtay et al. [67] }\end{array}$ & $\begin{array}{c}\text { First three } \\
\text { derivatives }\end{array}$ & $\begin{array}{c}\text { Second } \\
\text { +fourth }\end{array}$ & $\begin{array}{c}\text { First four } \\
\text { derivatives }\end{array}$ & $\begin{array}{c}\text { First five } \\
\text { derivative }\end{array}$ & $\begin{array}{c}\text { First six } \\
\text { derivatives }\end{array}$ \\
\hline DDC-1 & 2.03 & 1.83 & 2.21 & 1.83 & 1.78 & 1.78 \\
\hline DDC-2 & 2.04 & 1.81 & 2.22 & 1.81 & 1.75 & 1.75 \\
\hline DDC-3 & 2.07 & 1.83 & 2.08 & 1.82 & 1.77 & 1.77 \\
\hline Cummins-1 & 3.55 & 3.48 & 3.36 & 3.29 & 3.29 & 3.28 \\
\hline Cummins-2 & 3.58 & 3.55 & 3.95 & 3.42 & 3.42 & 3.41 \\
\hline Cummins-3 & 3.95 & 3.82 & 4.82 & 3.29 & 3.60 & 3.57 \\
\hline
\end{tabular}

\subsubsection{Stability of DCM}

The sum total of all the elements in the dispersion function is unity. For NOx and $\mathrm{CO} 2$ analyzers presented in this study, the dispersion is of the order of 7 to 8 seconds. Hence, a one hertz dispersion function will have 7 or 8 elements that sum up to unity. The average magnitude of each element is about 0.12 . For computing the values of the coefficients, DCM involves numerical differentiation of the dispersion function. If five hertz dispersion was considered, there are about 40 elements adding up to unity and the average magnitude of each element falls to 0.024 . In five hertz dispersion function was employed, the numerical differentiation involves differentiating smaller numbers (than in case of 1 hertz). It also involves five times more computations (than in case of 1 hertz) and 
hence the coefficients could not be correctly computed. For this reason, DCM is recommended only with 1 hertz data or when the elements of dispersion function are not more than ten.

\subsubsection{Fast Fourier Transform (FFT) and Inverse Fast Fourier Transform (IFFT)}

In order to seek a better reconstruction technique than DCM, a few signal processing techniques that are applicable to the emissions reconstruction were reviewed [98, 99]. The application of Fast Fourier Transform and Inverse Fast Fourier Transform was investigated. A convolution is an integral that expresses the amount of overlap of one function as it is shifted over another function. A thorough introduction and illustration of convolution is provided elsewhere [100].

\subsubsection{Modeling the analyzer system}

The system can be simply represented as in Figure 5-8. The input signal $\mathrm{x}(\mathrm{t})$ is unknown. The measured data by the analyzer is the output $y(t)$. The analyzer response to a unit instantaneous pulse is represented as $h_{m}$. Since the analyzers are assumed to be timeinvariant linear systems the response of the analyzers to an instantaneous pulse can be modeled as the transfer function $\mathrm{h}_{\mathrm{m}}$ of the analyzer. Since the analyzers are assumed to be invariant in time, there is one specific transfer function for any given analyzer. 


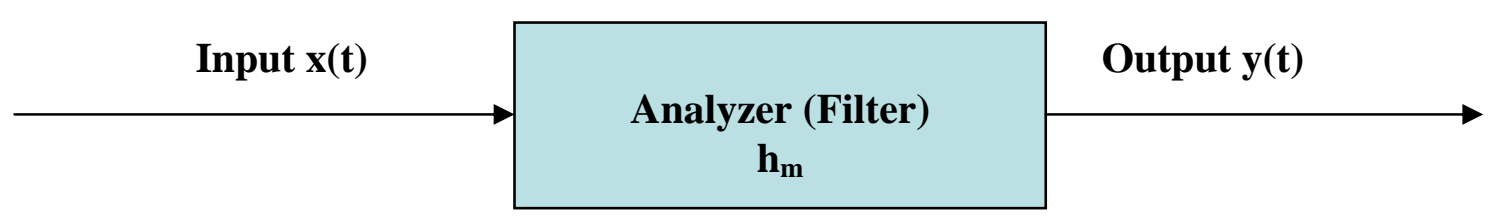

Figure 5-8. Representation of the system in time domain

\subsubsection{Theory of IFFT}

A forward Fourier transform is used to change the representation of a function in time domain to frequency domain. Fast Fourier Transform (FFT) converts a vector in time domain into a vector in frequency domain. In time domain, each of the vectors is series of discrete amplitude signals for a given discrete time. But, in the frequency domain, each of these vectors transform to a value of one spectral component for a given discrete frequency. The FFT for a given time-amplitude vector, $\mathrm{X}[\mathrm{n}]$ for a sample size of $\mathrm{N}$ is given by Equation 5-5 (a).

$$
X[k]=\sum[x(n) \exp (-2 \pi i k n / N)], \mathrm{n} \text { in }[0, \mathrm{~N}-1]
$$

To illustrate this, a simple discrete time-amplitude signal such as $[1,2,0,4,5]$ can be considered and an FFT can be applied to this. The corresponding discrete frequencyamplitude is given by the following vector.

$[12.0000,-0.0729+5.2043 \mathrm{i}, \quad-3.4271-2.0409 \mathrm{i}, \quad-3.4271+2.0409 \mathrm{i}, \quad-0.0729-5.2043 \mathrm{i}]$

The inverse Fast Fourier Transform (IFFT) changes the representation of the function in frequency amplitude vector space to a time-amplitude vector space. The IFFT 
for a given vector of discrete frequency-amplitude is generated by the inverse of the RHS in Equation 5-5 (b)

$$
\mathrm{x}[\mathrm{n}]=\sum[X(k) \exp (2 \pi i k n / N)], \mathrm{k} \text { in }[0, \mathrm{~N}-1]
$$

This IFFT can be applied to the vector generated by the FFT, which brings back the time-amplitude representation as $[1.000,2.000,0.000,4.000,5.000]$. The IFFT of the Matlab generates only the real values for a series of time-amplitude vector space.

In the time domain, the convolution of $\mathrm{x}(\mathrm{t})$ and $\mathrm{h}_{\mathrm{m}}$ generates $\mathrm{y}(\mathrm{t})$. The representation of the system in the time domain is given in Figure 5-8. The discrete convolution between two functions over an infinite time range can be expressed as a summation as in Eq. 5-6 (a)

$$
y(t)=\sum_{-\infty}^{\infty} h_{m}(t) x(n-t)
$$

A continuous representation of the convolution can be expressed in the finite range $[0, \mathrm{~N}]$ as shown by Eq. 5-6 (b).

$$
y(t)=\int_{0}^{N} x(t-\tau) h_{m}(t) d t
$$

The complicated convolution process in the time domain can be expressed as a simple multiplication in the frequency domain as in Eq. 5-7.

$$
\begin{aligned}
& Y(n)=X(n) . H_{w} \\
& \text { Hence } X(n)=Y(n) / H_{w}
\end{aligned}
$$


Then the Inverse Fast Fourier Transform (IFFT) will bring the reconstructed signal back into time domain.

\subsubsection{Illustrating and validating IFFT}

A brief illustration of the application of Fourier Transform is given in Figure 5-9. Figure 5-9 (a) shows the sample input to the analyzer. Figure 5-9 (b) shows the convolution of input and the analyzer dispersion function. The dispersion function used is the same as the one experimentally determined in section 3.2.3. This dispersion function is considered as the transfer function in the time domain. Figure 5-9 (c) shows reconstructed response using IFFT. It can be visualized that the reconstructed signal by IFFT can be superimposed very well on the original input signal. The ripples in the Figure 5-9 (c) could be attributed to the numerical rounding errors in reconstruction. The amplitude of these ripples will be higher with high frequency data and will increase exponentially with frequency of the data eventually leading to instability of reconstruction.

\subsubsection{Criterion for stability of IFFT}

The criterion for stability of IFFT is investigated. Revisiting Equation 5-6,

$$
Y(n)=X(n) . H_{w} \text { and } X(n)=Y(n) / H_{w} \text {. }
$$

If a 5 hertz dispersion function is considered, the values of the $\mathrm{Hw}$ becomes smaller and very high values are generated for $\mathrm{X}(\mathrm{n})$ and the reconstruction became unstable. This is a problem with low-pass filters, usually encountered in signal processing. For the emissions 
data in this study, when 5 hertz continuous data and 5 hertz dispersion function were employed for reconstruction, the procedure became unstable. Hence all the data and the dispersion function were reduced to 1 hertz for reconstruction.

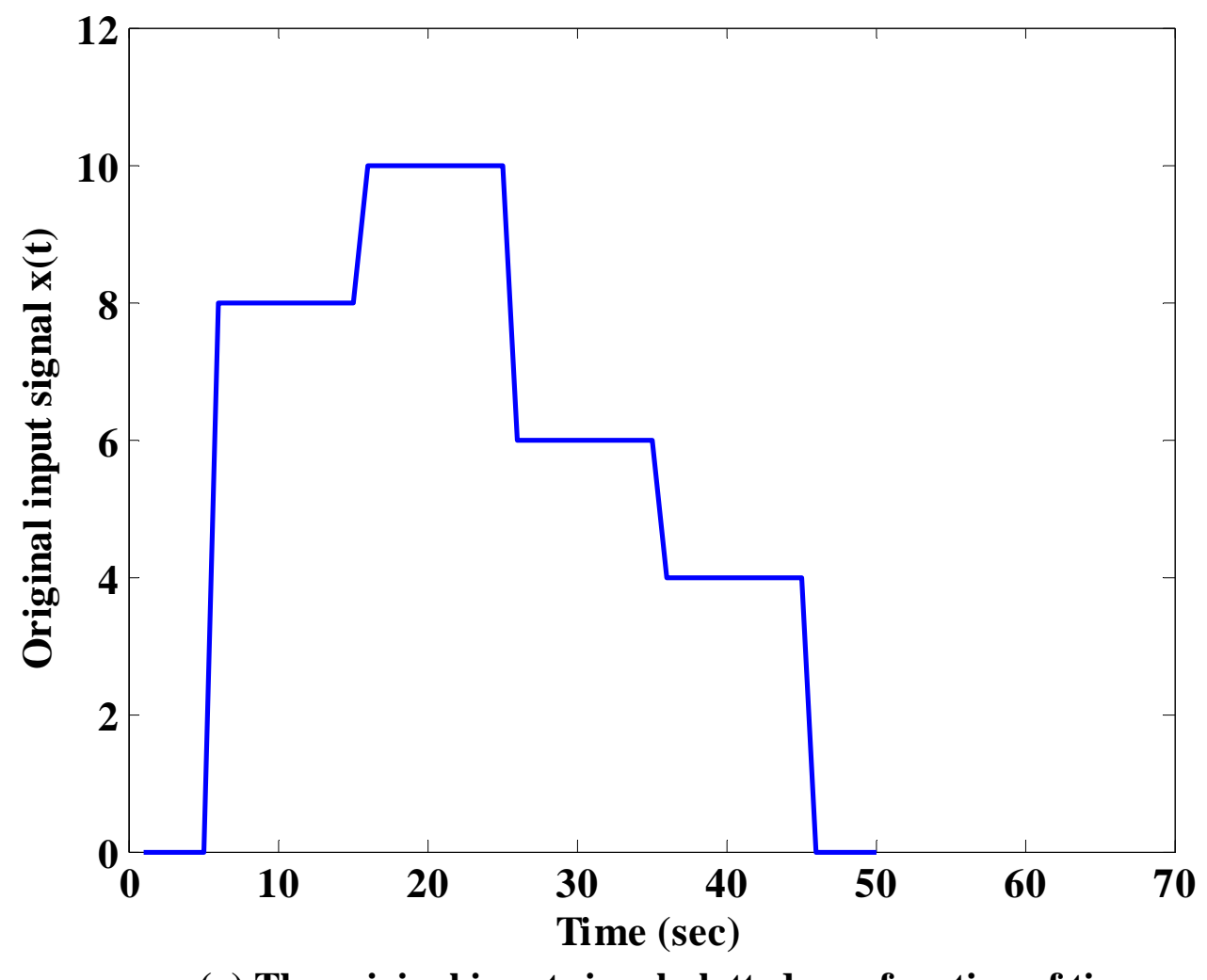

(a) The original input signal plotted as a function of time 


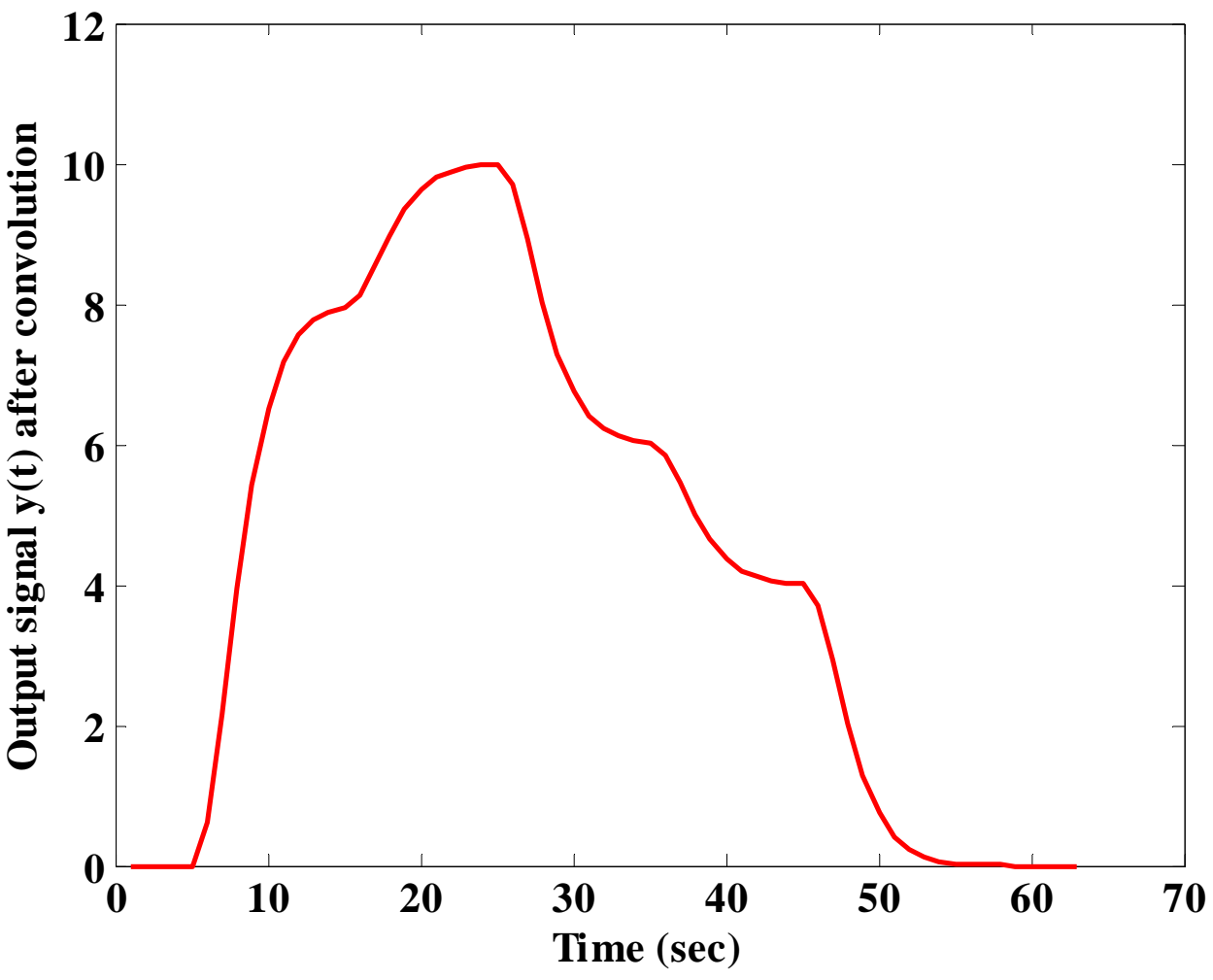

(b) Dispersed output signal 


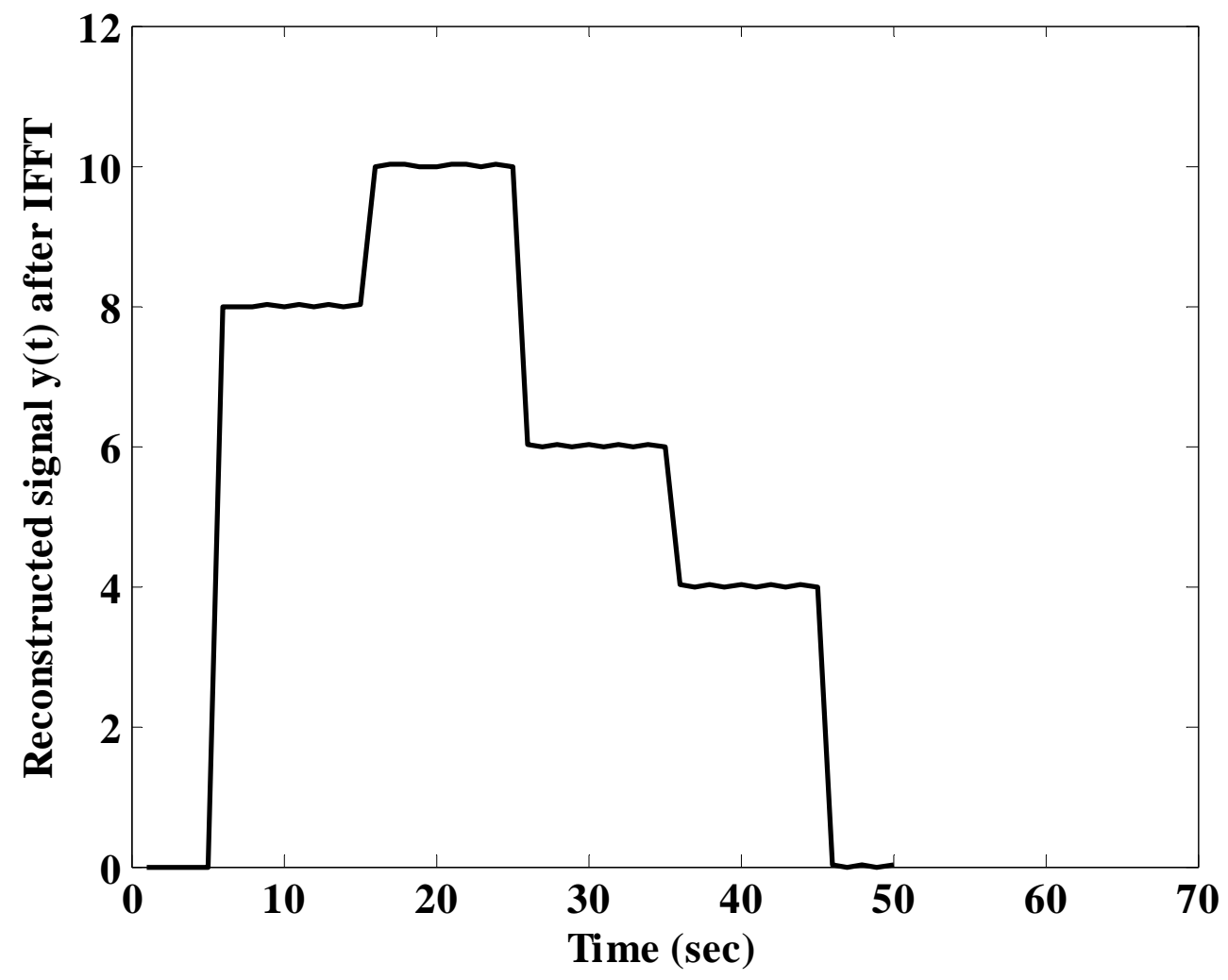

(c) The reconstructed signal using IFFT method

Figure 5-9. Illustration of FFT and IFFT

\subsubsection{Comparing reconstruction 'efficiency' of IFFT and DCM}

\subsection{IFFT vs. DCM for reconstructing $\mathrm{CO}_{2}$}

The data were collected from the chassis testing conducted in the WVU Transportable Heavy-Duty Vehicle Emissions Testing Laboratory on a Peterbilt Truck with a Caterpillar 3406E engine fitted to a 19-speed Eaton Fuller transmission with 550 hp. The drive cycle employed was UDDS cycle. The engine power was generated by the Engine Control Unit, which is based on the fuel consumption and the engine efficiency curves. The 
results were analyzed with the collaborated efforts of the authors and Lijuan Wang. The correlation of measured $\mathrm{CO}_{2}$ with power is shown in Figure 5-10 (a). In the entire analysis of $\mathrm{CO}_{2}$, the background $\mathrm{CO}_{2}$ in the ambient air was subtracted from the measured value to obtain the engine-out $\mathrm{CO}_{2}$. The reconstruction of the data was attempted using IFFT as shown in Figure 5-10 (b) and then using DCM as shown in Figure 5-10 (c). The correlation of the reconstructed (using IFFT) power with the measured power is shown in Figure 5-10 (d). While the reconstructed power has no realistic meaning, it gives an estimate of the effectiveness of the reconstructing technique. In this case, the correlation in Figure 5-10 (d) is lower than the correlation in Figure 5-10 (b) and 5-10 (c). This indicates that application of either of the reconstruction techniques (DCM and IFFT) is better than not applying any.

Reconstruction results from the engine tests on 2004 Cummins ISM 370 tested on the drive cycles FTP, TRANS and CRUISE were also presented in Table 5-4. In all these cases, the engine power was measured from the engine dynamometer. In both the cases (IFFT and DCM), the correlation of reconstructed emissions $\left(\mathrm{CO}_{2}\right)$ with power was better than the correlation of measured emissions $\left(\mathrm{CO}_{2}\right)$ with power. However, it could not be concluded that either of the methods could be more effective than the other in reconstruction. 


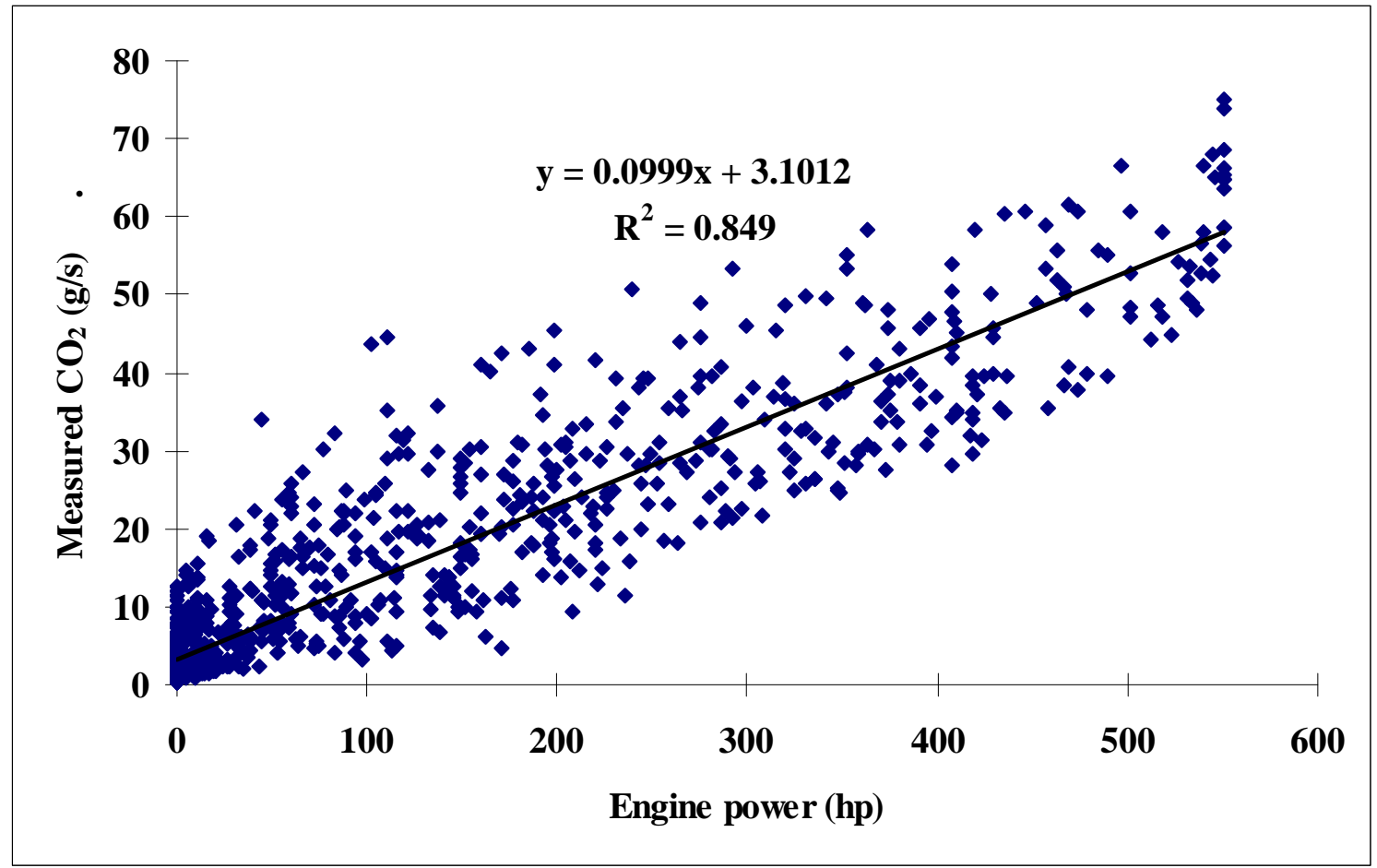

(a) Measured $\mathrm{CO}_{2}$ as a function of engine power

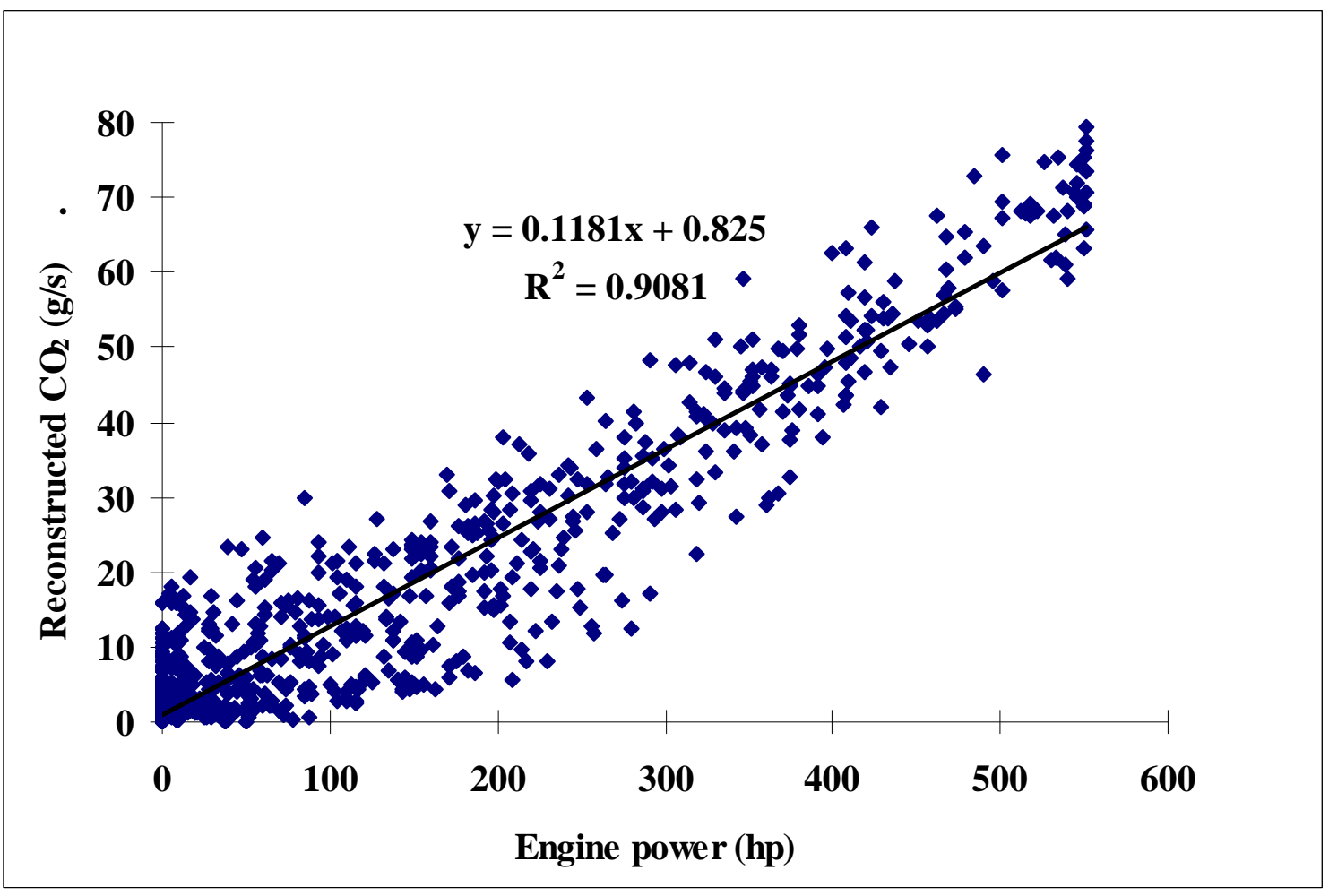

(b) Reconstructed $\mathrm{CO}_{2}$ (using IFFT) as a function of engine power 


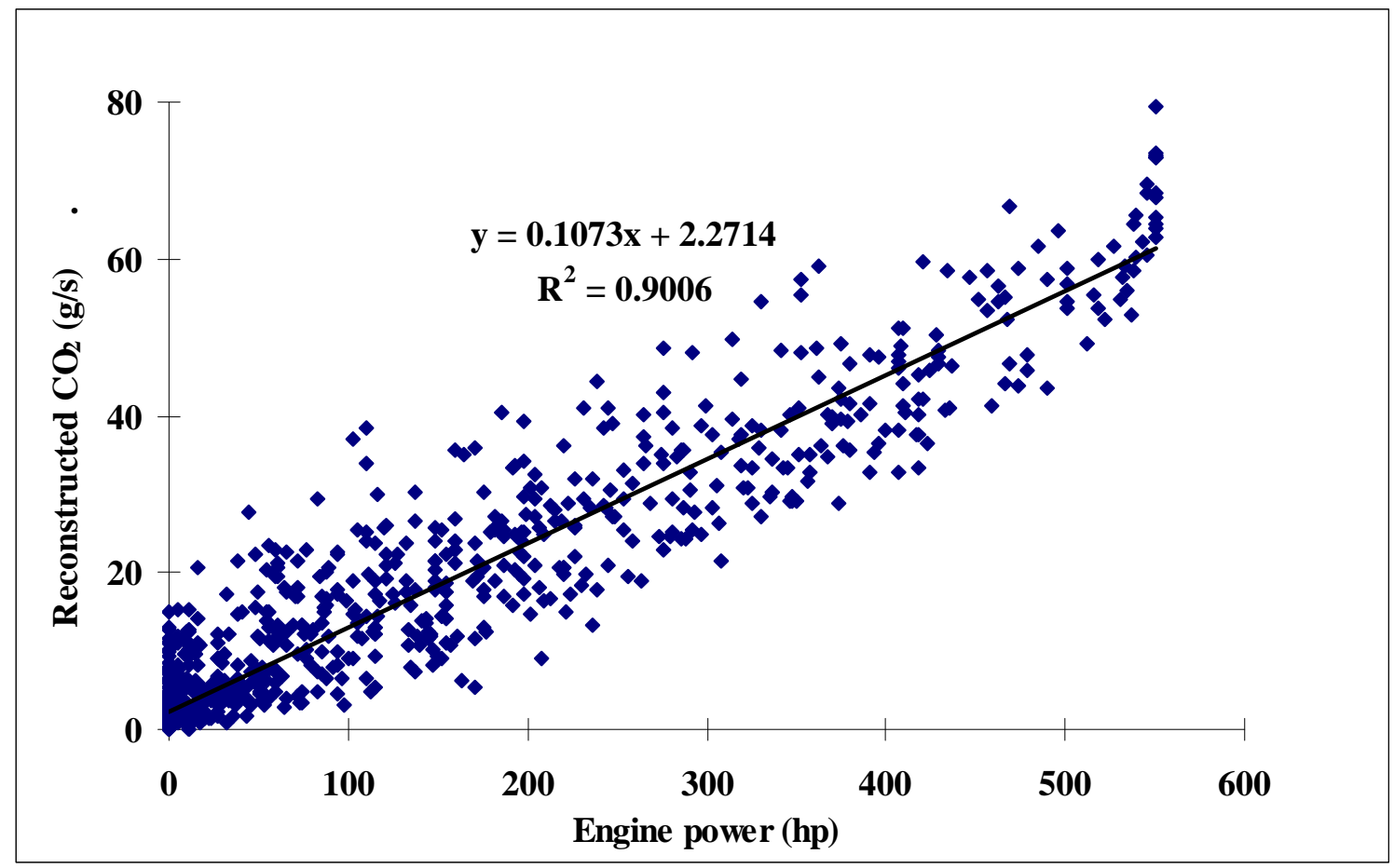

(c) Reconstructed $\mathrm{CO}_{2}$ (using DCM) as a function of engine power

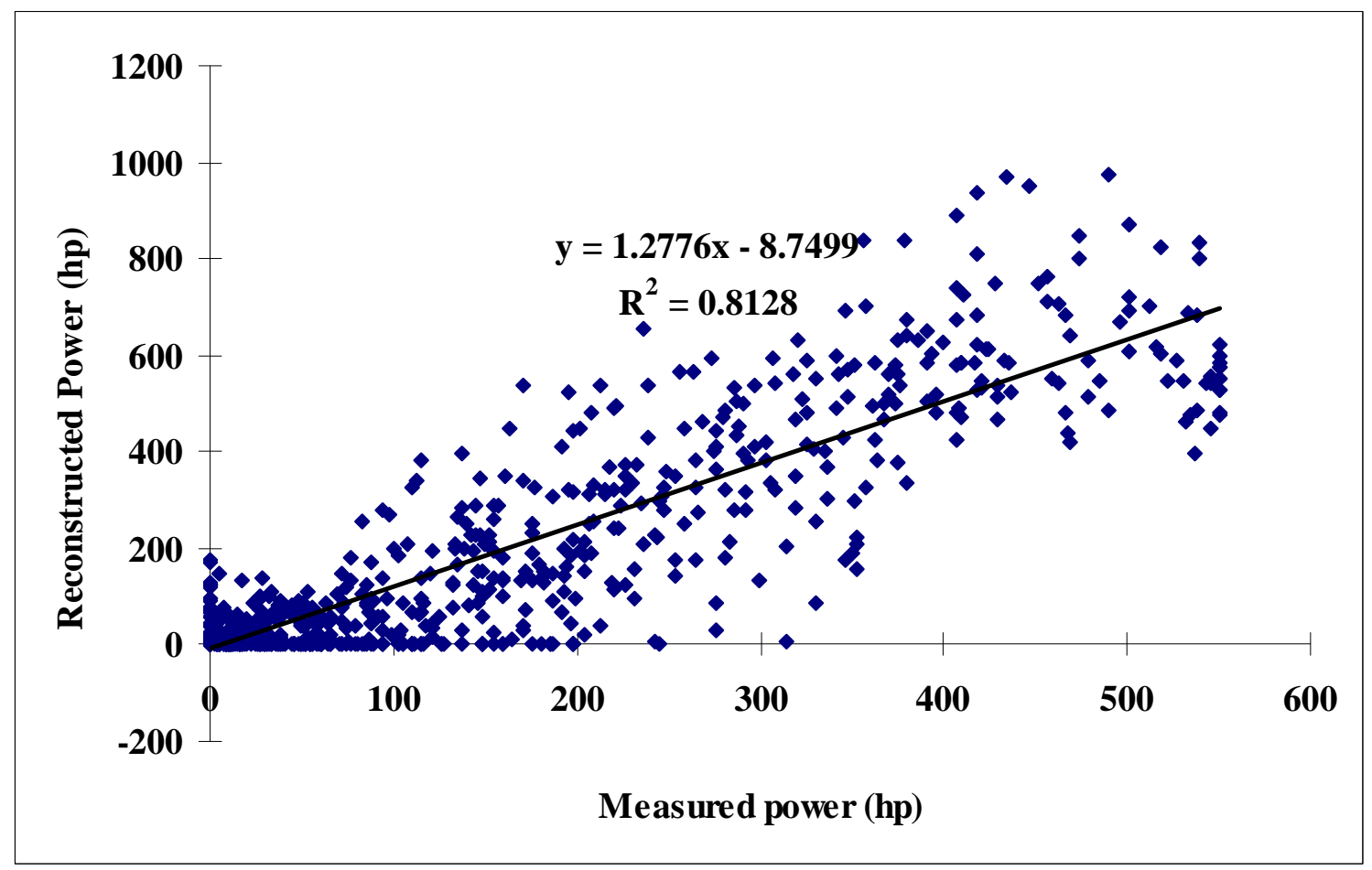

(d) Reconstructed power (using IFFT) as a function of measured power

Figure 5-10. Comparison of DCM and IFFT in reconstruction of $\mathrm{CO}_{2}$ emissions from Peterbilt truck with Caterpillar 3406 E engine tested on TEST_D cycle 
Table 5-4. Comparison of IFFT and DCM in reconstructing $\mathrm{CO}_{2}$

\begin{tabular}{|c|c|c|c|c|}
\hline Engine type & Test Cycle & $\begin{array}{c}\mathbf{( R}^{2} \text { ) Initial } \\
\text { (with power) }\end{array}$ & $\begin{array}{c}\left.\mathbf{( R}^{2}\right) \mathbf{D C M} \\
\text { (with power) }\end{array}$ & $\begin{array}{c}\mathbf{R}^{2} \text { ) IFFT } \\
\text { (with power) }\end{array}$ \\
\hline $\begin{array}{c}\text { 1996 Caterpillar } \\
\text { 3406E }\end{array}$ & UDDS & 0.849 & 0.9005 & 0.908 \\
\hline $\begin{array}{c}\text { 2004 CUMMINS } \\
\text { ISM370 }\end{array}$ & FTP & 0.775 & 0.7777 & 0.791 \\
\hline $\begin{array}{c}\text { 2004 CUMMINS } \\
\text { ISM370 }\end{array}$ & CRUISE & 0.7492 & 0.7500 & 0.7593 \\
\hline $\begin{array}{c}\text { 2004 CUMMINS } \\
\text { ISM370 }\end{array}$ & TRANS & 0.6604 & 0.6707 & 0.6909 \\
\hline \hline
\end{tabular}

\subsection{IFFT vs. DCM for reconstructing $\mathrm{NO}_{\mathrm{x}}$}

Similar cases were examined and the reconstruction of $\mathrm{NO}_{\mathrm{x}}$ was attempted using both DCM and IFFT approaches. The attempts for reconstruction are shown in Figure 5-11 and all the similar results were presented in Table 5-5. Neither method can be favored over the other in reconstruction. 


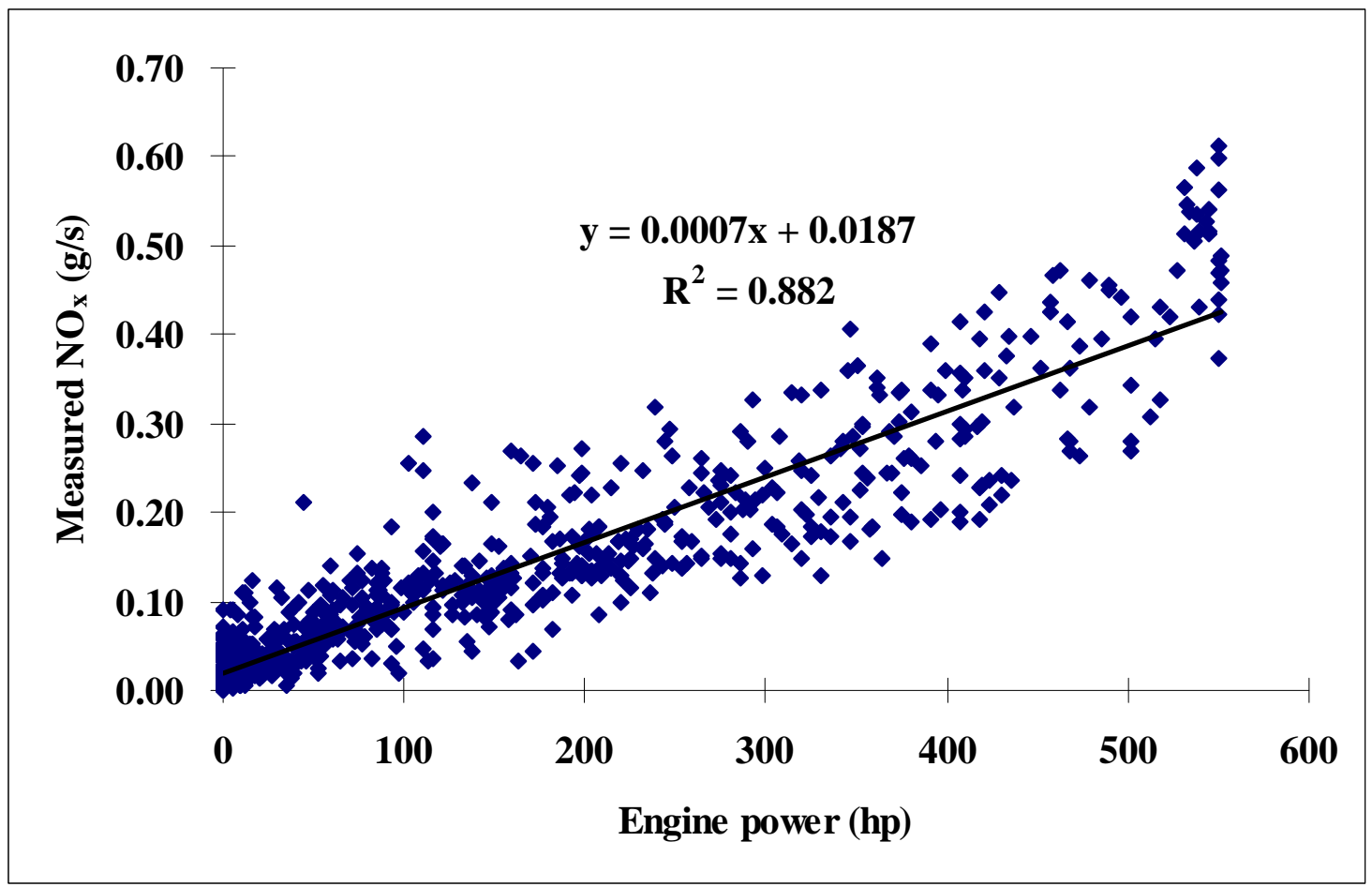

(a) Measured $\mathrm{NO}_{\mathrm{x}}$ as a function of engine power

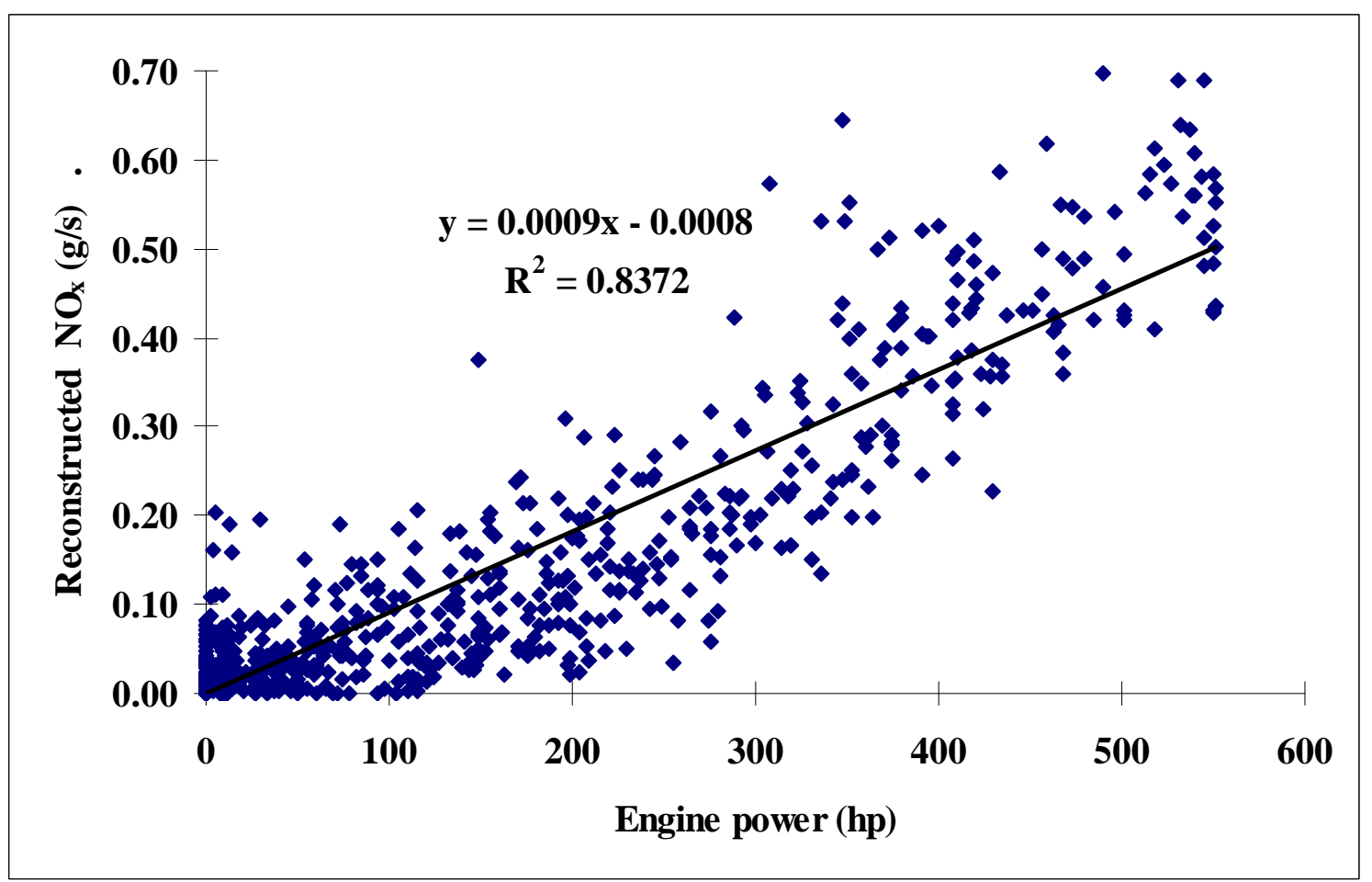

(b) Reconstructed $\mathrm{NO}_{\mathrm{x}}$ (using IFFT) as a function of engine power 


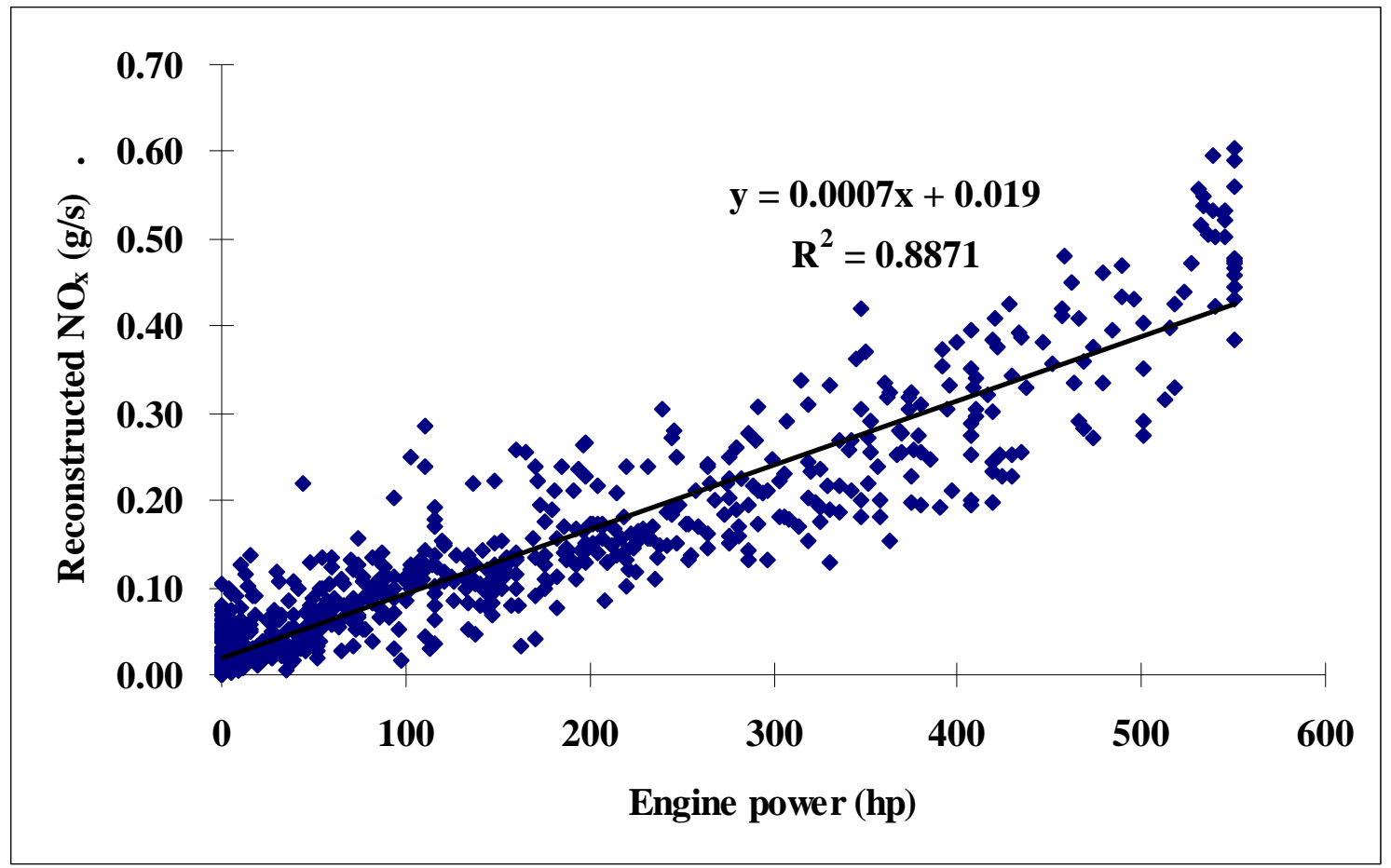

(c) Reconstructed $\mathrm{NO}_{\mathrm{X}}$ (using DCM) as a function of engine power

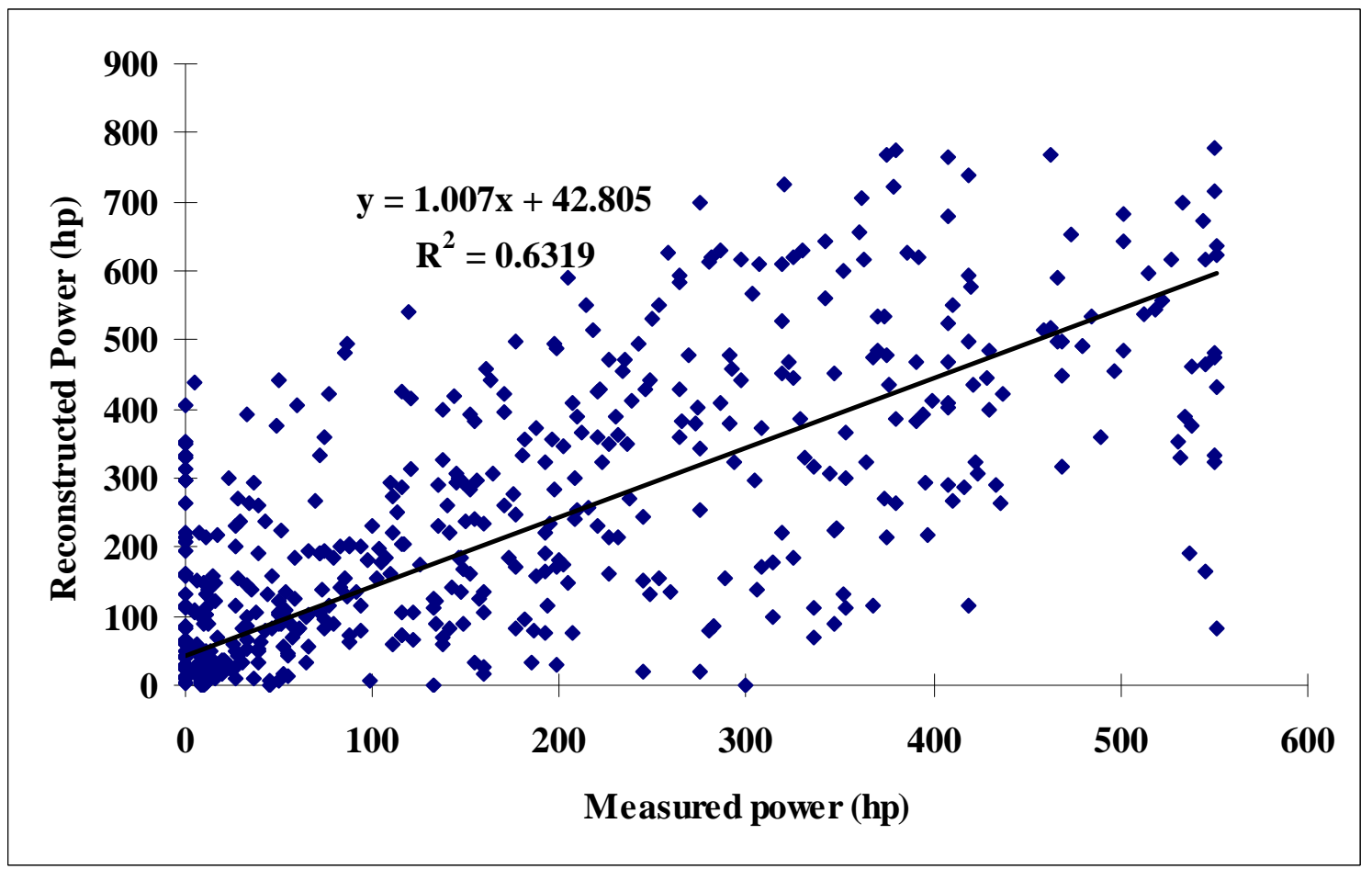

(d) Reconstructed power (using IFFT) as a function of measured power

Figure 5-11. Comparison of DCM and IFFT in reconstruction of $\mathrm{NO}_{\mathrm{x}}$ emissions from Peterbilt truck with Caterpillar 3406E engine tested on UDDS cycle 
Table 5-5 Comparison of DCM and IFFT in reconstructing $\mathrm{NO}_{\mathrm{x}}$

\begin{tabular}{|c|c|c|c|c|}
\hline Engine type & Test Cycle & $\begin{array}{c}\mathbf{( R}^{2} \text { ) Initial } \\
\text { (with power) }\end{array}$ & $\begin{array}{c}\left.\mathbf{( R}^{2}\right) \mathbf{D C M} \\
\text { (with power) }\end{array}$ & $\begin{array}{c}\mathbf{( R}^{2} \text { ) IFFT } \\
\text { (with power) }\end{array}$ \\
\hline $\begin{array}{c}\text { 1996 Caterpillar } \\
\text { 3406E }\end{array}$ & UDDS & 0.882 & 0.8871 & 0.8372 \\
\hline $\begin{array}{c}\text { 2004 CUMMINS } \\
\text { ISM370 }\end{array}$ & FTP & 0.7573 & 0.7617 & 0.7854 \\
\hline $\begin{array}{c}\text { 2004 CUMMINS } \\
\text { ISM370 }\end{array}$ & CRUISE & 0.7591 & 0.7686 & 0.8173 \\
\hline $\begin{array}{c}\text { 2004 CUMMINS } \\
\text { ISM370 }\end{array}$ & TRANS & 0.6535 & 0.6497 & 0.5620 \\
\hline
\end{tabular}

\subsubsection{Modified deconvolution technique (MDT)}

\subsubsection{Definition of blind-deconvolution}

In case of SIT, as explained earlier in Chapter 5, a known analyzer dispersion function, $\mathrm{H}$ was used. In case of a blind de-convolution, no information about the analyzer dispersion function is warranted as input.

In actual signal processing terms, 'blind deconvolution' is defined as a technique which recovers the target object from the set of blurry images in the presence of an unknown point spread function (PSF) [101]. A PSF simulates a filter, which is analogous to a dispersion function in this study. While traditional deconvolution techniques require a known PSF, a blind deconvolution technique also generates the PSF alongside the target object. In anomaly, given the analyzer output, the blind de-convolution generates analyzer input and the corresponding dispersion function associated with the analyzer. But this technique totally failed when applied to reconstruction of automotive emissions. 
Understanding the reasons warrants a clear knowledge about well-posed and ill-posed problems, which are explained in section 5.2.4.2.

\subsubsection{Reformulation of blind-deconvolution}

A well-posed problem is the one that has a one and only one solution. For example, a heated plate is placed in the center of the room and the distribution of temperature in the room after a certain time needs to be found out, the solution is unique. But in case of the converse, if the temperature distribution is known currently and the distribution at an earlier time needs to be found out, the problem will be ill-posed. The blind-deconvolution is an ill-posed problem When a problem is ill-posed it has infinite solutions. These infinite number of solutions need to be narrowed down based on certain constraints imposed on the If a problem is ill-posed, it needs to be re-formulated with additional assumptions.

Since the traditional blind-deconvolution is an ill-posed problem, 'a priori' information is required for a solution to be unique and convergent [102]. In the context of this research, this information could be either regarding the continuous input to the analyzer or the dispersion characteristics of the analyzer. The a priori knowledge could also include the fact that the instantaneous emissions are correlated well with power. The dispersion characteristics should be in reasonable agreement with those calculated experimentally (presented in Chapter 3). This analysis includes the a priori knowledge of dispersion characteristics. 


\subsubsection{Theory and application of modified deconvolution technique (MDT)}

\subsection{Obtaining a priori information}

The MDT uses some prior knowledge about the shape of the dispersion function and from the past knowledge; the shape resembles a gamma distribution. A two parameter ( $\mathrm{k}$ and $\theta$ ) gamma distribution $\mathrm{G}(\mathrm{t})$ can be represented by the Eq.5-8. This distribution was fitted to the known analyzer dispersion function as shown in the Figure 5-12.

$$
G(t)=\frac{(t / \theta)^{k-1}}{\theta} e^{-t / \theta}
$$

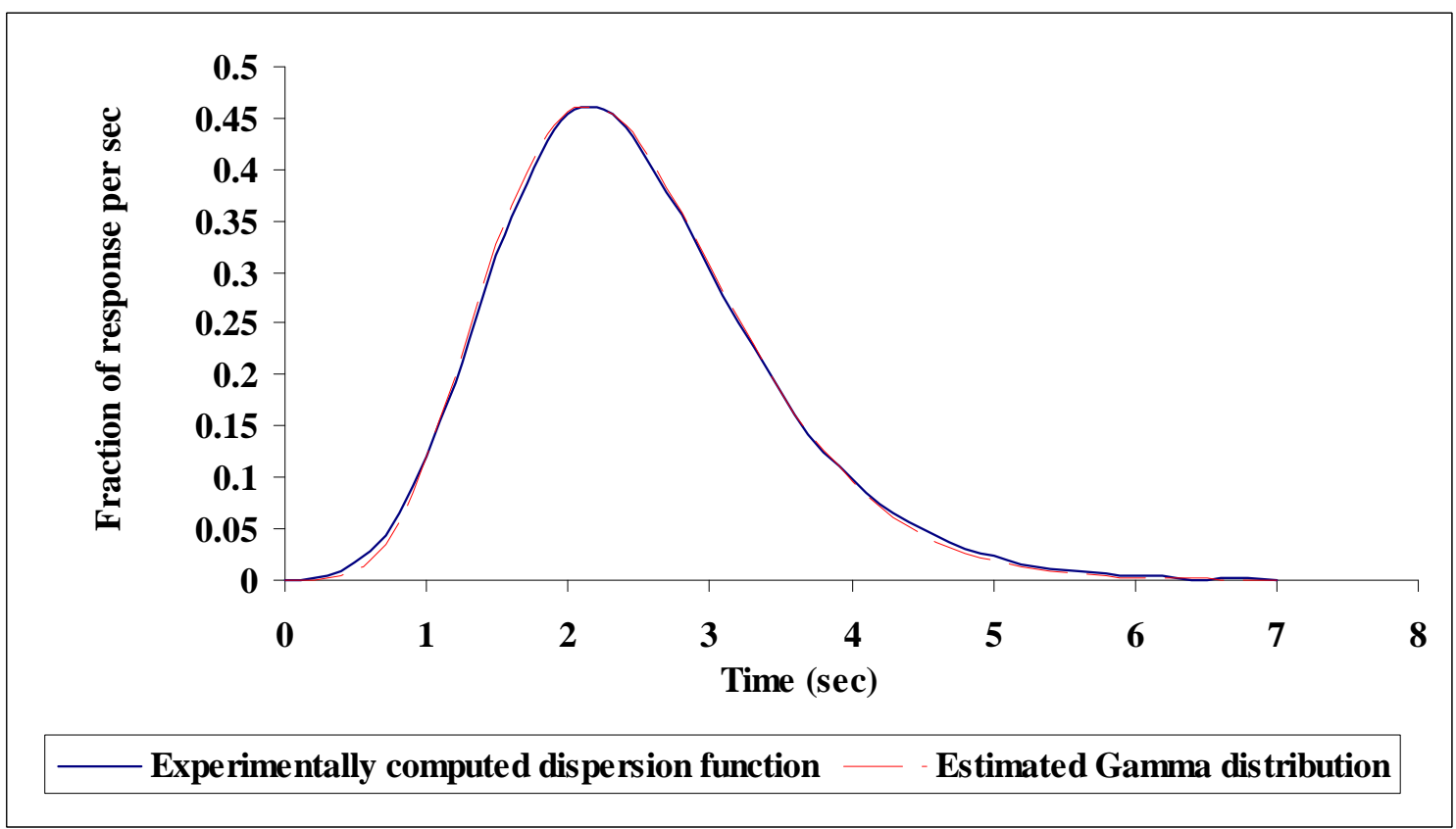

Figure 5-12. Fitting a gamma distribution to the dispersion function 
Equating the maximum values of the real $\mathrm{H}$ to the maximum of the gamma distribution and differentiating the distribution with respect to time, as shown in Eq. 5-9 generates the equations that yields the values of $\mathrm{k}$ and $\theta$. These values were considered the a priori information and were used while computing the back-transform.

$$
\frac{\mathrm{dG}}{\mathrm{dt}}(\mathrm{k}, \theta)=0
$$

\subsection{Computation of approximate output}

The FFT was computed for both the output, $\mathrm{Y}$ and for transfer function $\mathrm{H}$ as referred to earlier in Section 5.2.3. Then a simple division was employed in the frequency domain to compute the input $\mathrm{X}$ and IFFT of that input will transfer the input into the time-domain. $\mathrm{H}$, the transfer function, which was computed experimentally, has exact gamma distribution parameters $\mathrm{k}$ and $\theta$. The actual dispersion function of the analyzer could have parameters that are slightly different from the computed parameters by some margin, say $10 \%$. The following set of computations was done for the acceptable range of values of $K$ and $\theta$. We have $X(n) . H_{w}$ $=\mathrm{Y}(\mathrm{n})$; Hence $\mathrm{X}(\mathrm{n})=\mathrm{Y}(\mathrm{n}) / \mathrm{H}_{\mathrm{w}}$ and $\operatorname{IFFT}(\mathrm{X}(\mathrm{n}))=\mathrm{X}(\mathrm{t})$. Then the correlation of power with the computed input $\mathrm{X}(\mathrm{t})$ was maximized. This generated the values of $\mathrm{K}$ and $\theta$, which generated the optimum dispersion function and corresponding reconstructed input.

\subsection{Application of MDT for emission reconstruction}

The data from the Peterbilt truck with Caterpillar 3406E engine tested on UDDS cycle was again considered (the same was considered for reconstruction using IFFT) and the effect 
of reconstruction using MDT is shown in Figure 5-13. In either case, MDT increased the correlation of emissions with power. More importantly, the reconstructed input by MDT correlated better $\left(\mathrm{R}^{2}\right.$ of 0.9211$)$ with power than the input generated by IFFT $\left(\mathrm{R}^{2}\right.$ of 0.9081$)$ and $\mathrm{DCM}\left(\mathrm{R}^{2}\right.$ of 0.9006$)$.

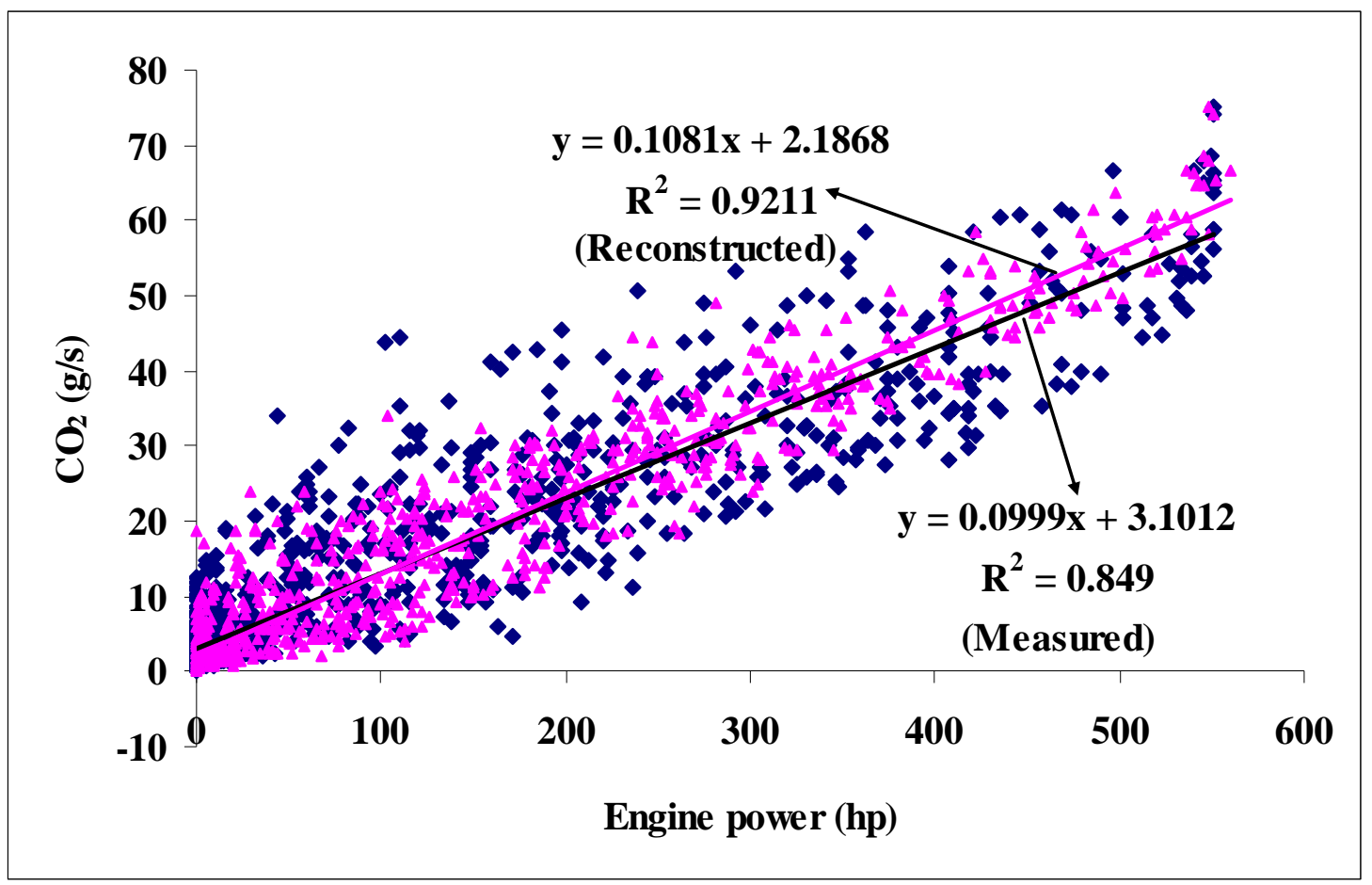

Figure 5-13 (a). MDT in reconstruction of $\mathrm{CO}_{2}$ emissions from Peterbilt truck with Caterpillar 3406E engine tested on UDDS cycle 


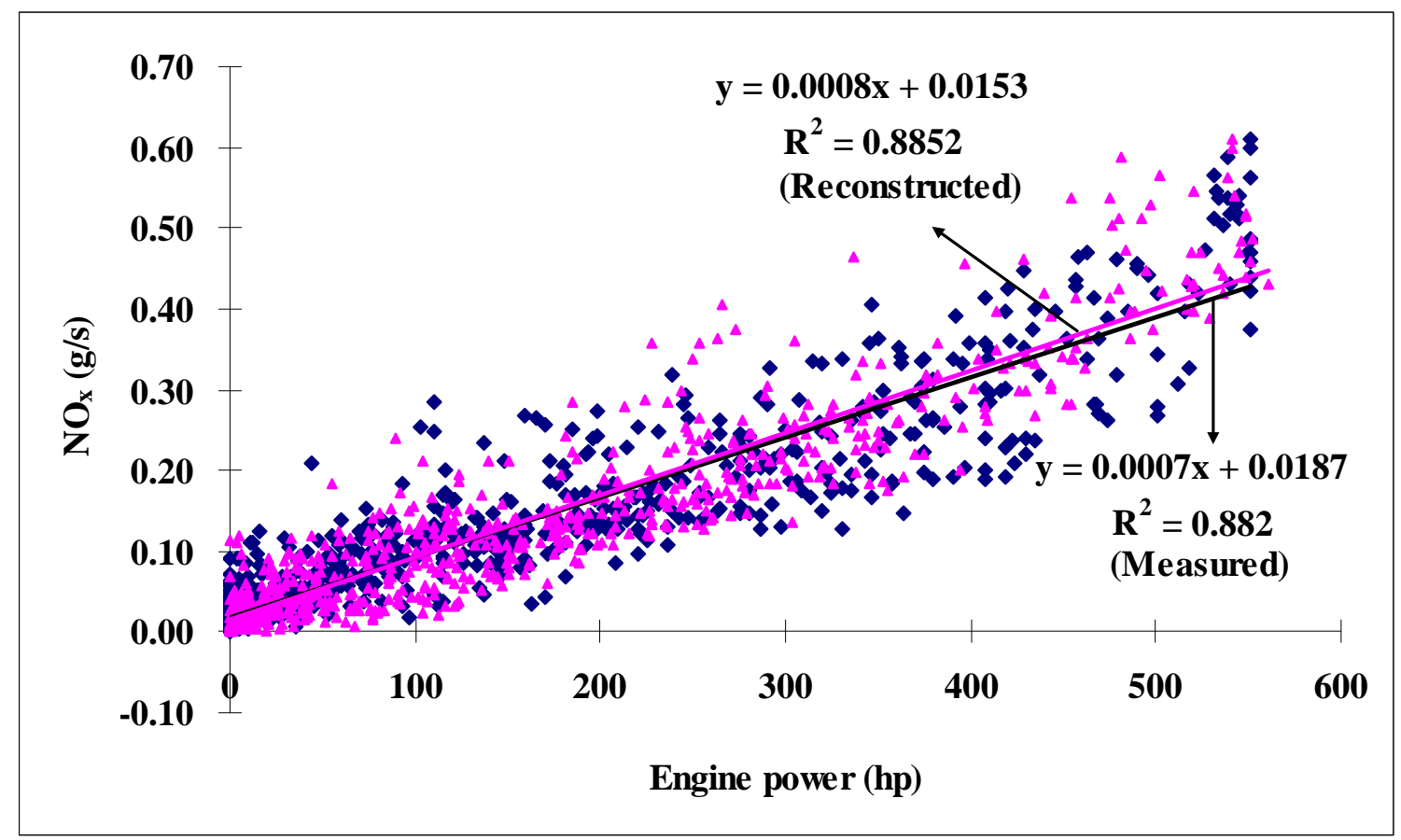

Figure 5-13 (b). MDT in reconstruction of $\mathrm{NO}_{\mathrm{x}}$ emissions from Peterbilt truck with Caterpillar 3406E engine tested on UDDS cycle

\subsubsection{Influence of the operating condition on emission reconstruction}

It was of interest to examine the effects of speed and acceleration ranges on the reconstruction procedure.

\subsubsection{Processed data and drive cycles}

Continuous emissions data were obtained from the chassis testing conducted on New Flyer 2006 transit bus with a Cummins ISM 280 engine. The specifications of the engine were presented in Table 4-3. The continuous data of speed and acceleration were also considered. The bus was tested on UDDS and WMATA Bus drive cycles. The speed profile of WMATA bus cycle is shown in Figure 5-14. 


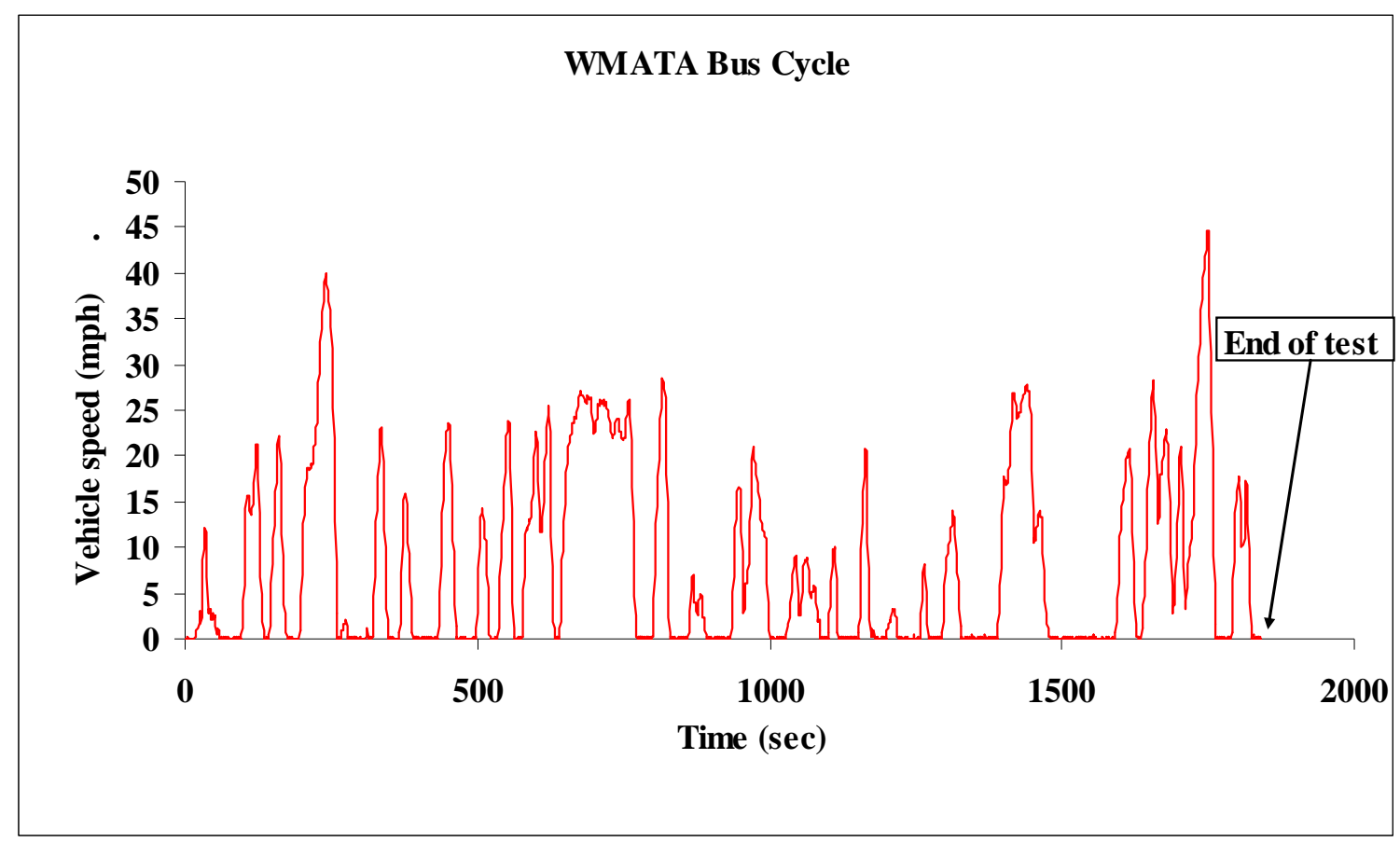

Figure 5-14. WMATA Bus Cycle

\subsection{Division of the data into bins}

For the analysis of the data, an operating condition of the vehicle is represented by the speed and acceleration of the vehicle. The data from each cycle were divided into 63 (9 $X$ 7) bins based on speed and acceleration ranges as shown in Table 5-6 (a). Each bin has a specific speed range and specific acceleration range. For example, in case of UDDS, the vehicle speed ranges from 0 to $57 \mathrm{mph}$. Hence the range of speeds for bins across the rows will be from 0 to $\frac{57}{7} \mathrm{mph}$ for the first column, $\frac{57}{7} \mathrm{mph}$ to $2 * \frac{57}{7} \mathrm{mph}$ for the second column and so on. The acceleration range was divided similarly into 9 equal rows. The sum total of the emissions in that bin were added up and averaged. The standard deviation of the emissions in each bin was also computed. Analyzing the emissions in each of these bins will associate the operating conditions with emissions data. 
Table 5-6 (a). Measured $\mathrm{CO}_{2}(\mathrm{~g} / \mathrm{s})$ for different combinations of speed and acceleration from a New Flyer 2006 Transit bus tested on UDDS drive cycle.

Average \pm standard deviation of measured $\mathrm{CO}_{2}(\mathrm{~g} / \mathrm{sec})$ for each bin

$\rightarrow$ Increasing Speed in mph (Total speed range is divided into seven equal ranges)

\begin{tabular}{|c|c|c|c|c|c|c|c|}
\hline $\begin{array}{c}\text { Increasing } \\
\text { Acceleration } \\
\text { In } \mathrm{m} / \mathrm{s}^{2} \\
\downarrow\end{array}$ & {$[0,8.1)$} & {$[8.1,16.3)$} & {$[16.3,24.4)$} & {$[24.4,32.6)$} & {$[32.6,40.7)$} & {$[40.7,48.8)$} & {$[48.8,57)$} \\
\hline$[-1.7,-1.4)$ & $\begin{array}{c}2.761 \\
\pm 2.618\end{array}$ & $\begin{array}{c}3.210 \\
\pm 1.770\end{array}$ & $\begin{array}{c}2.664 \\
+2.363\end{array}$ & $\begin{array}{c}3.605 \\
\pm 1.404\end{array}$ & $\begin{array}{c}3.715 \\
\pm 1.154\end{array}$ & $\begin{array}{c}4.106 \\
\pm 0.245\end{array}$ & $\begin{array}{c}4.195 \\
\pm 0.007\end{array}$ \\
\hline$[-1.4,-1.1)$ & - & $\begin{array}{c}5.418 \\
+5.859\end{array}$ & $\begin{array}{r}6.520 \\
\pm 7.751\end{array}$ & $\begin{array}{c}5.025 \\
\pm 4.281\end{array}$ & $\begin{array}{c}5.023 \\
\pm 2.894\end{array}$ & $\begin{array}{c}4.491 \\
\pm 1.817\end{array}$ & $\begin{array}{c}4.262 \\
\pm 0.205\end{array}$ \\
\hline$[-1.1,-0.7)$ & - & $\begin{array}{r}15.840 \\
+6.784\end{array}$ & $\begin{array}{c}7.561 \\
+8.826\end{array}$ & $\begin{array}{c}9.531 \\
\pm 4.643\end{array}$ & $\begin{array}{c}9.559 \\
+3.695\end{array}$ & $\begin{array}{c}6.475 \\
\pm 2.023\end{array}$ & $\begin{array}{c}6.963 \\
\pm 2.218\end{array}$ \\
\hline$[-0.7,-0.4)$ & $\begin{array}{r}10.334 \\
\pm 0.104\end{array}$ & $\begin{array}{c}5.267 \\
\pm 6.781\end{array}$ & - & $\begin{array}{c}4.221 \\
\pm 1.124\end{array}$ & $\begin{array}{c}6.469 \\
\pm 3.059\end{array}$ & $\begin{array}{c}5.745 \\
\pm 3.552\end{array}$ & $\begin{array}{c}4.356 \\
\pm 0.837\end{array}$ \\
\hline$[-0.4,-0.1)$ & $\begin{array}{l}14.145 \\
\pm 1.412\end{array}$ & $\begin{array}{c}7.088 \\
\pm 7.587\end{array}$ & $\begin{array}{r}12.996 \\
\pm 6.978\end{array}$ & $\begin{array}{r}19.631 \\
+9.801\end{array}$ & $\begin{array}{r}21.233 \\
+8.198\end{array}$ & $\begin{array}{r}12.924 \\
\pm 7.188\end{array}$ & - \\
\hline$[-0.1,0.3)$ & - & - & $\begin{array}{c}16.742 \\
\pm 6.817\end{array}$ & $\begin{array}{r}10.962 \\
\pm 4.055\end{array}$ & $\begin{array}{r}12.547 \\
\pm 4.887\end{array}$ & $\begin{array}{r}16.510 \\
\pm 9.223\end{array}$ & - \\
\hline$[0.3,0.6)$ & - & - & $\begin{array}{l}21.890 \\
+1.967\end{array}$ & $\begin{array}{r}20.423 \\
+5.099\end{array}$ & $\begin{array}{r}20.836 \\
\pm 6.816\end{array}$ & $\begin{array}{r}28.739 \\
\pm 0.710\end{array}$ & - \\
\hline$[0.6,0.9)$ & - & - & $\begin{array}{r}20.797 \\
+0.403\end{array}$ & $\begin{array}{r}19.228 \\
\pm 5.043\end{array}$ & $\begin{array}{r}18.882 \\
\pm 4.317\end{array}$ & - & - \\
\hline$[0.9,1.3)$ & - & - & - & $\begin{array}{r}25.365 \\
+5.627\end{array}$ & $\begin{array}{r}23.312 \\
+5.773\end{array}$ & - & - \\
\hline
\end{tabular}

While the above procedure was followed in analyzing the measured data, same was followed to analyze the reconstructed data as shown in Table 5-6 (b). MDT was employed for reconstruction and the experimentally computed dispersion function was used (shown 
in section 3.2.3). After the data were reconstructed, the emission values in each of the bins changed. The ratio of the average emissions in each bin before and after reconstruction was computed and plotted in Figure 5-15.

Table 5-6 (b). Reconstructed $\mathrm{CO}_{2}(\mathrm{~g} / \mathrm{s})$ for different combinations of speed and acceleration from a New Flyer 2006 Transit bus tested on UDDS drive cycle.

Average \pm standard deviation of reconstructed $\mathrm{CO}_{2}(\mathrm{~g} / \mathrm{sec})$ for each bin

$\rightarrow$ Increasing Speed in mph (Total speed range is divided into seven equal ranges)

\begin{tabular}{|c|c|c|c|c|c|c|c|}
\hline $\begin{array}{c}\text { Increasing } \\
\text { Acceleration } \\
\text { In } \mathrm{m} / \mathrm{s}^{2} \\
\downarrow\end{array}$ & {$[0,8.1)$} & {$[8.1,16.3)$} & {$[16.3,24.4)$} & {$[24.4,32.6)$} & {$[32.6,40.7)$} & {$[40.7,48.8)$} & {$[48.8,57)$} \\
\hline$[-1.7,-1.4)$ & $\begin{array}{c}6.753 \\
\pm 0.626\end{array}$ & $\begin{array}{r}6.996 \\
\pm 1.503\end{array}$ & $\begin{array}{c}6.912 \\
\pm 1.013\end{array}$ & $\begin{array}{c}6.506 \\
+1.175\end{array}$ & $\begin{array}{c}6.559 \\
+1.064\end{array}$ & $\begin{array}{c}7.020 \\
+1.020\end{array}$ & $\begin{array}{c}7.620 \\
\pm 0.104\end{array}$ \\
\hline$[-1.4,-1.1)$ & $\begin{array}{c}7.326 \\
\pm 0.666\end{array}$ & $\begin{array}{c}8.637 \\
+3.150\end{array}$ & $\begin{array}{c}8.151 \\
\pm 1.718\end{array}$ & $\begin{array}{c}7.519 \\
\pm 1.476\end{array}$ & $\begin{array}{c}8.187 \\
\pm 1.258\end{array}$ & $\begin{array}{c}7.449 \\
\pm 0.112\end{array}$ & $\begin{array}{c}7.449 \\
\pm 0.112\end{array}$ \\
\hline$[-1.1,-0.7)$ & - & $\begin{array}{c}9.200 \\
\pm 1.960\end{array}$ & $\begin{array}{c}8.024 \\
\pm 2.096\end{array}$ & $\begin{array}{c}9.339 \\
\pm 2.186\end{array}$ & $\begin{array}{c}9.121 \\
\pm 1.876\end{array}$ & $\begin{array}{c}8.213 \\
\pm 1.225\end{array}$ & $\begin{array}{c}8.458 \\
+1.609\end{array}$ \\
\hline$[-0.7,-0.4)$ & $\begin{array}{c}8.190 \\
\pm 0.934\end{array}$ & $\begin{array}{c}8.193 \\
+2.984\end{array}$ & - & $\begin{array}{c}8.326 \\
+1.234\end{array}$ & $\begin{array}{c}9.257 \\
+1.448\end{array}$ & $\begin{array}{c}8.009 \\
\pm 2.139\end{array}$ & $\begin{array}{c}8.429 \\
\pm 0.208\end{array}$ \\
\hline$[-0.4,-0.1)$ & $\begin{array}{c}8.833 \\
\pm 0.650\end{array}$ & $\begin{array}{c}8.704 \\
\pm 2.234\end{array}$ & $\begin{array}{c}9.281 \\
\pm 2.096\end{array}$ & $\begin{array}{r}11.455 \\
+3.563\end{array}$ & $\begin{array}{r}12.821 \\
\pm 3.134\end{array}$ & $\begin{array}{c}9.910 \\
\pm 2.055\end{array}$ & - \\
\hline$[-0.1,0.3)$ & - & - & $\begin{array}{r}10.734 \\
\pm 1.269\end{array}$ & $\begin{array}{r}9.310 \\
\pm 1.911\end{array}$ & $\begin{array}{c}9.669 \\
+2.139\end{array}$ & $\begin{array}{r}12.274 \\
\pm 3.104\end{array}$ & - \\
\hline$[0.3,0.6)$ & - & - & $\begin{array}{c}11.882 \\
+0.220\end{array}$ & $\begin{array}{r}11.509 \\
\pm 2.282\end{array}$ & $\begin{array}{l}11.654 \\
\pm 2.192\end{array}$ & $\begin{array}{c}15.262 \\
\pm 0.104\end{array}$ & - \\
\hline$[0.6,0.9)$ & - & - & $\begin{array}{r}11.573 \\
\pm 0.141\end{array}$ & $\begin{array}{r}10.800 \\
\pm 0.830\end{array}$ & $\begin{array}{r}10.864 \\
\pm 0.723\end{array}$ & - & - \\
\hline$[0.9,1.3)$ & - & - & - & $\begin{array}{c}12.577 \\
\pm 0.974\end{array}$ & $\begin{array}{r}12.290 \\
\pm 0.927\end{array}$ & - & - \\
\hline
\end{tabular}




\subsubsection{Average emissions in each bin}

The average emissions in each operating bin before and after reconstruction are analyzed. The ratio of the average of the reconstructed emissions to the average of measured emissions is calculated for every bin and is plotted in Figure 5-15. For UDDS and for WMATA drive cycles, ratio increased with increase of speed. However, the ratio decreased with acceleration. Also, for lower accelerations, for both the drive cycles, the reconstructed emissions are about 50 to 150 percent higher than the corresponding measured emissions for most of the bins.

However the ratio is sensitive to acceleration changes in both the cycles. The higher the acceleration, the lower are the reconstructed emissions. This implies that the analyzer system tends over-read by the input signal at higher accelerations such as starting from rest. However, at lower accelerations (for most of the operating speeds), such as when the vehicle is cruising at almost constant speed, the analyzer dispersion explains the overall amplitude reduction. This implies that the signal of the analyzer is more reliable when the vehicle is at constant speed than when accelerating.

Figure 5-16 (a) presents a bin in which the acceleration is zero. When the analyzer measured emissions from such an operating condition, the dispersed signal appears as a dotted black curve. When reconstructed, the signal is a rectangular wave represented by a continuous line. In this case, the reconstruction concentrates the emissions explaining why the reconstructed average is higher than the measured average. Figure 5-16 (b) represents a case in which the vehicle is experiencing constant acceleration. Even in this case, the reconstruction increased the average bin emissions. 


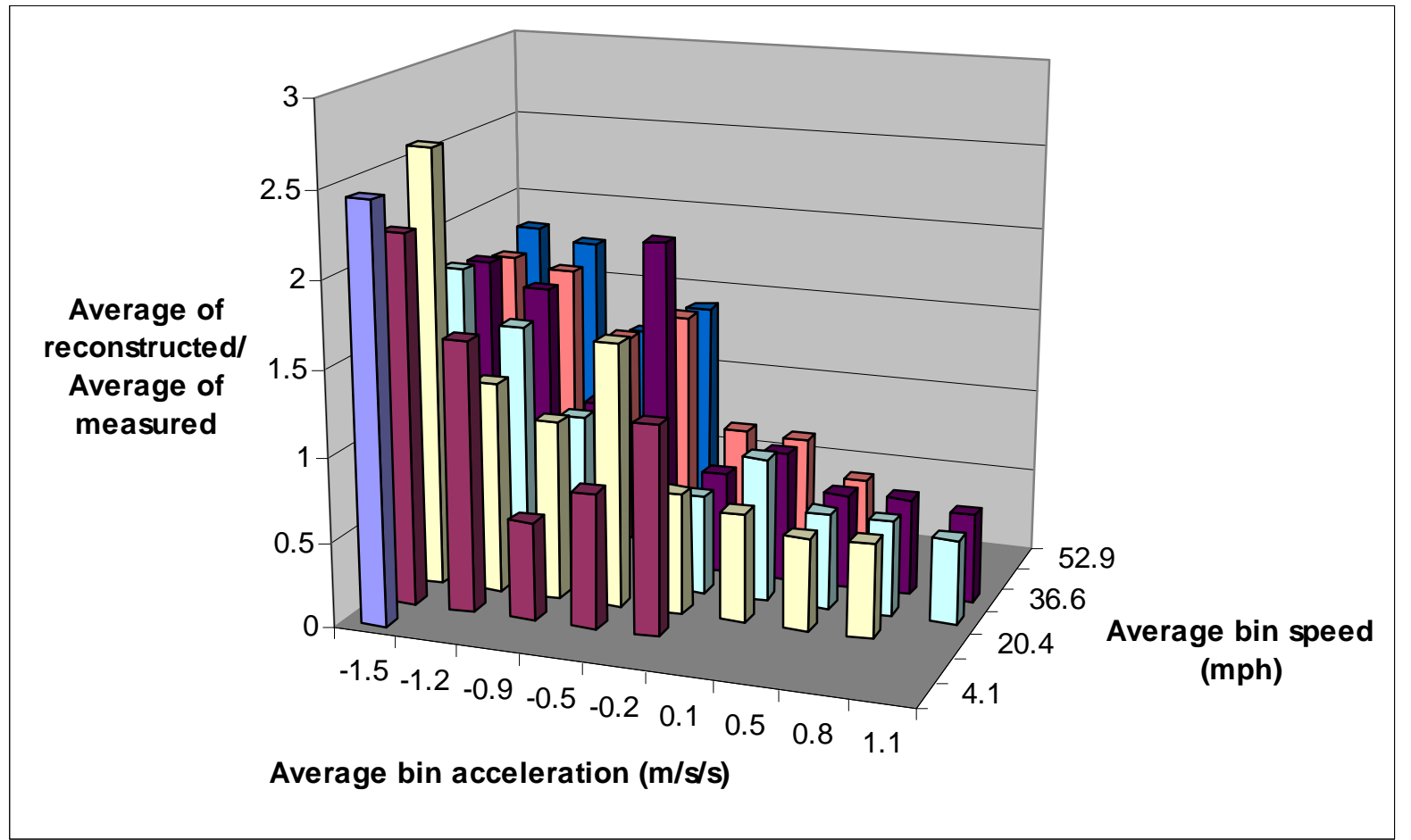

Figure 5-15 (a). The ratio of bin average of the reconstructed to measured $\mathrm{CO}_{2}$ for New Flyer 2006 Transit bus tested on UDDS drive cycle

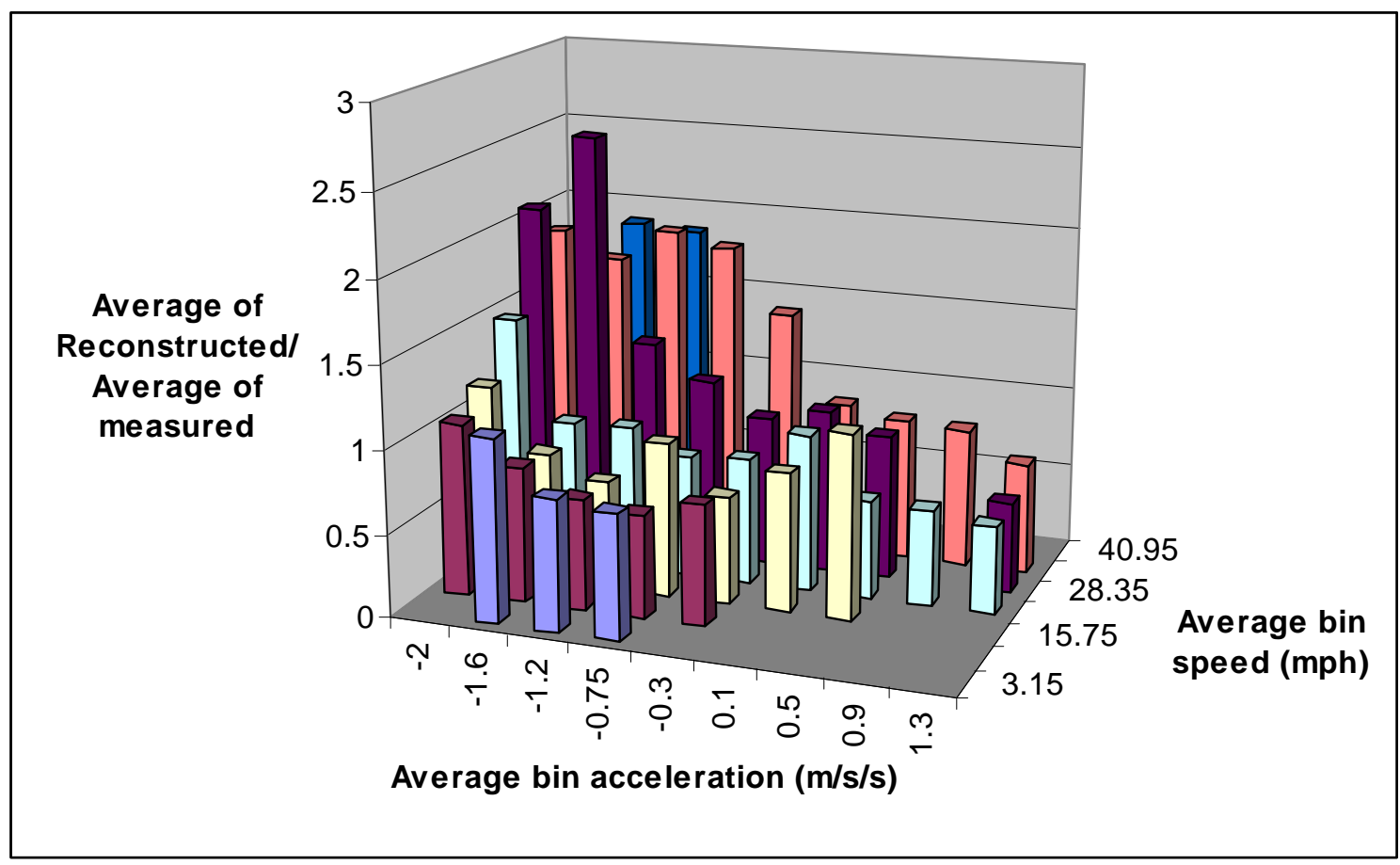

Figure 5-15 (b). The ratio of bin average of the reconstructed to measured $\mathrm{CO}_{2}$ for New Flyer 2006 Transit bus tested on WMATA drive cycle 


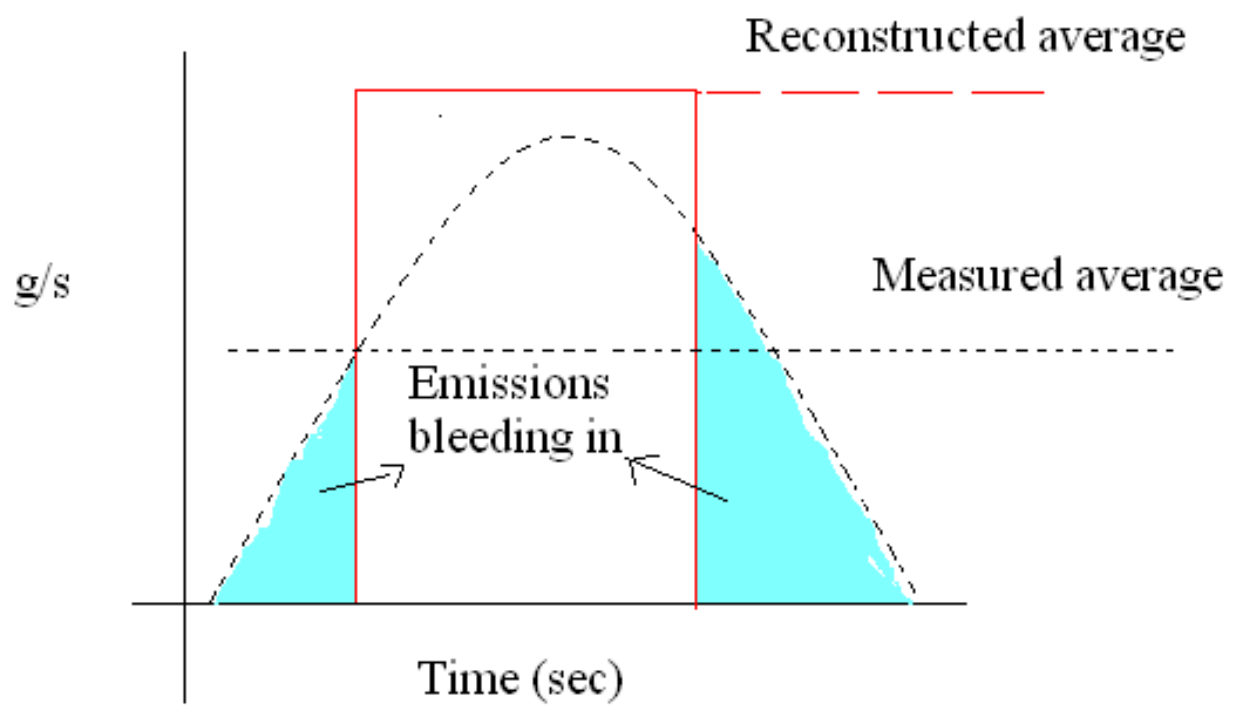

Figure 5-16 (a) Effect of reconstruction on bin with constant speed

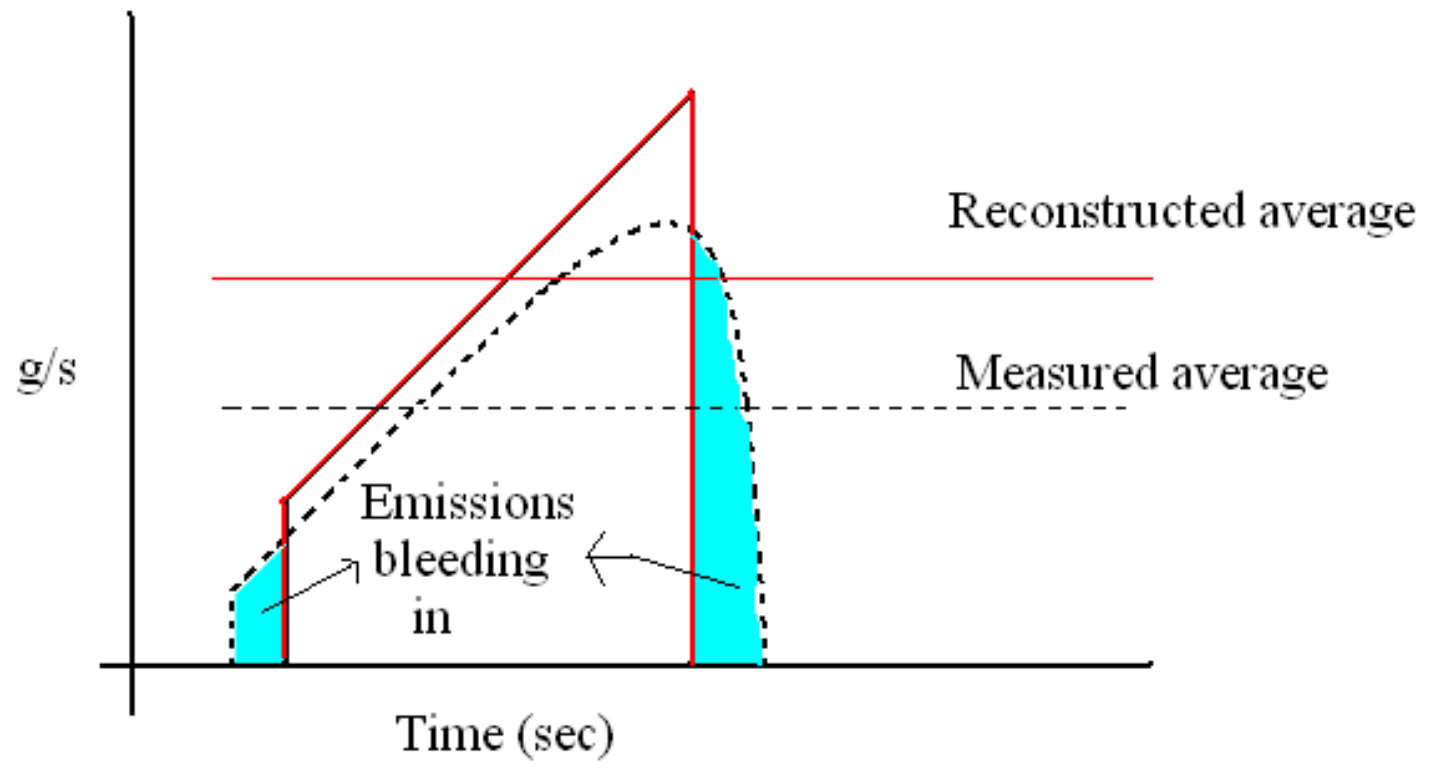

Figure 5-16 (b) Effect of reconstruction on bin with constant acceleration 


\subsubsection{4}

The standard deviation of emissions in each bin

The standard deviation of the emissions in each bin is computed as a percentage of the average emissions in that particular bin. The values of percent standard deviations were computed both before and after reconstruction. The ratio of the percent standard deviations of reconstructed to the measured $\mathrm{CO}_{2}$ were plotted in Figure 5-17. Figure 5-17 (a) corresponds to UDDS drive cycle and 5-17 (b) corresponds to WMATA Bus cycle. In both the cases, the standard deviation was reduced for most bins because of reconstruction. The reason for this can be explained from Figure 5-16 (a) and 5-16 (b), where the emissions bleed into the bin from the adjacent bins because of the reconstruction. Hence there will be a drop in the standard deviation. While there is no particular pattern evident in the ratio across bins, the ratio tends to be higher at higher speeds. This implies that the 'bleeding' is stabilized at higher speeds.

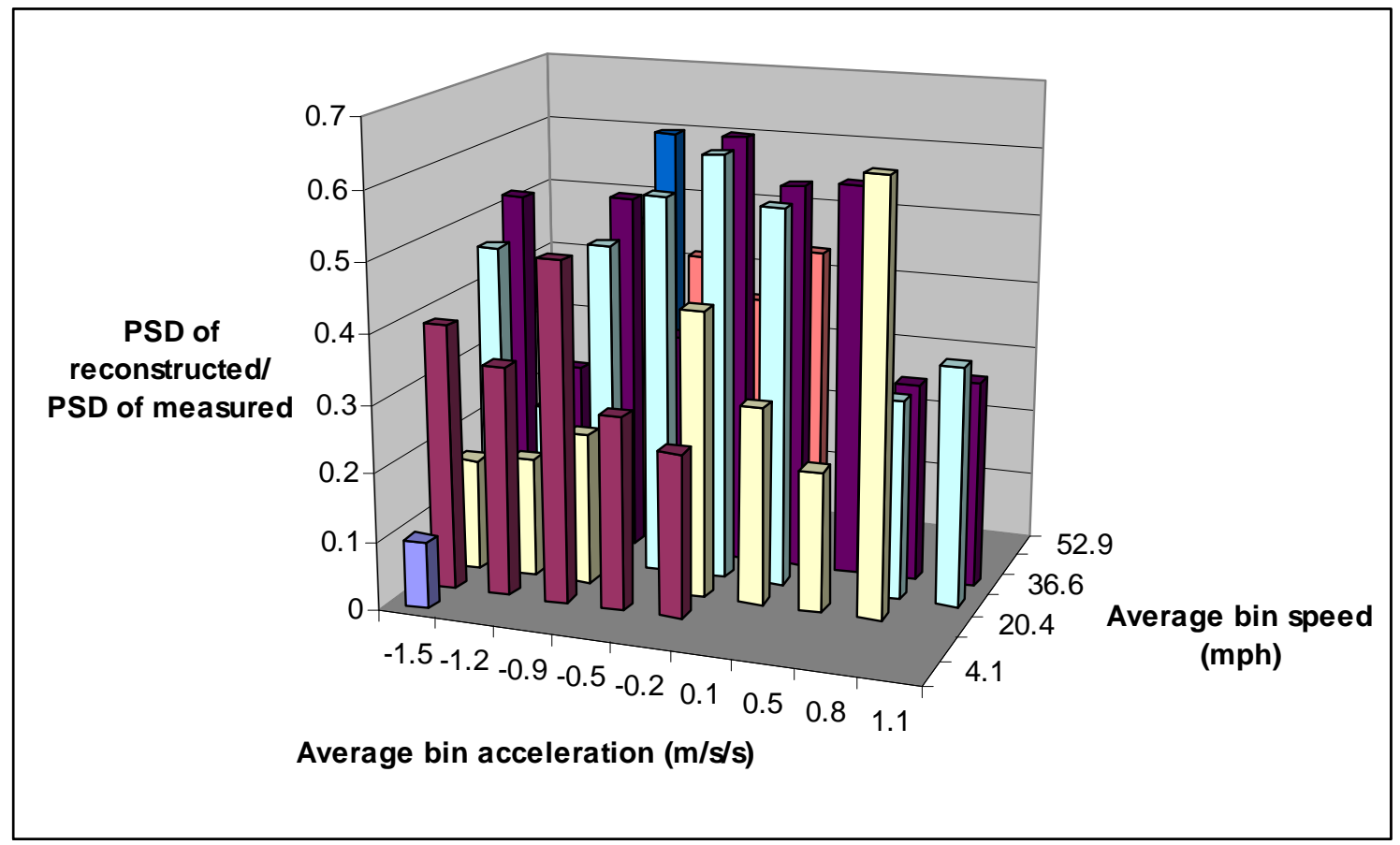

Figure 5-17 (a). The ratio of percent standard deviation of the reconstructed to measured $\mathrm{CO}_{2}$ for New Flyer 2006 Transit bus tested on UDDS drive cycle 


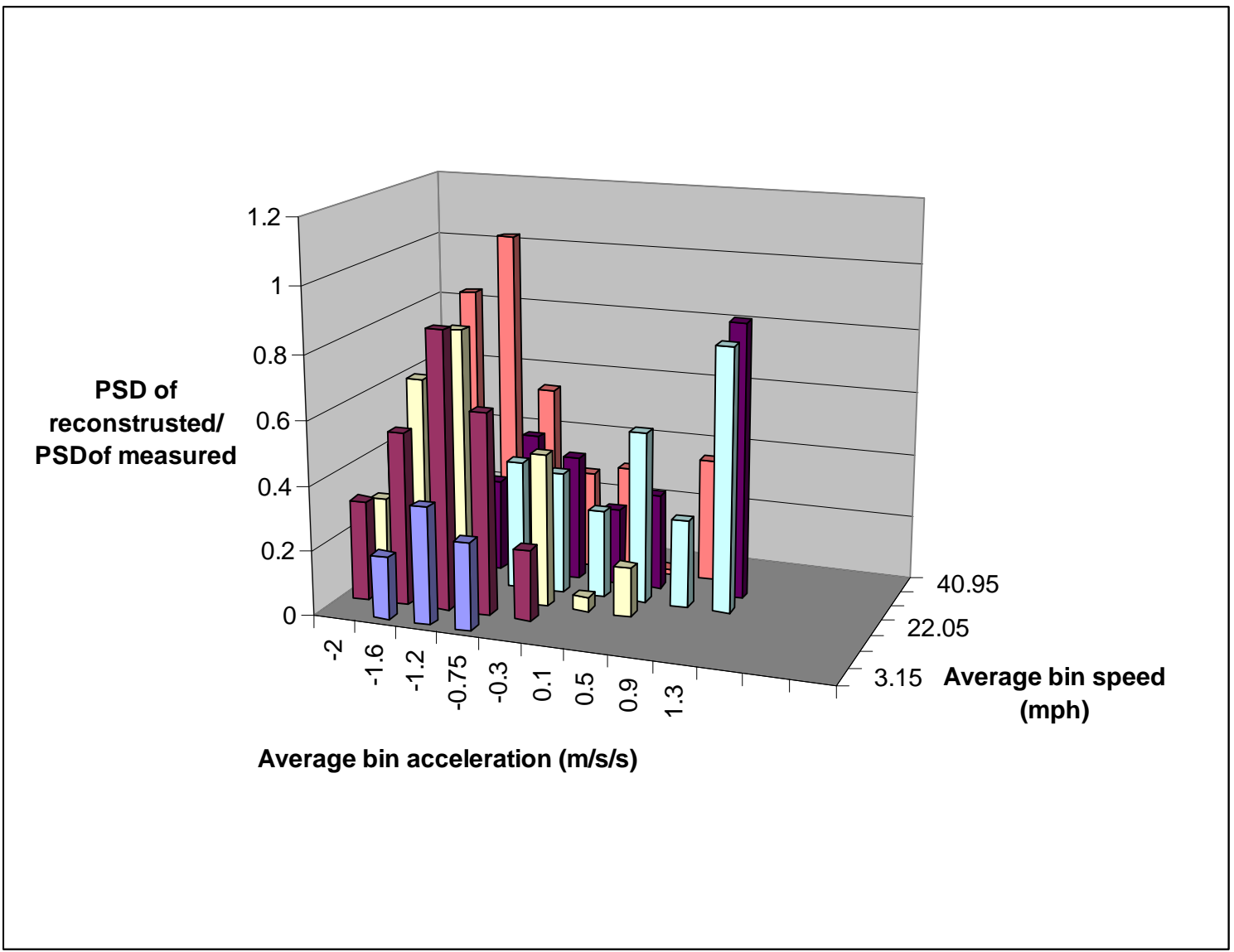

Figure 5-17 (b). The ratio of percent standard deviation of the reconstructed to measured $\mathrm{CO}_{2}$ for New Flyer 2006 Transit bus tested on WMATA drive cycle 


\section{CONCLUSIONS AND RECOMENDATIONS}

This chapter consists of summary of the entire research work, conclusions drawn from the results, applications of this research and recommendations for extending the work.

\subsection{Summary of the research}

Emissions measured by the analyzer differ from the actual instantaneous emissions because the actual data gets dispersed according to the dispersion characteristics specific to the analyzer. The dispersion characteristics of analyzer were first determined experimentally. Then these characteristics were used to generate a 'forward transform' by convolution of the instantaneous data with the dispersion function of the analyzer system. Axle power was assumed to be instantaneous and a forward transform is applied to the axle power to generate a dispersed axle power. The dispersed axle power is better correlated with the measured emissions than the measured axle power, which indicates that the axle power is better correlated with instantaneous data.

Four methods of reconstruction are presented in this study: Sequential Inversion Technique (SIT), Differential Coefficients Method (DCM), Inverse Fast Fourier Transform (IFFT) and Modified Deconvolution Technique (MDT). SIT failed in practical applications. DCM involves least squares minimization and this accounts for small errors in the computation of the dispersion function. Trials were made to improve the DCM by adding more derivatives, and by trying different numerical ways to compute the derivatives, but the improvements in either of the cases were minimal. IFFT was able to reconstruct just as well as DCM; however the Fast Fourier Transform (FFT) of the 
dispersion function should be high enough to ensure stability of the method. In other words, the dispersion function should not have elements that were almost equal to zero for the method to be stable.

When reconstruction was attempted using traditional blind deconvolution, the results became unstable. Hence MDT uses some a priori information (in this case, the dispersion characteristics of analyzer) for reconstruction. MDT employs fitting a gamma distribution to the dispersion function and searches for the best possible distribution within a prescribed range to improve the reconstruction. The a priori information stabilized the reconstruction and the reconstructed emissions were found to be 3\% more correlated (than the measured emissions) with the axle power.

The measured continuous data of $\mathrm{CO}_{2}$ mass flow rate from the New Flyer 2006 transit bus was divided into several operating bins, each bin having a specific speed and acceleration range. MDT was used to generate continuous reconstructed emissions from the measured continuous data. This reconstructed data is again divided into identical bins following a similar procedure. By comparing the two sets of bins, it was found that at low accelerations, the average mass flow rate of the measured $\mathrm{CO}_{2}$ was lesser than that of the reconstructed $\mathrm{CO}_{2}$. However, the reverse was found true at high accelerations. This was because of the emissions bleeding from one bin to an other due to analyzer dispersion.

\subsection{Conclusions}

From the results obtained from the application of different reconstructing techniques, some interesting conclusions can be drawn. 
Primarily, it can be concluded that the emissions measured by the analyzer could be represented as a convoluted product of unknown instantaneous emissions and the analyzer dispersion function. A simple convolution of an instantaneous operating variable such as axle power with a dispersion function generated an output which is more correlated with the measured emissions. Hence, there is clearly more accurate continuous data than those recorded by the analyzer.

Secondly, reconstruction of instantaneous emissions is more stable when the data set is of lower frequencies. High frequency data made the reconstruction unstable. This is primarily because of the computational errors rolling into the reconstruction.

Thirdly, the knowledge about the transient dynamics of the analyzer system is critical for reconstruction. In other words, the experimental computation of the dispersion function for the analyzer system needs to be trust-worthy and as accurate as possible. The elements of the dispersion function can be fitted into a gamma distribution and the parameters of the distribution can be given a range. This could help the reconstruction to be

more accurate by accounting for the experimental errors in computing the dispersion function.

\subsection{Recommended theme for heavy-duty emissions reconstruction}

In reconstructing any continuous set of heavy duty emissions, the following theme is recommended. Since IFFT is extremely uncomplicated, it is recommended initially for any given set of heavy-duty emissions data and dispersion function. If the dispersion function is determined experimentally and is trust-worthy, IFFT can be very accurate. However, if the method becomes unstable, then DCM or MDT can be employed. 
DCM and MDT are more complex and rugged methods and since they account for the variations in the dispersion function, they are recommended in case when IFFT becomes unstable or if the reconstructed emissions seem inaccurate.

\subsection{Applications of the research work}

\subsubsection{Application in the field of inventory modeling}

This work could help the instantaneous emissions inventory models such as MOVES [38], which predict the emissions by relating emissions signals to vehicle operating variables such as vehicle speed and acceleration. The reconstruction techniques can be incorporated into the MOVES algorithm to compensate for the delay and dispersion of the emissions data and when combined with the existing emission prediction technique of this could be a powerful tool in instantaneous emissions modeling. This reconstruction technique could be incorporated into several other emissions prediction models such as COPERT [46]. The existing emissions inventory models could be refined using the reconstruction techniques suggested in this research work.

\subsubsection{Application of reconstruction for data analysts}

The emissions reconstruction could be appreciated by the calibrators who measure the emissions for testing and certification procedures. They can apply the reconstruction technique to any of the emissions measured by a time-invariant analyzer system. In other words, they can not only compensate for the delay of the emissions (as they are currently doing with cross-correlation techniques for time-alignment of data with operating 
conditions of the vehicle), but also for the associated dispersion in the analyzer. While the analyzers have a specific response time, the calibrators can now estimate how much of dispersion could be associated with the measured data.

\subsubsection{Application in the field of engine certification by EPA}

The EPA could apply this work in NTE certification. Currently, engines are certified for a period of thirty seconds in an NTE window which is defined by operating conditions of the vehicle. This study has shown that the some of the emissions in a window could be 'lost'. Currently with a 30 second window, analysis has shown that up to 3 percent of emissions can be lost. This study has also shown that when the vehicle is accelerating, the emissions measurement analyzers distort the signal more than when the vehicle is operating at steady speed. The reconstruction techniques, if applied by EPA for emissions certification in a thirty second window, could eliminate distortions produced by the measurement systems and produce a much clearer picture of how the vehicle behaves (with regards to emissions) in the NTE window.

\subsection{Recommendations for future work}

Modified blind deconvolution presented in this research can be refined and modified. For the given analyzer in this study, the gamma distribution generated a better fit to the dispersion function than any other distributions did. However, for another research study, Weibull, Gaussian, or any other distribution can be used based on the shape of the dispersion function arising from the sampling system and analyzer. 
It was understood through bin-wise reconstruction that the efficiency of reconstruction depends on the operating condition of the engine or the vehicle. The fact that the emissions correlate well with power can also be used as a priori information in reconstructing emissions using MDT. Several models were developed by other researchers (Wang) which involve emissions modeling based on the vehicle design and operating parameters. These models can be used as a priori knowledge to improve the algorithm.

A complex algorithm can be developed based on the reconstruction techniques described in this study. For example, if emissions for a 1000 second cycle have to be reconstructed, and since the techniques for reconstruction carries numerical errors from one computation to the other, a long series of computations could generate unstable results. In such a case, the reconstruction can be stabilized by isolating the reconstruction for the first 100 seconds of the cycle and then check if the emissions are within an acceptable range, and then proceed to the next 100 seconds and so on. However, this procedure may require human inspection of the continuous data.

This study and the future research work on reconstruction techniques could be applied by the engine certifiers, not only in the field of heavy-duty emissions, but also to any situation where emissions are measured using a known analyzer system. Improving the efficiency of reconstruction could lead to re-examination of the length of the windows that can be used for certification procedure. Hopefully, this research work will be a foundation for improving the accuracy of measurement required for certification and will take the society one step further to breathing cleaner air. 


\section{REFERENCES}

1. Health Effects Institute, Diesel Exhaust, A Critical Analysis of Emissions, Exposure, and Health Effects (A Special Report of the Institute's Diesel Working Group), Health Effects Institute, Cambridge, MA, 1995.

2. Watts, W. F. Jr., Assessment of Occupational Exposure to Diesel Emissions, Diesel Exhaust: A Critical Analysis, pp. 107-123, Health Effects Institute, Cambridge, MA, 1995.

3. Graham, J. A., O'Neil, J., Claxton, L. D., Otto, D. A., Goldstein, B. D., Automobile Emissions: Primary Health Effects and Concerns, SAE Technical Paper 840908, 1984.

4. Kolomeychuk, R., Yeager, L., Spiegel, J., Yassi, A., Effects of Automotive Emissions, Proceedings of Air Pollution Control Association, Vol. 5, pp. 31-33, 1984.

5. Morgan, W. K., Reger, R. B., Tucker, D. M., Health Effects of Diesel Emissions, Annals of Occupational Hygiene, Vol. 41, n 6, pp. 643-658, 1997.

6. Duscio, D., Proietti, L., Giarrusso, S., Fantauzzo, R., Rapisarda, V., Calandra, C., Health Effects of Diesel Exhaust, Advances in Air Pollution, Vol.13, pp. 387-399, 2003.

7. Environmental Protection Agency (EPA), Air Quality Index-A Guide to Air Quality and Your Health (published on 8/31/03), Information Retrieved from the Website:www.epa.gov on 20th May, 2007.

8. California Air Resources Board (CARB), Almanac Emission Projection Data, Information Retrieved from the Website:www.arb.ca.gov on April 10, 2007. 


\section{Kirchstetter, W. T., Harley, A. R., Kreisberg, N. M., Stolzenburg, M. R.,}

Hering, S. V., On-Road Measurement of Fine Particle and Nitrogen Oxide Emissions from Light- and Heavy-Duty Vehicles, Atmos. Environ.1, Vol. 33, pp. 2955-2968, 1999.

10. The Environmental Literacy Council, Clean Air Act, Information Retrieved from the Website:www.enviroliteracy.org/article.php/6.html, the Environmental Literacy Council, 2002.

11. Thompson, G., Gautam, M., Clark, N. N., Lyons, D., Inference of Torque and Power from Heavy-Duty Diesel Engines for On-Road Emissions Monitoring, SAE Technical Paper 2002-01-0614, 2002.

12. Code of Federal Regulations, Title 40, Part 86, Subpart N, Emission Regulations for New Otto-Cycle and Diesel Heavy-Duty Engines, Gaseous and Particulate Exhaust Test Procedures, 2004.

13. Dieselnet, Emission Test Cycles: Heavy-Duty FTP Transient Cycle, Information Retrieved from the Website:www.dieselnet.com, on $25^{\text {th }}$ June, 2006. www.dieselnet.com/standards/cycles/ftp_trans.html

14. Dieselnet, Emission Standards: USA: Heavy-Duty Truck and Bus Engines, Information Retrieved from the Website:www.dieselnet.com, on March 17, 2006. www.dieselnet.com/standards/us/hd.html.

15. The Environmental Literacy Council, Clean Air Act, Information Retrieved from the Website:www.enviroliteracy.org/article.php/6.html, on March 12, 2002.

16. Dieselnet, Diesel Emissions Online, Information Retrieved from the Website www.dieselnet.com on Jan 17, 2005. 
17. Dieselnet, Series 60-Still the Fuel Economy Leader, Product Brochure, Detroit Diesel Corporation, 2005, Information Retrieved from the Website:www.dieselnet.com on Dec 6, 2006, www.detroitdiesel.com/public/brochures/6sa303.pdf.

18. Yanowitz, J., Alleman, T. L., Ryan, L. B., McCormick, R. L., Graboski, M. S., Chassis Dynamometer Study of Emissions from 21 In-Use Heavy-Duty Diesel Vehicles, Environmental Science and Technology, Vol. 33, pp. 209-216, 2000.

19. Osenga, M., Diesel Industry Confronts the Emission Settlement EPA Enforcement of the Clean Air Act Affects Entire Diesel Engine Industry, Diesel Progress, North American Edition, (Published on 12/1/98), 1998.

20. Federal Register, Notice of Filing a Consent Decree Under the Clean Air Act, Office of the Federal Register, National Archives and Records Administration, Washington, DC, Vol. 33, n 212, Nov 3, 1998.

21. Dieselnet, Applicability and Test Cycles, United States Heavy-Duty Truck and Bus Engines, Information Retrieved from www.dieselnet.com on Aug 31, 2005.

22. Dieselnet, NTE Test Procedure and NTE Limits, Information Retrieved from the Website:www.dieselnet.com on Aug 31, 2005.

23. Krishnamurthy, M., Characterization of In-Use Emissions from On-Highway Heavy- Duty Diesel Engines. Masters Thesis, Department of Mechanical and Aerospace Engineering, West Virginia University, 2003.

24. USEPA Office of Transportation and Air Quality, In Use Testing Program for Heavy-Duty Diesel Engines and Vehicles, Technical Support Document, Document EPA 420-R-05-006, 2005. 
25. Working Group on Off-Cycle Emissions, EPA Answers to Questions from March 22nd 2004 NTE Presentation. Information Retrieved from the Website:

http://www.oica.net on Jan 15, 2006.

26. DG Entr (Enterprise), In-Use Conformity Testing of Emissions Control Devices, Study on Emission Control Technology for Heavy-Duty Vehicles, Study Prepared for the European Commission, May 2002.

27. USEPA, Control of Emissions of Air Pollution from 2004 and Later Model Year Heavy-Duty Highway Engines and Vehicles, Revision of Light-Duty Truck Definition, 40 CFR Parts 85 and 86, 1999.

28. Iddo, W., NTE Control Area Evaluation With Respect to the Real-World Engine Operation Envelope, Prepared for the 13th Meeting of the Working Group on Off-Cycle Emission, (Presented 5-7 April 2006), 2006.

29. USEPA, Test Plan to Determine PEMS Measurement Allowances for the Gaseous Emissions Regulated Under the Manufacturer-run-Heavy-Duty Diesel Engine In-Use Testing, DOCKET OAR-2004-0072-0069, (May 20, 2005) Program, 2005.

http:/www.epa.gov/otaq/highway-diesel/regs/testplan.pdf.

30. Butler, J. W., Kornisk, T. J., Reading, A. R., Kotenko, T. L., Generating Dynamometer Quality Data On-board Vehicles for Real-World Emission Measurements, Proceedings of the Ninth CRC On-Road Vehicle Workshop, April19-21, San Diego, CA, 1999.

31. Kihara, N., Tsukamoto, T., Matsumoto, K., Ishida, K., Kon, M., Murase, T., Real-time On-Board Measurement of Mass Emission of NOx, Fuel Consumption, Road 
Load, and Engine Output for Diesel Vehicles, SAE Technical Paper No. 2000-01-1141, 2000.

32. Jetter, J., Maeshiro, S., Hatcho, S., Klebba, R., Development of an On-Board Analyzer for Use on Advanced Low Emission Vehicles, SAE Technical Paper No. 2000-01$1140,2000$.

33. Mackay, G. I., Nadler, S. D., Karecki, D. R., Schiff, H. I., Butler, J. W., Gierczak, C. A., Jesion, G., Dynamometer Inter-comparison of Automobile Exhaust Gas $\mathrm{CO} / \mathrm{CO}_{2}$ Ratios and Temperature Between On-Board Measurements and a Remote Sensing Near Infrared Diode Laser System, Phase 1b Report to the Coordinating Research Council and National Renewable Energy Laboratory, 1994.

34. Gautam, M., Clark, N. N., Lyons, D. W., Long, Jr., T. R., Howell, A. D., Loth, J. L., Palmer, G. M., Bata, R. M., Design Overview of a Heavy Duty Mobile Vehicle Emissions Testing Laboratory, ASME DE-VOL. 40, Advanced Auto. Tech., pp.199-207, WAM, Atlanta, 1991.

35. Riddle, W., Design and Evaluation of the Emissions Measurement Components for a Heavy-Duty Diesel Powered Vehicle Mobile Emissions Measurement System (MEMS), Masters Thesis, Department of Mechanical and Aerospace Engineering, West Virginia University, 2001.

36. Shade, B., A Performance Evaluation of the MEMS: An On-Road Emissions Measurement System Study, Masters Thesis, Department of Mechanical and Aerospace Engineering, West Virginia University, 2000.

37. Gautam, M., Clark, N. N., Thompson, G. J., Carder, D. K., Lyons, D. W., Development of In-use Testing Procedures for Heavy-Duty Diesel-Powered Vehicle 
Emissions, Department of Mechanical and Aerospace Engineering, West Virginia University, Morgantown, WV, 2000.

38. Koupal, J., Draft Design and Implementation Plan for EPA's Multi-Scale Motor Vehicle and Equipment Emission System (MOVES), U.S. EPA Technical Report \#420-P02-006, October 2002.

39. USEPA, MOVES 2004: Energy and Emission Inputs, Office of Transportation and Air Quality, USEPA Draft Report, EPA 420-P-05-003, March 2005.

40. Weinblatt, H., Dulla, R. G., Clark, N. N., A Vehicle Activity Based Procedure for Estimating Emissions of Heavy-Duty Vehicles, Journal of Transportation Research, TRR 1842, pp. 64-72, 2003.

41. Air Resources Board, State of California, Mobile Source Emission Inventory Program- On Road Motor Vehicle Emission Inventory (MVEI) Models, Information Retrieved from the world wide web, http://www .arb.ca.gov on Jan 6, 2006.

42. Brzezinski, D. J., Newell, T. P., A Revised Model for Estimation of Highway Vehicle Emissions: Mobile6, EPA Report No.EPA-420-S-99-001, 1999.

43. Coordinating Research Council, Report $C R C$-APRAC-91, Proceedings of the CRC-APRAC On-Road Vehicle Emissions Work-Shop, Los Angeles, CA, 1991.

44. Coordinating Research Council, Report CRC-APRAC-94, Proceedings of the Fourth CRC-APRAC-94 On-Road Vehicle Emissions Work-Shop, San Diego, CA, 1994.

45. Fujita, E., Comparison of Emission Estimates and Ambient Concentrations of CO, NOMHC and $N O_{x}$ in California's South Coast Air Basin, International Specialty Conference on Emission Inventory Issues in the 1990s, Durham, North Carolina, 1991. 


\section{Ntziachristos, L., Samaras, Z., Eggleston, S., Gorissen, N., Hassel, D.,}

Hickman, A. J., Joumard, R., Rijkeboer, R., Zierock, K. H., COPERT Computer

Program to Calculate Emissions from Road Transport-Methodology and Emission Factors,

Technical Report 49, European Environment Agency, 2000.

47. Barth, M., An, F., Norbeck, J., Ross, M., Modal Emissions Modeling: A Physical Approach, Transporation Research Record 1520, pp. 81-88, 1996.

48. Barth, M. J., The Development of a Comprehensive Modal Emission Model, Proceedings of the Seventh CRC On-Road Vehicle Emissions Workshop, Coordinating Research Council, Atlanta, GA, pp. 6.53- 6.71, 1997.

49. Washington, S., Wolf, J., Guensler, R., A Binary Recursive Partitioning Method for Modeling Hot-Stabilized Emissions from Motor Vehicles, 76th Annual Meeting, Transportation Research Board, Washington, DC, 1997.

50. Strum, J., Almbauer, R., Sudy, C., Pucher, K., Application of Computational Methods for the Determination of Traffic Emissions, Journal of the Air \& Waste Management Association, Vol. 47, pp. 1204-1210, 1997.

51. Traver, M. L., Atkinson, R. J., Atkinson, C. M., Neural Network-Based Diesel Engine Emissions Prediction Using In-Cylinder Combustion Pressure, SAE Technical Paper 1999-01-1532, Warrendale, PA, 1999.

52. Jost, P., Hassel, D., Sonnborn, K., Weber, F., Emissions and Fuel Consumption Modeling Based on Continuous Measurements, Report of the Institute of Combustion Engines and Thermodynamics, TU-GRAZ, Austria, Vol. 64, 1992. 
53. Andrei, P., Real World Heavy-Duty Emissions Modeling, Masters Thesis, Department of Mechanical and Aerospace Engineering, West Virginia University, 2001.

54. Jost, P., Joumard, R., Hickman, J., Influence of Instantaneous Speed and Acceleration on Hot Passenger Car Emissions and Fuel Consumption, SAE Technical Paper 950928, 1995.

55. Weilenmann, M., Bach, C., Rudy, C., Aspects of Instantaneous Emissions Measurement, International Journal of Vehicle Design, Vol. 27, pp. 94-104, 2001.

56. Messer, J. T., Clark, N. N., Lyons, D. W., Measurement Delays and Modal Analysis for a Heavy-Duty Transportable Emissions Testing Laboratory, SAE Technical Paper 950218, 1995.

57. Messer, J. T., Measurement Delays and Modal Analysis for Two Heavy-Duty Transportable Emissions Testing Laboratories and a Stationary Engine Emission Testing Laboratory, Masters Thesis, Department of Mechanical and Aerospace Engineering, West Virginia University, 1995.

58. Hawley, J. G., Brace, C. J., Cox, A., Ketcher, D., Stark, R., Influence of TimeAlignment on the Calculation of Mass Emissions on a Chassis Dynamometer, SAE Technical Paper 2003-01-0395, 2003.

59. Ramamurthy, R., Heavy-Duty Emissions Inventory and Prediction, Masters Thesis, Department of Mechanical and Aerospace Engineering, West Virginia University, Morgantown, West Virginia, 1999. 
60. Clark, N. N., Jarrett, R. P., Atkinson, C. M., Field Measurements of Particulate Matter Emission and Exhaust Opacity from Heavy-Duty Vehicles, Journal of Air and Waste Management Association, Vol. 49, pp. 76-84, 1999.

\section{Hawley, J. G., Bannister, C. D., Brace, C. J., Cox, A., Ketcher, D., Stark, R.,} Further Investigations on Time-Alignment, SAE Technical Paper 2004-01-1441, 2004.

62. Levenspiel, O, Chemical Reaction Engineering, Second Edition, John Wiley \& Sons, Singapore, 1972.

63. Liang, T. F., Yong, K. A, Axial Dispersion of Solids in Rotary Solid Flow Systems, Journal of Applied Scientific Research, Vol.10, pp. 465- 470, 2004.

64. Trinidad, P., Ponce, C. A., Walsh, F. C., the Application of Flow Dispersion Models to the FM01-LC Laboratory Filter-Press Reactor, Electrochimica Acta, Vol. 52, n 2, pp. 604-613, 2006.

65. Ramamurthy, R., Clark, N. N., Lyons, D. W., Atkinson, C. M., Models for Predicting Transient Heavy-Duty Vehicle Emissions, SAE Technical Paper 982652, 1998.

66. Ganesan, B., Clark, N. N., Relationship between Instantaneous and Measured Emissions in Heavy-Duty Applications, SAE Technical Paper 2001-01-3536, 2001.

67. Weilenmann, M., Soltic, P., Ajtay, D., Describing and compensating gas transport dynamics for accurate instantaneous emission measurements, Atmos. Environ Vol. 37, pp. 5137-5145, 2003.

68. Pilley, A. D., The Transient Response Characteristics of Emissions Analyzers, Ricardo International Publication DP 87/0064. 
69. George, S., Characterization of In-Use Emissions from Marine Engines, Masters

Thesis, Department of Mechanical and Aerospace Engineering, West Virginia University, 2004.

70. Bane, B. R., A Comparison of Steady State and Transient Emissions from HeavyDuty Diesel Engines, Masters Thesis, Department of Mechanical and Aerospace Engineering, West Virginia University, 2002.

71. Aravelli, A., Real Time Measurement of Oxides of Nitrogen from Heavy-Duty Diesel Engines, Masters Thesis, Department of Mechanical and Aerospace Engineering, West Virginia University, 2003.

72. Nayak, G. A., Development of a Test Method to Measure In-Use Emissions from Stationary and Portable Diesel Sources, Masters Thesis, Department of Mechanical and Aerospace Engineering, West Virginia University, 2004.

73. Cambustion, Fast Gas Analyzers, Information retrieved from the website www.cambustion.com on June 29, 2006.

74. Cambustion Limited, fNOx 400, Users Manual.

75. Clark, N. N., Gautam, M., Bata, R. M., Loth, J. L., Palmer, G. M., Wang, W. G., Lyons, D. W., Design and Operation of a New Transportable Emissions Laboratory for Emissions Testing of Heavy-Duty Trucks and Buses, Heavy Vehicle Systems, Special Series, International Journal of Vehicle Design, Vol. 21, n 6, pp. 285-299, 1995.

76. Clark, N. N., Lyons, D. W., Gautam, M., Bata, R. M., Wang, W. G., Norton, P., Chandler, K., Natural Gas and Diesel Transit Bus Emissions Review and Recent Data, SAE Technical Paper 973203, 1997. 
77. Clark, N. N., Gautam, M., Wayne, W. S., Lyons, D. W, Thompson, G., HeavyDuty Vehicle Chassis Dynamometer Testing for Emissions Inventory, CRC Report No. E 55/59, Coordinating Research Council, Inc. Alpharetta, GA, 2007.

78. Ferguson, D. H. ,Gautam, M., Wang, W. G., Clark, N. N., Lyons, D. W., Bata, R. M., Palmer, G. M., Katragadda, S., Exhaust Emissions from In-Use Heavy-Duty Vehicles Tested on a Transportable Transient Chassis Dynamometer, SAE Technical Paper $922436,1992$.

79. Gautam, M., Ferguson, D. H., Wang, W. G., Bata, R. M., Clark, N. N., Lyons, D. W., Palmer, G. M., Katragadda, S., In-Use Emission and Performance Monitoring of Heavy-Duty Vehicles Using a Transportable Transient Chassis Test Facility, SAE Technical Paper 921751, 1992.

80. Salem, M. I., Mucino, V. H., Gautam, M., Speed Dependent Rolling Resistance Evaluation of a Twin Roller Chassis Dynamometer for Heavy-Duty Vehicles, International Journal of Computer Applications in Technology, Vol.12, pp. 349-357, 1999.

81. Clark, N. N., Gautam, M., Wayne, W. S., Lyons, D. W., Thompson, G., California Heavy Heavy-Duty Diesel Truck Emissions Characterization for Project E55/59 Phase 1.5, CRC E-55/59, Phase 1.5 Final Report, 2004.

82. Jacobs, T., Assanis, D., Filipi, Z., The Impact of Exhaust Gas Recirculation on the Performance and Emissions of a Heavy-Duty Diesel Engine, SAE Technical Paper 200301-1068, 2003.

83. Baert, R. S. G., Beckman, D. E.,Veen, A., Efficient EGR Technology for Future Heavy-Duty Diesel Engine Emission Targets, SAE Technical Paper 1999-01-0837, 1999. 
84. Kohketsu, S., Exhaust Gas Recirculation in Turbocharged Diesel Engines, Proceedings of JASE Convention, 9638266, 1996.

85. Hiereth, U., Gaertner, M., Loehle, C., Pfender, H., Investigation of cooling and recirculating exhaust gases in heavy-duty truck engines. Development of an exhaust gas cooler, Proceedings of 18th International Vienna Motor Symposium Series, Vol. 306, pp. 321-340, 1997.

86. Yamada, T., Ikeya, N., and Kondoh, N., New EGR system for heavy duty diesel engines, SAE Technical Paper 980775, 1998.

87. McKain, D. L., Clark, N. N., Daniel, T. I., Hoppie, J. A., Chassis Test Cycle Development for Engine Test Compliance on Heavy-Duty Vehicles, SAE Technical Paper $980407,1998$.

88. Gautam, M., Clark, N. N., Riddle, W., Nine, R., Wayne, W. S., Maldonado, H., Agrawal, A., Carlock, M., Development and Initial Use of Heavy-Duty Diesel Truck Test Schedule for Emissions Characterization, SAE Technical Paper 2002-01-1753, 2002.

89. Clark, N. N., Gautam, M., Wayne, W. S., Riddle, W., Nine, R. D., Lyons, D. W., Xu, S., Examination of Heavy Heavy-Duty Diesel Truck Chassis Dynamometer Schedule, SAE Technical Paper 2004-01-2904, 2004.

90. William, M. D., Thayer, G., Barth. M. J., Smith, L. L., The TRANSIMS Approach to Emission Estimations, Report No. LA-UR-99-471, Los Alamos National Laboratory, 1999. 
91. Jost, P., Jourmard, R., Hickman, J., Influence of Instantaneous Speed and Acceleration on Hot Passenger Car Emissions and Fuel Consumption, SAE Technical Paper 950928, 1995.

92. Samuel, S., Morrey, D., Fowkes, M., Taylor, D. H. C., Austin, L., Felstead, T., Latham, S., The Most Significant Vehicle Operating Parameter for Real-World Emissions Levels, SAE Technical Paper 2004-01-0636, 2004.

93. Ramamurthy, R., Clark, N. N., Lyons, D. W., Atkinson, C. M., Models for Predicting Transient Heavy-Duty Vehicle Emissions, SAE Technical Paper 982652, 1998.

94. Madireddy, R. M., Clark, N. N., Sequential Inversion Technique and Differential Coefficients Approach for Accurate Instantaneous Measurement, International Journal of Engine Research, Vol. 7, pp. 437-446, 2006.

95. Ramamurthy, R., Clark, N. N., Atmospheric Emissions Inventory Data for HeavyDuty Vehicles, Environmental Science and Technology, Vol. 33, pp. 55-62, 1999.

96. Clark, N. N., Madireddy, M. R., Gautam, M., Wayne, S. W., Thompson, G., Lyons, D. W., Atmospheric Emissions Inventory Data for 2003 and Later Model-Year Heavy-Duty Vehicles.

97. Ajtay, D., Weilenmann, M., Compensation of the exhaust gas transport dynamics for accurate instantaneous emission measurements, Environmental Science and Technology, Vol.38, pp. 5141-5148, 2004.

98. Beaumont, A. D., Noble, A. D., Pilley, A. D., Signal reconstruction techniques for improved measurement of transient emissions, SAE Paper 9002333. 
99. Daboczi, T., Kollar, I., Multi-parameter optimization of inverse filter algorithms, IEEE Transactions on Instrumentation and Measurement. Vol. 45, pp. 417-422, 1996.

100. Smith, W. S., The scientist and engineer's guide to digital signal processing, Retrieved from the Website: http://www.dspguide.com/ch6.htm on Jan 14, 2008.

101. Signal reconstruction theory and its applications, Tsinghua University Press, pp. $135-138,1991$.

102. Jiang, M., Wang, G., Development of blind image deconvolution and its applications, Journal of X-Ray Science and Technology, Vol.11, pp. 13-19, 2003. 